\title{
ECOLOGIA E CONTROLE DE ÁCAROS (ACARI) DA SERINGUEIRA (Hevea brasiliensis Muell. Arg.) NO ESTADO DE MATO GROSSO
}

\section{NOELI JUAREZ FERLA}

Biólogo

Orientador: Prof. Dr. GILBERTO JOSÉ DE MORAES

Tese apresentada à Escola Superior de Agricultura "Luiz de Queiroz", Universidade de São Paulo, para obtenção do Título de Doutor em Ciências, Área de Concentração: Entomologia.

P I R A C I C A B A

Estado de São Paulo - Brasil

Dezembro - 2001 
Dados Internacionais de Catalogação na Publicação (CIP) DIVISĀO DE BIBLIOTECA E DOCUMENTAÇĀO - ESALQ/USP

Ferla, Noeli Juarez

Ecologia e controle de ácaros (Acari) da seringueira (Hevea brasiliensis Muell. Arg.) no Estado de Mato Grosso / Noeli Juarez Ferla. - - Piracicaba, 2001.

$141 \mathrm{p}$.

Tese (doutorado) - Escola Superior de Agricultura Luiz de Queiroz, 2001. Bibliografia.

1. Acari 2. Ecologia animal 3. Insetos parasitos 4. Seringueira 1. Título 


\section{AGRADECIMENTOS}

Ao Prof. Gilberto J. de Moraes, pela orientação, apoio, estímulo e confiança demonstrado durante nosso convívio.

Ao Prof. Carlos H. W. Flechtmann, por sua disponibilidade em colaborar com a realização do trabalho e por seu estímulo no estudo da Acarologia.

Ao Professor Francisco A. M. Mariconi, pela ajuda na escolha dos produtos químicos e na definição da metodologia de estudo.

Ao colega e amigo Marcel Tanzini, por sua ajuda e companheirismo durante o desenvolvimento do estudo.

Ao Professor Reinaldo J. F. Feres, por sua disponibilidade em confirmar as novas espécies de eriofideos e por seu auxílio na identificação dos tetraniquídeos.

Ao Professor Celso Omoto, por ceder seu laboratório para realizar as aplicações dos agroquímicos.

Ao pesquisador Olivier Bonato, pela análise estatística dos dados da distribuição de Calacarus heveae Feres na planta.

Aos Profs. do Departamento de Entomologia, Fitopatologia e Zoologia Agrícola 
(ESALQ/USP), pela ajuda, colaboração no desenvolvimento deste trabalho e nas disciplinas no decorrer do curso de pós-graduação.

A todos os colegas do curso de pós-graduação, em especial aos colegas do setor de Zoologia (Aloyséia, Andréa, Aníbal, Antônio Carlos, Cláudia, Cristiane, Denise, Edmílson, Jeferson, Lázaro, Manoel, Michely, Renata e Zacarias), pela amizade e companheirismo.

Aos Professores Eliot W. Kitajima e Bruno Leite e à Técnica Silvana Machado, do Núcleo de Apoio à Pesquisa (ESALQ/USP), pela colaboração e suporte na realização das fotografias em microscópio eletrônico.

Aos meus familiares, em especial a minha esposa e filhas, que sempre apoiaram meu trabalho.

Às empresas Plantações Edouard Michellin Ltda. e Triângulo Agro-Industrial Ltda. pelo financiamento do projeto e pelo apoio logístico à realização do mesmo.

Aos funcionários Caio Franchechi e Nilson de Souza, da empresa Triângulo AgroIndustrial Ltda., pelo apoio na contagem das populações de ácaros, pela coleta dos ácaros e pelo envio de folhas de seringueira.

Aos funcionários Cássio Scomparim e Etiéne Grallien, da empresa Plantações Edouard Michellin Ltda. pelo apoio no desenvolvimento do trabalho e pelo envio de folhas de seringueira. Ao funcionário Valdecir da Souza Cruz pela contagem e coleta dos ácaros.

Ao Conselho Nacional de Pesquisa (CNPq), pela concessão de bolsa para a realização do curso de pós-graduação. 
À minha esposa Josélia e minhas filhas Júlia e Laura, pela amizade, amor e dedicação 


\section{SUMÁRIO}

Página

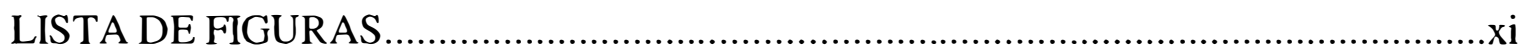

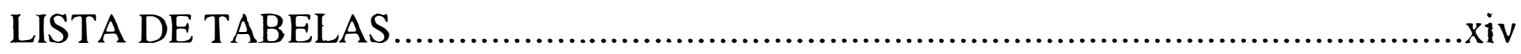

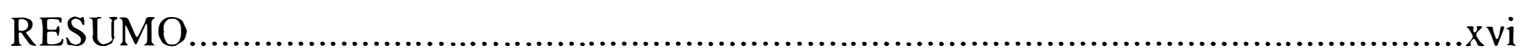

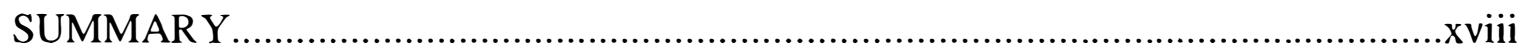

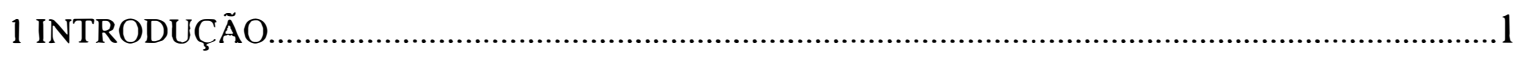

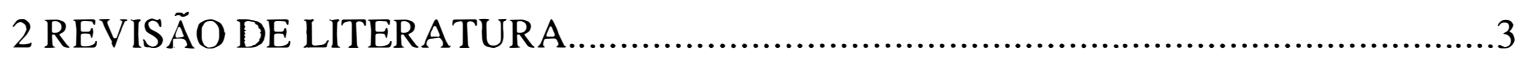

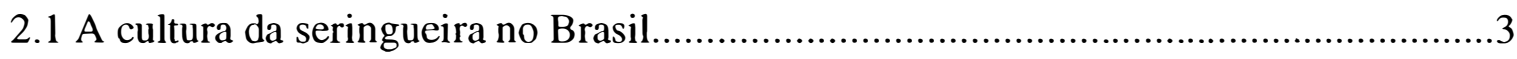

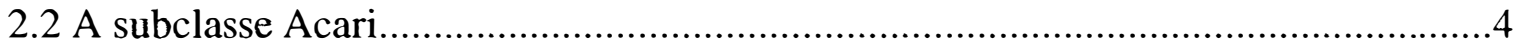

2.3 Ácaros em seringueira no Brasil.................................................................

2.4 Dano causado por ácaros na cultura da seringueira..........................................6

3 DISTRIBUIÇÃO ESPACIAL E PLANO DE AMOSTRAGEM DE Calacarus heveae FERES

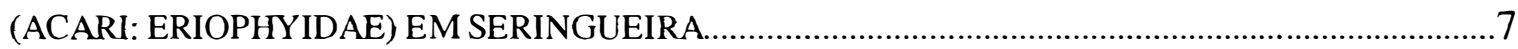

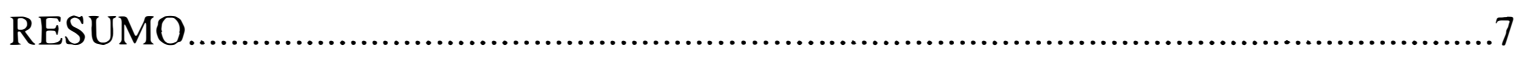

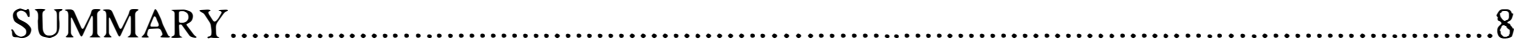

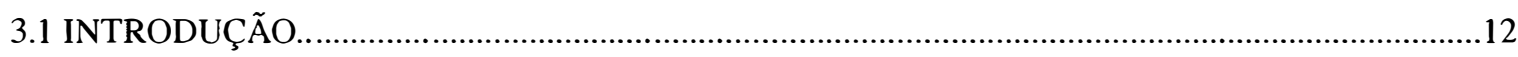

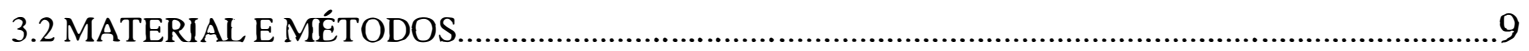

3.2.1 Distribuição de Calacarus heveae na planta: seleção de uma unidade de amostragem....................10

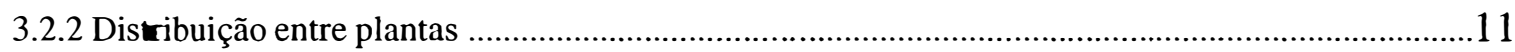

3.2.3 Correlação entre densidade populacional e proporção de folhas atacadas........................................11

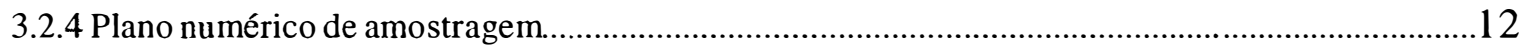

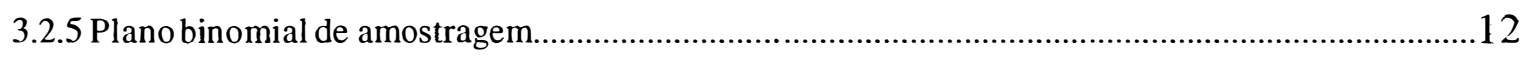


3.3.1 Distribuição de Calacarus heveae na planta de seringueira..................................13

3.3.2 Distribuição de Calacarus heveae de acordo com a distância a partir da periferia da copa..

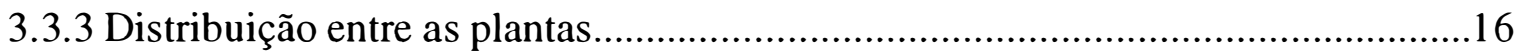

3.3.4 Correlação entre densidade populacional e proporção de folhas tacadas...............16

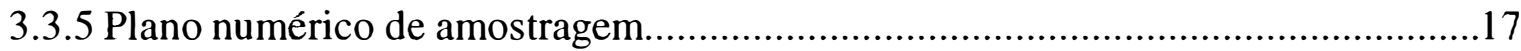

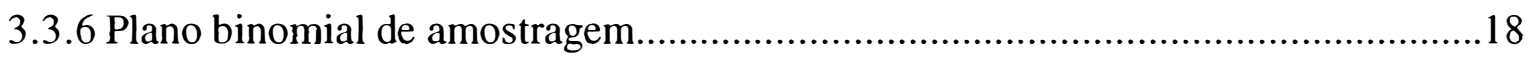

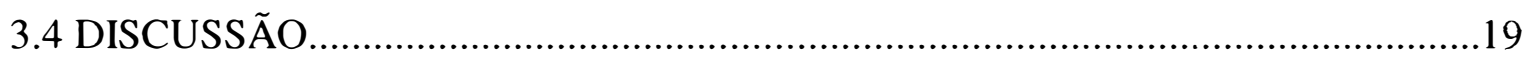

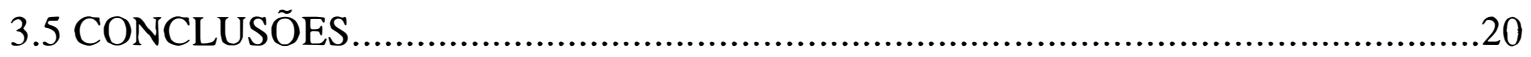

4 ÁCAROS (ARACHNIDA: ACARI) DA SERINGUEIRA (Hevea brasiliensis Muell. Arg.)

NO ESTADO DO MATO GROSSO............................................................................................

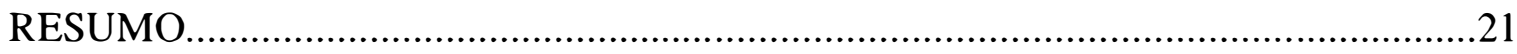

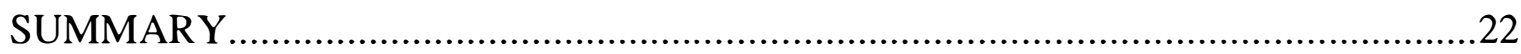

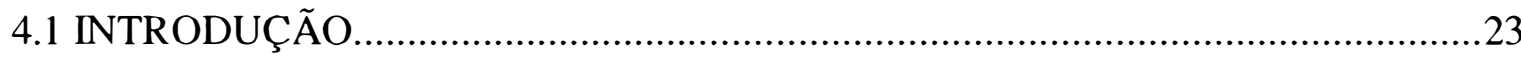

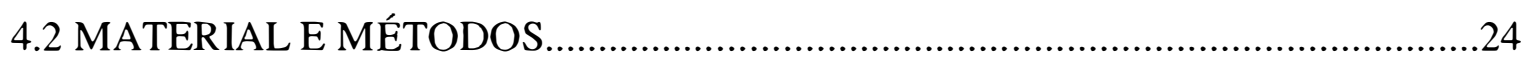

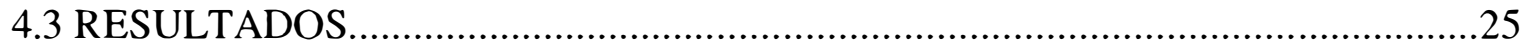

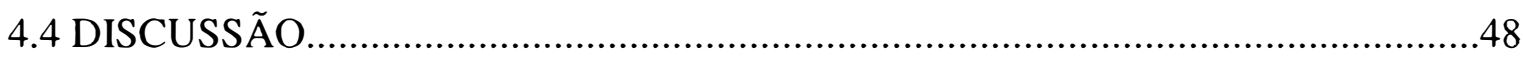

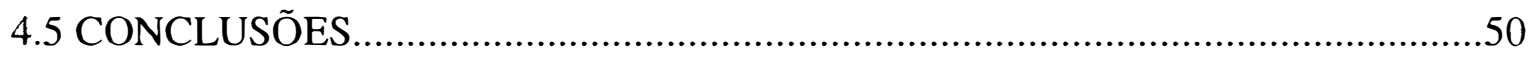

5 FLUTUAÇÃO POPULACIONAL E EVOLUÇÃO DOS SINTOMAS DE DANO CAUSADOS POR ÁCAROS (ACARI) EM SERINGUEIRA, NO ESTADO DO MATO GROSSO...............................51

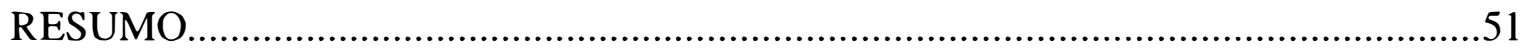

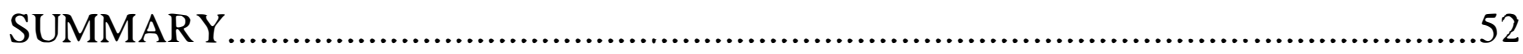

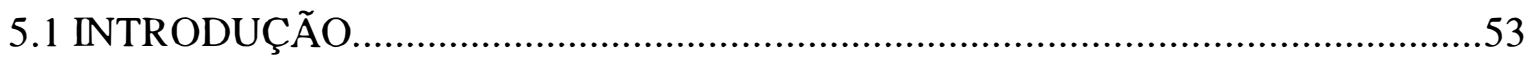

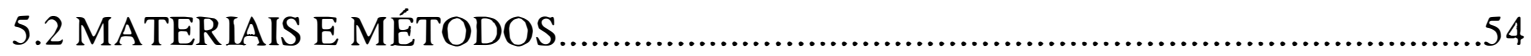

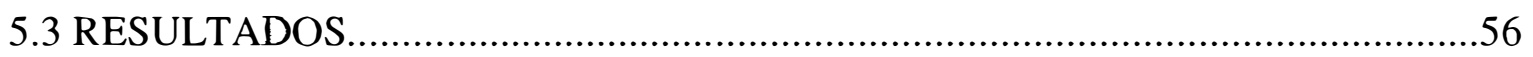

5.3.1 Dinâmica populacional das famílias encontradas...................................................56 
5.3.2 Espécies acarinas mais comuns. 63

5.3.3Prevalência de espécies de Eriophyidae e Phytoseiidae ............................................66

5.3.4 Dano causado e sintomas de ataque....................................................................68

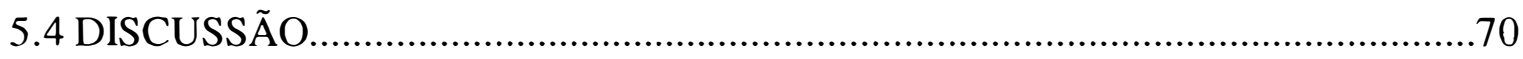

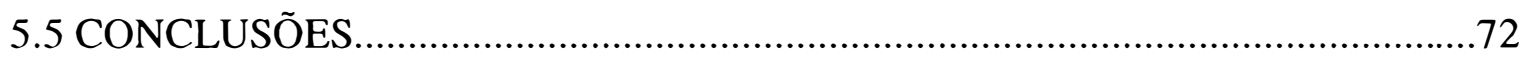

6 CICLO BIOLÓGICO DE Calacarus heveae FERES (ACARI: ERIOPHYIDAE)...................................73

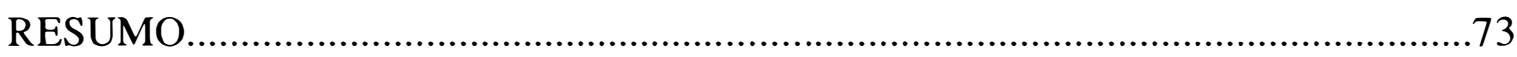

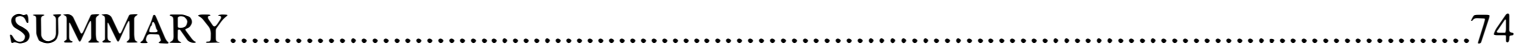

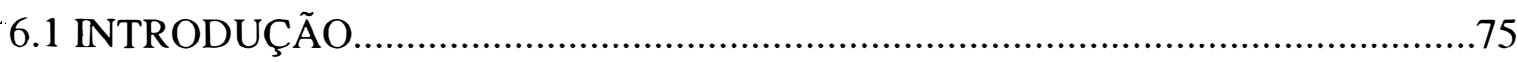

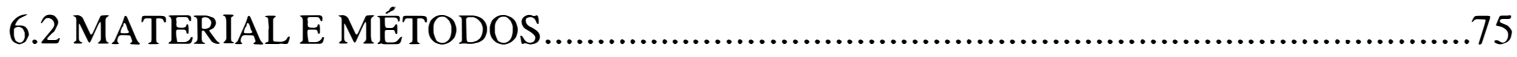

6.3 RESULTADOS

6.3.1 Características biológicas dos estádios imaturos...................................................77

6.3.2 Características biológicas do estádio adulto..........................................................79

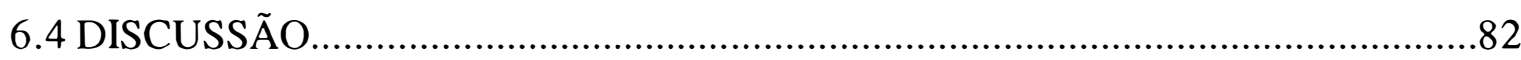

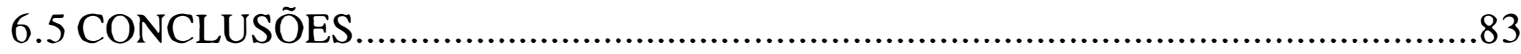

7 EFEITO DE DIFERENTES CONCENTRAÇÕES DE AGROQUÍMICOS EM Calacarus heveae FERES E Tenuipalpus heveae BAKER (ACARI: ERIOPHYIDAE E TENUIPALPIDAE)........84

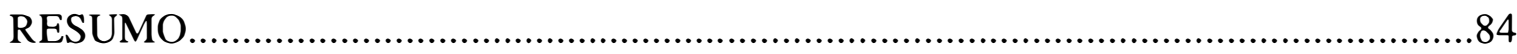

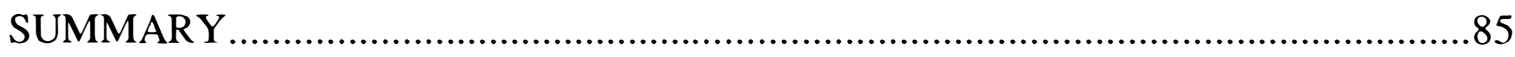

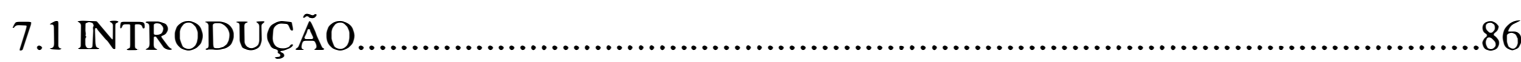

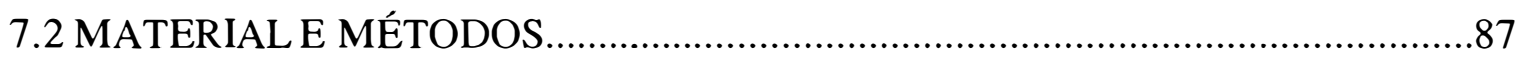

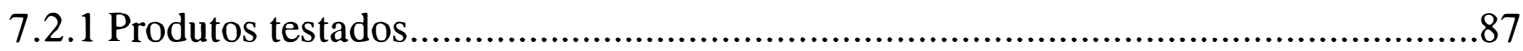

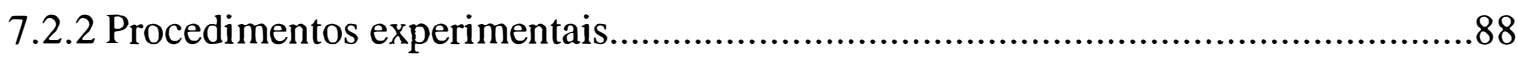

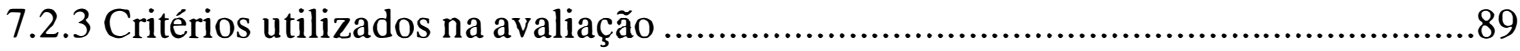

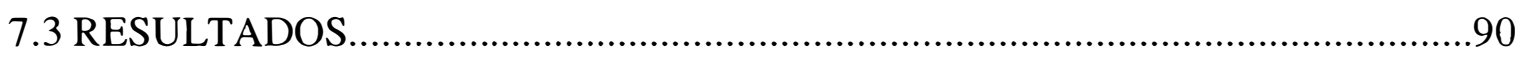

7.4 DISCUSSÃO

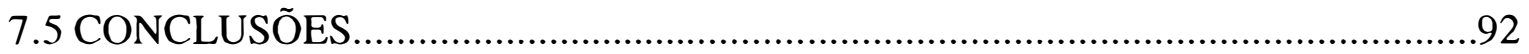


8 FECUNDIDADE DOS PREDADORES Agistemus floridanus, Euseius concordis $\mathrm{E}$ Neoseiulus anonymus (ACARI) EM DIFERENTES TIPOS DE ALIMENTO.........................................93

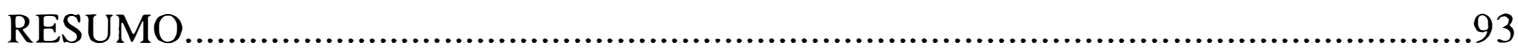

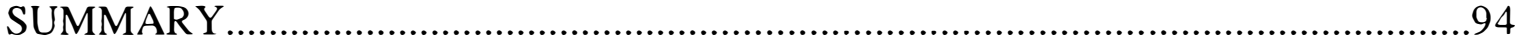

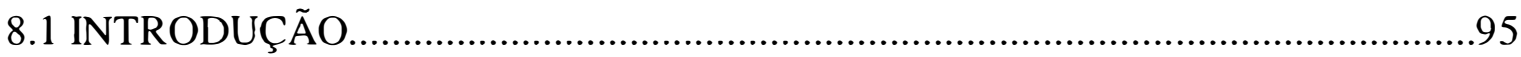

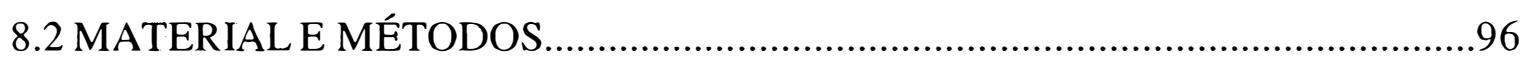

8.2.1 Procedimentos experimentais com Agistemus floridanus................................97

8.2.2 Procedimentos com Euseius concordis e Neoseiulus anonymus .........................97

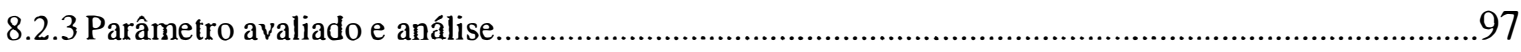

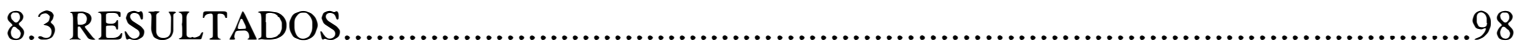

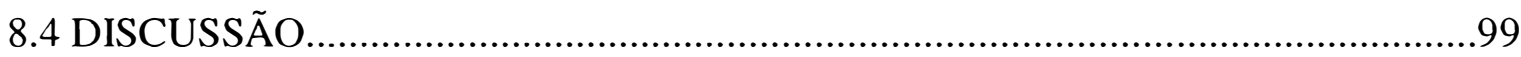

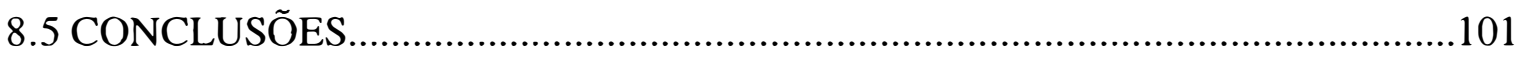

9 TABELA DE VIDA DE Agistemus floridanus (ACARI: STIGMAEIDAE)......................................102

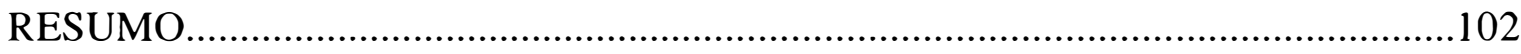

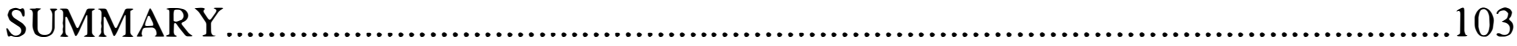

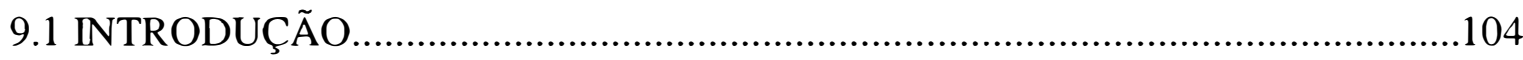

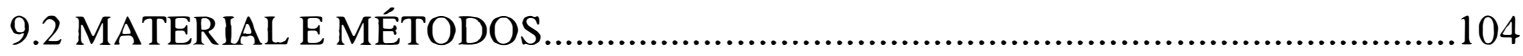

9.2.1 Biologia de Agistemus floridanus....................................................... 105

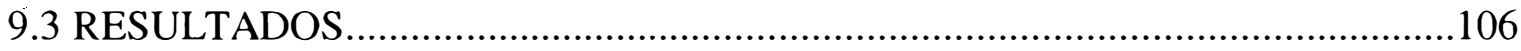

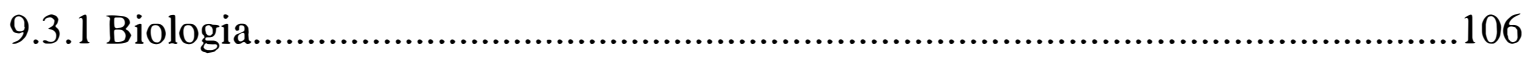

9.3.2 Tabela de vida e fertilidade................................................................ 107

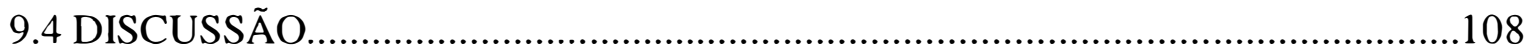

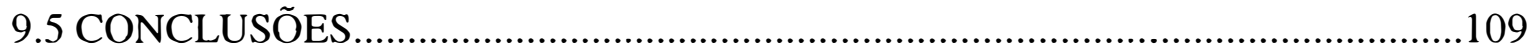

10 SELETIVIDADE DE AGROQUÍMICOS EM ÁCAROS PREDADORES COMUMENTE ENCONTRADOS EM SERINGUEIRA NO CENTRO-OESTE DO BRASIL ........................................110

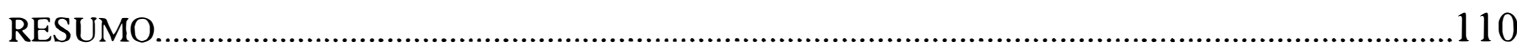

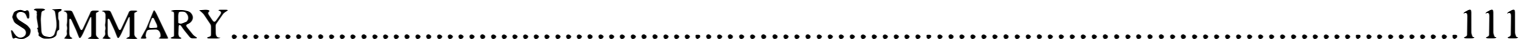

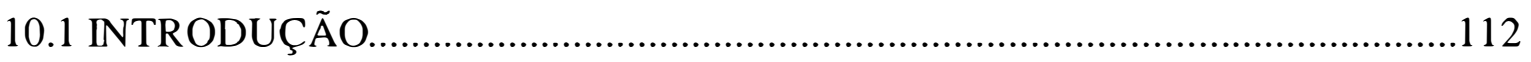




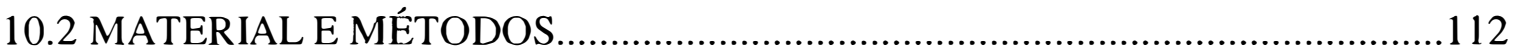

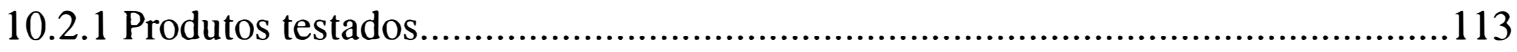

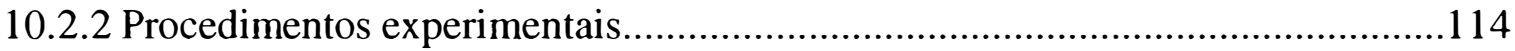

10.2.3 Critérios utilizados na avaliação ....................................................................115

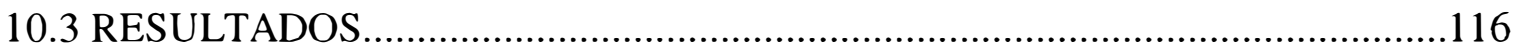

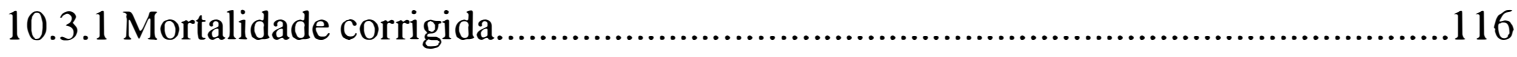

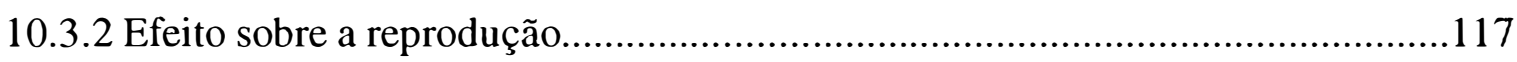

10.3.3 Efeito total dos agroquímicos sobre os predadores.............................................119

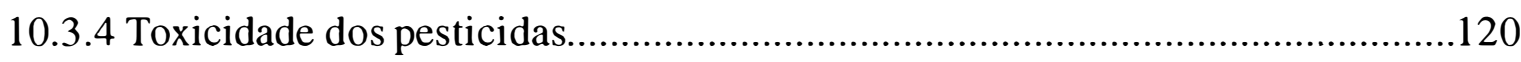

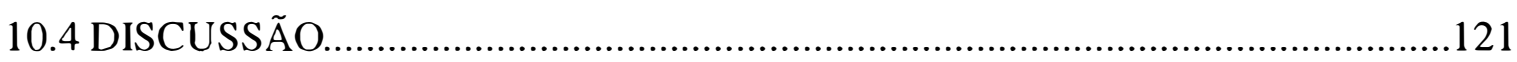

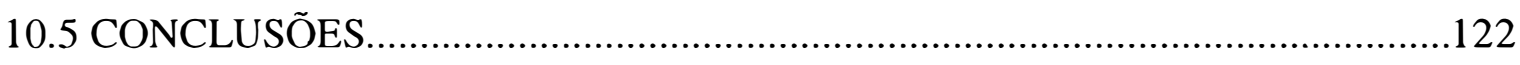

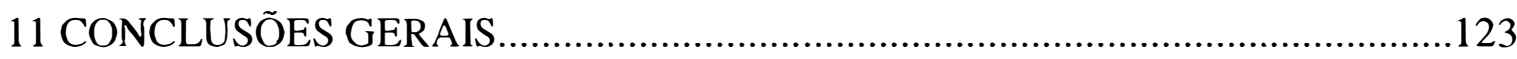

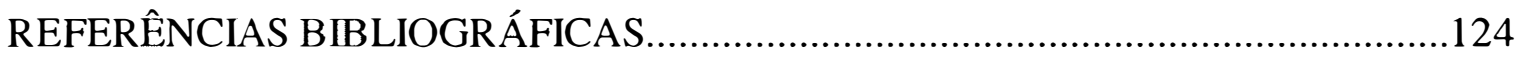




\section{LISTA DE FIGURAS}

Página

1 Número médio (A, B), percentagem de ácaros presentes em cada estrato $(C, D)$ e proporção de folhas infestadas $(E, F)$ por estrato, em plantas de seringueira nos municípios de Itiquira e Pontes e Lacerda, no Estado do Mato Grosso .14

2 Relação entre o logaritmo do número de Calacarus heveae por folha e o logaritmo de sua variância nas 180 folhas amostradas mensalmente, entre setembro de 1998 e agosto de 1999, nos clones PB 260 e IAN 873 em Itiquira e Pontes e Lacerda, respectivamente

3 Relação entre o número médio de ácaros por folha e as folhas infestadas com Calacarus heveae. A curva indica a estimativa desta relação segundo o modelo de Wilson \& Room, modificado segundo Schallje et al. (1991).

4 Número mínimo de amostras necessárias para estimar a densidade de Calacarus heveae, usando o plano de amostragem numérica para um determinado nível de precisão.

5 Número mínimo de amostras necessárias par estimar a densidade de Calacarus heveae, usando a avaliação da presença ao ausência de ácaros nas folhas para um determinado nível de precisão.

6 Níveis de dano causado por ácaros nos clones avaliados nos municípios de Itiquira e Pontes e Lacerda (nível 1 : folhas sem dano; níveis 2, 3 e 4: danos crescentes e intermediários; nível 5 : toda a face adaxial amarelada). .56

7 Flutuação populacional (ácaros/folha) dos ácaros encontrados no clone FX 3864 de seringueira em Pontes e Lacerda, Mato Grosso $(\mathrm{E}=$ Eriophyidae; $\mathrm{Te}=$ Tenuipalpidae; $\mathrm{Tr}=$ Tetranychidae $; \mathrm{P}=$ Phytoseiidae $; \mathrm{C}=$ Cunaxidae $; \mathrm{O}=$ Acaridae, 
Cheyletidae, Tarsonemidae, Tydeidae, Stigmaeidae, Winterschmidtiidae)

8 Flutuação populacional (ácaros/folha) dos ácaros encontrados no clone RRIM 600 de seringueira em Pontes e Lacerda, Mato Grosso (E = Eriophyidae;

$\mathrm{Te}=$ Tenuipalpidae; $\mathrm{Tr}=$ Tetranychidae $; \mathrm{P}=$ Phytoseiidae $; \mathrm{C}=$ Cunaxidae;

$\mathrm{O}=$ Acaridae, Cheyletidae, Tarsonemidae, Tydeidae, Stigmaeidae,

Winterschmidtiidae)

9 Flutuação populacional (ácaros/folha) dos ácaros encontrados no clone IAN 873

de seringueira em Pontes e Lacerda, Mato Grosso $(\mathrm{E}=$ Eriophyidae; $\mathrm{Te}=$ Tenuipalpidae $; \mathrm{Tr}=$ Tetranychidae $; \mathrm{P}=$ Phytoseiidae $; \mathrm{C}=$ Cunaxidae $; \mathrm{O}=$ Acaridae,

Cheyletidae, Tarsonemidae, Tydeidae, Stigmaeidae, Winterschmidtiidae). 60

10 Flutuação populacional (ácaros/folha) dos ácaros encontrados no clone IAN 713 de seringueira em Pontes e Lacerda, Mato Grosso $(\mathrm{E}=$ Eriophyidae; $\mathrm{Te}=$ Tenuipalpidae; $\mathrm{Tr}=$ Tetranychidae; $\mathrm{P}=$ Phytoseiidae $; \mathrm{C}=$ Cunaxidae $; \mathrm{O}=$ Acaridae, Cheyletidae, Tarsonemidae, Tydeidae, Stigmaeidae, Winterschmidtiidae).

11 Flutuação populacional (ácaros/folha) dos ácaros encontrados no clone PB 260 de seringueira em Itiquira, Mato Grosso $(\mathrm{E}=$ Eriophyidae; $\mathrm{Te}=$ Tenuipalpidae; $\mathrm{Tr}=$ Tetranychidae; $\mathrm{P}=$ Phytoseiidae $; \mathrm{C}=$ Cunaxidae $\mathrm{O}=$ Acaridae, Cheyletidae, Tarsonemidae, Tydeidae, Stigmaeidae.

12 Flutuação populacional (ácaros/folha) dos ácaros encontrados no clone PR 255 de seringueira em Itiquira, Mato Grosso ( $\mathrm{E}=$ Eriophyidae; Te = Tenuipalpidae; $\operatorname{Tr}=$ Tetranychidae $; \mathrm{P}=$ Phytoseiidae $; \mathrm{C}=$ Cunaxidae $; \mathrm{O}=$ Acaridae, Cheyletidae, Tarsonemidae, Tydeidae, Stigmaeidae, Wintershmidtiidae)

13 Freqüência da ocorrência das principais espécies de eriofídeos nos clones de seringueira avaliados nos município de Pontes e Lacerda $(\mathrm{A}=$ clone FX 3864; $\mathrm{B}=$ clone RRIM 600; C = IAN 873; D = clone IAN 713) e Itiquira (E = clone PB 260; $\mathrm{F}=$ clone $\mathrm{PR} 255)$

14 Frequiência da ocorrência das principais espécies de fitoseídeos presentes nos clones de seringueira avaliados nos municípios de Pontes e Lacerda (A = clone FX 3864; $\mathrm{B}=$ clone RRIM 600; $\mathrm{C}=$ IAN 873; $\mathrm{D}=$ clone IAN 713) e Itiquira 
$(\mathrm{E}=$ clone $\mathrm{PB} 260 ; \mathrm{F}=$ clone PR 255), no Estado do Mato Grosso. "Outros" = 13 outras espécies de Phytoseiidae encontradas neste estudo.

15 Danos provocados por ácaros em folhas de seringueira entre agosto de 1999 a julho de 2000, nos municípios de Itiquira e Pontes e Lacerda no Estado

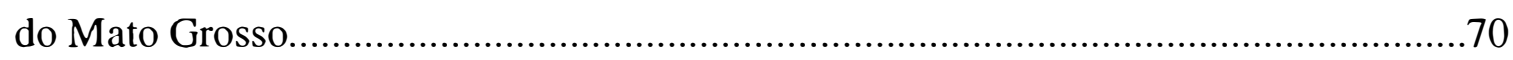

16 Espécime de Calacarus heveae fazendo a ecdise.................................................78

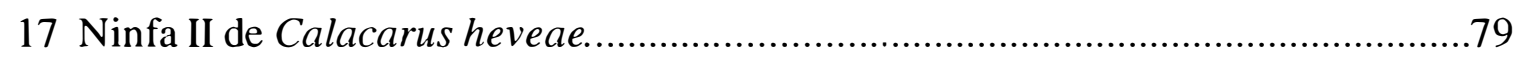

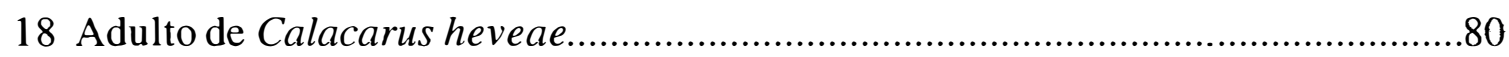

19 Oviposição média diária de fêmeas não fecundadas de Calacarus heveaea, 2

$8 \pm 1^{\circ} \mathrm{C}(12 \mathrm{~h})$ na fotofase e $25 \pm 1^{\circ} \mathrm{C}(12 \mathrm{~h})$ na escotofase e umidade relativa de $90 \pm 5 \%$ em folíolos de seringueira do clone PB 260, $(\mathrm{N}=16)$. 81

20 Espermatóforo de Calacarus heveae obtidos em colônias de laboratório. .82

21 Efeito sobre a reprodução Euseius concordis e Neoseiulus anonymus calculada através da divisão da oviposição das fêmeas em cada tratamento pela oviposição média da testemunha, mantidos sobre círculos de folhas de seringueira tratados com diferentes produtos químicos. Piracicaba. 1999

22 Efeito total calculado levando em conta a mortalidade das fêmeas de Euseius concordis e Neoseiulus anonymus no tratamento, corrigida em função da mortalidade na testemunha e o efeito na reprodução. Piracicaba. 1999-2000. 


\section{LISTA DE TABELAS}

Página

1 Diferença entre o número médio de ácaros e proporção de folhas infestadas por $C$. heveae, em diferentes distâncias da periferia da copa da planta de seringueira, nos clones PB 260 e IAN 873, entre os meses de setembro de 1998 a maio de 1999, em Itiquira e Pontes e Lacerda, no Estado do Mato Grosso.

2 Proporção (\%) das espécies acarinas encontradas em plantações de seringueira, nos municípios de Itiquira e Pontes e Lacerda, Mato Grosso, entre setembro de 1998 a julho de 2000.

3 Duração e viabilidade (machos e fêmeas) das diferentes fases imaturas de Calacarus heveae, em dias, a $25,5 \pm 1^{\circ} \mathrm{C}$, fotofase de 12 horas e umidade relativa de $90 \pm 5^{\circ} \mathrm{C}$ em folíolos de seringueira da variedade PB 260. 78

4 Longevidade, reprodução e fecundidade de Calacarus heveae, a $28 \pm 1^{\circ} \mathrm{C}$ (12h) na ftofase e $25,5 \pm 1^{\circ} \mathrm{C}(12 \mathrm{~h})$ na escotofase e umidade relativa de $90 \pm 5^{\circ} \mathrm{C}$ em folíolos de seringueira da variedade PB 260.

5 Agroquímicos testados quanto ao efeito em Calacarus heveae e Tenuipalpus heveae. Piracicaba. 1999

6 Mortalidade corrigida de Calacarus heveae e Tenuipalpus heveae (士erro padrão da média) em diferentes concentrações de agroquímicos, após 24 horas da aplicação de diferentes produtos.

7 Oviposicão média diária ( \pm erro padrão da média) de Agistemus floridanus, Euseius concordis e Neoseiulus anonymus em diferentes tipos de alimento, a $25 \pm 1^{\circ} \mathrm{C}$ e umidade relativa de $80 \pm 5 \%$ 99

8 Duração média, em dias ( \pm erro padrão da média) das fases imaturas e 
adulta de Agistemus floridanus alimentando-se de Tenuipalpus heveae a $25 \pm 1^{\circ} \mathrm{C}$, fotofase de 12 horas e umidade relativa de $80 \pm 5 \%$

9 Parâmetros médios ( \pm erro padrão da média) da biologia de fêmea adultas de Agistemus floridanus acasaladas e não acasaladas, alimentando-se de Tenuipalpus heveae a $25 \pm 1^{\circ} \mathrm{C}$, fotofase de 12 horas e umidade relativa de $80 \pm 5 \% \ldots \ldots \ldots \ldots \ldots \ldots \ldots \ldots . . . . .108$ 10 Agroquímicos testados quanto ao efeito sobre Euseius concordis e Neoseiulus anonymus. Piracicaba. 1999-2000. 11 Mortalidade corrigida (\%) de Euseius concordis e Neoseiulus anonymus em teste residual em diferentes concentrações de agroquímicos, após 8 dias, a $25 \pm 1^{\circ} \mathrm{C}$,

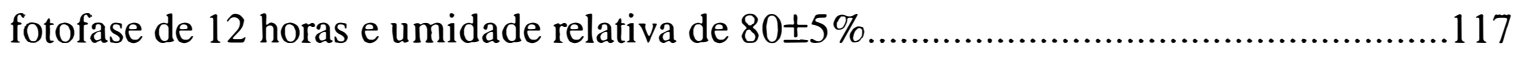
12 Classe de toxicidade ${ }^{1}$ de pesticidas sobre fêmeas adultas de Euseius concordis e Neoseiulus anonymus em teste residual de laboratório, de acordo com a escala estabelecida pela IOBC/WPRS. Piracicaba, 1999 


\title{
ECOLOGIA E CONTROLE DE ÁCAROS (ACARI) DA SERINGUEIRA (Hevea brasiliensis Muell. Arg.) NO ESTADO DE MATO GROSSO
}

\author{
Autor: NOELI JUAREZ FERLA \\ Orientador: Prof. Dr. GILBERTO JOSÉ DE MORAES
}

RESUMO

Este trabalho se refere a estudos de espécies acarinas presentes na cultura da seringueira, nos municípios de Itiquira e Pontes e Lacerda, ambos localizados no Estado do Mato Grosso. Foi estudada a distribuição de Calacarus heveae Feres em seringueira, selecionada uma unidade de amostragem mais representativa e desenvolvido um plano de amostragem para o estudo da flutuação populacional de $C$. heveae. Para conhecer as espécies acarinas presentes na seringueira em Mato Grosso foram feitas mensalmente avaliações em 6 clones suscetíveis a $C$. heveae. Em Itiquira, foram escolhidos os clones PB 260 e PR 255, e, em Pontes e Lacerda, os clones IAN 713, IAN 873, FX 3864 e RRIM 600. Para os clones PB 260 e IAN 873, as amostragens foram realizadas de agosto de 1998 a julho de 2000; para os clones PR 255, IAN 713, FX 3864 e RRIM 600, as coletas foram realizadas de agosto de 1999 a julho de 2000. Foi encontrado um total de 4270 ácaros pertencentes a 12 famílias nos municípios. Em Itiquira, a espécie mais freqüente foi $C$. heveae e em Pontes e Lacerda, foi Phyllocoptruta seringueirae Feres. A biologia de $C$. heveae foi estudada em câmara climatizada a $28 \pm 1^{\circ} \mathrm{C}$ na fotofase $(12 \mathrm{~h})$, $25 \pm 1^{\circ} \mathrm{C}$ na escotofase $(12 \mathrm{~h})$, e umidade relativa de $90 \pm 5 \%$. Dicofol, endosulfan, 
formetanate, metomil, monocrotofós, óxido de fenbutatina e propargite causaram alta mortalidade de $C$. heveae nas duas concentrações testadas, enquanto que acefato, nas duas concentrações testadas, foi o único agroquímico a provocar baixa mortalidade de $C$. heveae. Apenas dicofol, nas duas concentrações testadas, causou alta mortalidade de Tenuipalpus heveae Baker. Dentre os predadores mais comuns encontrados na cultura da seringueira, Agistemus floridanus Gonzalez demonstrou aceitar uma variedade maior de alimento. Este foi o único predador a apresentar alta oviposição quando alimentado com C. heveae e T. heveae. Euseius concordis (Chant) e A. floridanus apresentaram aproximadamente os mesmos níveis de oviposição quando alimentados com pólen, chegando a 1,0 ovo/fềmea/dia. Neoseiulus anonymus (Chant \& Baker) apresentou maior oviposição que os demais predadores quando alimentado com Oligonychus gossypii (Zacher) e Tetranychus mexicanus (McGregor). A biologia de $A$. floridanus foi estudada a $25 \pm 1{ }^{\circ} \mathrm{C}$, fotofase de 12 horas e umidade relativa de $80 \pm 5 \%$. A maioria dos parâmetros biológicos foi diferente entre as fềmeas acasaladas e não acasaladas. Observou-se pela taxa líquida de reprodução $\left(\mathrm{R}_{0}\right)$ que $A$. floridanus tem uma capacidade de aumento de 13,2 vezes em cada geração, com duração média de uma geração $(\mathrm{T})$ de cerca de 19,2 dias. A razão intrínseca de incremento populacional $\left(r_{m}\right)$ foi de 0,16 , enquanto a razão finita de aumento $(\lambda)$, isto é, o número de fêmeas adicionadas à população foi de 1,1 . Nos estudos realizados para definir a seletividade de agroquímicos às espécies $E$. concordis e $N$. anonymus, endosulfan a 320 ppm, dicofol a 100 ppm, óxido de fenbutatina a 100 e 320 ppm foram inócuos a $E$. concordis, enquanto que endosulfan a 320 ppm e dicofol a 100 ppm foram inócuos a N. anonymus. 
ECOLOGY AND CONTROL OF MITES (ACARI) ON RUBBER TREE (Heveae brasiliensis Muell. Arg.) IN THE STATE OF MATO GROSSO

\author{
Author: NOELI JUAREZ FERLA \\ Adviser: Dr. GILBERTO JOSÉ DE MORAES
}

\title{
SUMMARY
}

This work refers to studies of mite species found on rubber trees in Itiquira and Pontes e Lacerda, both in the State of Mato Grosso. It consisted of the study of the distribution of Calacarus heveae Feres in rubber tree plants, the selection of a representative sampling unity and the development of a sampling plan for the study the fluctuation of the population of $C$. heveae. In order to know the mite species on rubber trees in Mato Grosso monthly valuations were conducted on 6 clones susceptible to $C$. heveae. The clones studied in Itiquira were PB 260 and PR 255, whereas the clones studied in Pontes e Lacerda were IAN 713, IAN 873, FX 3864 and RRIM 600. For the clones PB 260 and IAN 873, the samplings were conducted between August 1998 and July 2000; for the clones IAN 713, IAN 873, FX 3864 and RRIM 600, the samplings were conducted August 1999 and July 2000. A total of 4270 mites, belonging to 12 families, was collected. In Itiquira, the most frequent specie was $C$. heveae and in Pontes e Lacerda Phyllocoptruta seringueirae Feres. The biology of $C$. heveae was studied at $28 \pm 1^{\circ} \mathrm{C}$ in the phtotophase $(12 \mathrm{~h}), 25 \pm 1^{\circ} \mathrm{C}$ in the dark phase (12h), and $90 \pm 5 \%$ relative humidity. Dicophol, endosulfan, formetanate, methomil, monocrotophos, oxid of fenbutanine and propargite caused high mortality of $C$. heveae in both concentrations 
tested, while acephato, in both concentrations tested, was the only pesticide that caused low mortality of $C$. heveae. Only dicophol, in both concentrations tested, caused high mortality of Temuipalpus heveae Baker. Among the most common predators collected Agistemus floridamus Gonzalez accepted the largest variety of food items. This was the only predator to have high oviposition rate when fed $C$. heveae and $T$. heveae as prey. Euseius concordis (Chant) and $A$. floridamus had approximately the same oviposition rate on, ca. reaching 1,0 egg/female/day. Neoseiulus anonymus (Chant \& Baker) had highest oviposition rates when fed the tetranychids Oligonychus gossypii (Zacher) and Tetranychus mexicamus (McGregor). The biology of A. floridanus was studied at $25,5 \pm 1^{\circ} \mathrm{C}$, photophases of 12 hours and $80 \pm 5 \%$ relative humidity. Most biological parameters differed between mated and non-mated females. The net reproductive rate (Ro) indicated that the population of A. floridamus increases 13,2 times in each generation; the mean developmental fine of each generation (T) was 19,2 days. The intrinsic rate of population increase $(\mathrm{rm})$ was 0,16 , while the finite rate of increase $(\lambda)$, was of 1,1 . Studies conducted to evaluate the selectivity of pesticide to $E$. concordis and $N$. anonymus indicated that endosulfan at $320 \mathrm{ppm}$, dicophol at $100 \mathrm{ppm}$, oxid of fenbutanine at 100 and $320 \mathrm{ppm}$ were harmless to E. concordis, while endosulfan at 320 ppm and dicophol at $100 \mathrm{ppm}$ were harmless to $N$. anonymus. 


\section{INTRODUÇÃO}

A borracha natural é fabricada do látex produzido por árvores da família Euphorbiaceae, vulgarmente conhecidas como seringueiras, que pertencem ao gênero Hevea. As seringueiras apresentam folhas compostas, trifoliadas, longo-pecioladas, pilosas ou glabras. Todas as 11 espécies deste gênero são lenhosas e arbóreas. Dentre estas espécies, destaca-se Hevea brasiliensis Muell. Arg. por apresentar superioridade na produção e na qualidade do látex (Gonçalves et al., 1983).

A seringueira é comumente atacada por diversas espécies de insetos e ácaros nas áreas onde é cultivada, sendo algumas destas espécies consideradas pragas de importância (Manual Técnico, 1983; Silva, 1972). Apesar da cultura da seringueira ser nativa e explorada economicamente na região amazônica desde o século XVIII, pouco se sabe sobre os ácaros presentes nesta cultura. A maioria dos trabalhos realizados, até o momento, se refere à descrição de novas espécies ou relata a presença de espécies atacando esta cultura. Muito pouco é conhecido sobre a flutuação populacional ou o papel desempenhado pelos ácaros em seringueira. Os ácaros passaram a ser considerados economicamente importantes nesta cultura a partir dos anos 90 , quando foram responsabilizados por danos causados que resultaram na redução de produtividade. Os ácaros fitófagos mais encontrados em seringueira pertencem às famílias Eriophyidae, Tarsonemidae, Tenuipalpidae e Tetranychidae (Fazolin \& Pereira, 1989; Flechtmann, 1989; Feres, 2000). Dentre estes, Calacarus heveae Feres e Temuipalpus heveae Baker são considerados os mais importantes (Feres, 1992; Feres 2000). C. heveae prefere a face adaxial dos folíolos (Feres, 1992; Vieira \& Gomes, 1999), causa a perda do brilho, amarelecimento, bronzeamento e conseqüente queda prematura dos mesmos (Feres, 1992 e 2000). Segundo Vieira \& Gomes (1999), o ataque 
de $C$ heveae pode provocar níveis de desfolha acima de $75 \%$ em clone da variedade RRIM 600. Segundo Feres (2000), alguns produtores do Estado de São Paulo afirmam que $C$. heveae ocasiona perdas de até $30 \%$ na produção de látex. T. heveae é um tenuipalpídeo que predomina na face abaxial dos folíolos, embora, quando em altas infestações, seja também encontrado na face adaxial (Feres, 2000). Causa amarelecimento das folhas atacadas, contribuindo para a queda prematura.

Os projetos de controle biológico aplicado de espécies nativas são tecnicamente mais complicados do que os de espécies invasoras. Uma espécie nativa já tem associações com uma variedade de inimigos naturais presentes no local considerado, que deveriam mantê-la sob controle efetivo. No entanto, as práticas de cultivo de uma cultura tendem, freqüentemente, a favorecer o aumento populacional de organismos fitófagos nativos e, paralelamente, a reduzir a eficácia dos inimigos naturais responsáveis por seu controle natural. Uma das formas de fomentar o controle biológico das pragas nativas é a modificação de práticas agrícolas, visando a favorecer as atividades dos inimigos naturais (Van den Bosch et al., 1982).

Conhecer a biologia e a flutuação das espécies de ácaros presentes na cultura da seringueira é um dos pré-requisitos para definir as espécies de maior importância. A partir destas informações, será possível estabelecer programas de manejo que visem a manter as populações de ácaros fitófagos abaixo do nível de dano.

Este trabalho teve por objetivo estudar a fauna acarina presente na seringueira, conhecer a ecologia das principais espécies de ácaros fitófagos e predadores presentes nesta cultura, no Estado do Mato Grosso, e estudar alguns aspectos do controle de $C$. heveae e $T$. heveae. 


\section{REVISÃO DE LITERATURA}

\subsection{A cultura da seringueira no Brasil}

A partir do início da exploração de seringais nativos, em 1841, a borracha passou a desempenhar importante papel na economia brasileira, com o apogeu entre 1880 e 1910, quando constituiu o segundo produto na pauta de exportações brasileiras (Virgens Filho, 1983). A primeira tentativa de implantação de seringais em monocultivo no país foi feita por Henry Ford, que plantou seringais em Fordlândia e Belterra nos anos de 1928 e 1932, respectivamente, no Estado do Pará. Nos anos 70 e 80, através de programas de estímulo governamental, foram implantados seringais nos Estados da Bahia, Mato Grosso e São Paulo (Vetorazzi \& Viegas, 1983).

Com a expansão da produção de borracha na Ásia, o Brasil perdeu a hegemonia mundial por não conseguir competir com os preços praticados pelos asiáticos. Nos anos 50, com o aumento da demanda interna de borracha natural, em virtude do início da indústria automobilística, e com o declínio da produção, o Brasil passou de exportador a importador da borracha natural.

$\mathrm{Na}$ atualidade, em função da extração crescente nos seringais adultos e da entrada em produção de novas áreas de plantio, a produção vem se expandindo no Brasil. Estima-se que a produção nacional atenda hoje cerca de $38 \%$ do consumo interno, concentrando-se esta principalmente nos Estados de São Paulo (34\%), Mato Grosso (29\%) e Bahia (15\%) (Cortez \& Martin, 1996). 


\subsection{A subclasse Acari}

Os organismos do filo Arthropoda se caracterizam por apresentar exoesqueleto quitinoso e apêndices articulados. Neste filo existe o subfilo Chelicerata, sendo a classe Arachnida o principal grupo. Os aracnídeos são quelicerados, principalmente terrestres, dentre os quais se inclui a subclasse Acari (Krantz, 1978).

A subclasse Acari compreende os ácaros e carrapatos que diferem dos demais aracnídeos pela ausência de segmentação aparente e divisão do corpo (Flechtmann, 1977; Krantz, 1978; Evans, 1992). A perda da segmentação levou os autores a considerar os ácaros como artrópodes altamente especializados e membros de um grupo que se afastou muito cedo de outras linhas de evolução do filo Arthropoda (Flechtmann, 1977).

A subclasse Acari é dividida nas superordens Anactinotrichida e Actinotrichida. A primeira é subdividida nas ordens Holothyrida, Ixodida, Mesostigmata e Notostigmata, enquanto que a segunda é subdividida nas ordens Astigmata, Oribatida e Prostigmata (Evans, 1992).

Os ácaros plantícolas de maior importância pertencem às ordens Prostigmata, contendo a maioria das espécies fitófagas, e Mesotigmata, composta principalmente por predadores.

$\mathrm{Na}$ ordem Prostigmata, destacam-se as famílias Eriophyidae, Tarsonemidae, Tenuipalpidae e Tetranychidae, que contém as espécies mais importantes (Jeppson et al., 1975). Destacam-se também as famílias Anystidae, Cheyletidae, Bdellidae, Cunaxidae, Stigmaeidae e Tydeidae (subfamília Pronematinae), constituídas de espécies predominantemente predadoras (Flechtmann, 1986; Laing \& Knop, 1985).

$\mathrm{Na}$ ordem Mesostigmata, os ácaros da família Phytoseiidae constituem o principal grupo de ácaros predadores de ácaros fitófagos, principalmente do ponto de vista aplicado (Moraes et al., 1986). 


\section{3 Ácaros em seringueira no Brasil}

A composição de espécies de ácaros em plantas do gênero Hevea é relativamente pouco conhecida no Brasil, à exceção de alguns trabalhos que relatam ácaros das ordens Astigmata, Mesostigmata e Prostigmata (Bergmann, 1991; Fazolin \& Pereira, 1989; Feres, 1992; Feres, 1998; Feres, 2000; Feres, 2001; Flechtmann, 1989; Flechtmann \& Arleu, 1984; Silva, 1972).

$\mathrm{Na}$ ordem Astigmata, apenas um representante da família Acaridae, Tyrophagus putrescentiae (Schrank), e um representante da família Winterschmidtiidae, Oulenzia sp., foram relatados nesta cultura (Feres, 2000).

Dentre os Mesostigmata, apenas ácaros da família Phytoseiidae foram relatados em seringueira (Bergmann, 1991; Flechtmann \& Arleu, 1984; Feres, 2000), sendo reconhecidas 8 espécies: Euseius citrifolius Denmark \& Muma, Euseius concordis (Chant), Galendromus annectens (DeLeon), Galendromus mexicanus Muma, Iphiseiodes sp.; Neoseiulus anonymus (Chant \& Baker), Neoseiulus barkeri Hughes e Typhlodromus (Anthoseius) transvaalensis (Nesbitt).

$\mathrm{Na}$ ordem Prostigmata, espécies acarinas de 8 famílias são citadas nesta cultura (Bergmann, 1991; Fazolin \& Pereira, 1989; Flechtmann \& Arleu, 1984; Feres, 1992; Feres, 1998; Feres, 2000 Silva, 1972). Nas famílias Cheyletidae e Cunaxidae foram identificados Hemicheyletia wellsi (Baker) e Pseudobonzia sp., respectivamente. Já na família Eriophyidae, 3 espécies são conhecidas: Calacarus heveae Feres, Phyllocoptruta seringueirae Feres e Schevtchenkella petiolula Feres. Na família Stigmaeidae, duas espécies não identificadas dos gêneros Agistemus e Zetzellia foram relatadas por Feres (2000). Dentre os Tarsonemidae, foram relatados Daidalotarsonemus sp., Polyphagotarsonemus latus (Banks) e Tarsonemus sp., enquanto que na família Tenuipalpidae foram relatados Brevipalpus phoenicis (Gijskes) e Tenuipalpus heveae Baker. Na família Tetranychidae, são conhecidas 5 espécies: Allonychus braziliensis (McGregor), Eutetranychus banksi (McGregor), Oligonychus coffeae (Nietner), Oligonychus gossypii (Zacher) e Tetranychus mexicanus (McGregor). Dentre os Tydeidae, uma espécie de Lorryia sp. foi relatada por Flechtmann \& Arleu (1984) e 
mais 6 espécies foram citadas por Feres (2000) nesta cultura: Lorryia formosa Cooreman, Lorryia boycei (Baker), Tydeus kenyensis Baker, Tydeus sp., Pronematus sp. e Parapronematus sp..

\subsection{Dano provocado por ácaros na cultura da seringueira}

Poucos trabalhos foram realizados até o momento para conhecer os danos provocados por ácaros na cultura da seringueira. Estes trabalhos mencionam 4 espécies como danosas a esta cultura.

Severa desfolha da seringueira, devido ao ataque de $C \cdot$ heveae, foi relatada pela primeira vez no Estado de São Paulo, em abril e maio de 1991. Esta espécie tem sido responsabilizada pelo bronzeamento e queda prematura das folhas (Feres, 1992). Segundo Vieira \& Gomes (1999), esta mesma espécie causou, nos meses de maio e

junho, o desfolhamento prematuro de até $75 \%$ das plantas do clone PB 260, no Estado de São Paulo. Feres (2000) afirmou que alguns produtores de seringueira estimam que $C \cdot$ heveae ocasione perdas de até $30 \%$ na produção de látex de $H$. brasiliensis.

Foram observadas altas populações de O. gossypii nos Estados do Acre e do Amazonas, no período seco, entre agosto e setembro. Os sintomas de ataque se evidenciam nos meses de outubro a dezembro, caracterizando-se pelo bronzeamento das duas faces do folíolo (Fazolin \& Pereira, 1989).

A ação de $P$. latus se restringe aos brotos e gemas. As folhas crescem deformadas, podendo se fender, e sua face abaxial pode se tornar bronzeada. Plantas severamente atacadas têm o crescimento paralisado (Flechtmann \& Arleu, 1984).

Altas populações de $T$. heveae foram observadas no Estado de São Paulo e Goiás, sendo considerada uma das espécies que contribui para o desfolhamento prematuro da seringueira (R.J.F. Feres, informação pessoal). 


\section{DISTRIBUIÇÃO ESPACIAL E PLANO DE AMOSTRAGEM DE Calacarus heveae (ACARI: ERIOPHYIDAE) EM SERINGUEIRA}

\section{RESUMO}

Calacarus heveae Feres é um eriofideo descrito de espécimes coletados em plantas de seringueira (Hevea brasiliensis Muell. Arg.) na região noroeste do Estado de São Paulo. Este ácaro prefere a face adaxial dos folíolos e pode causar a perda do brilho, amarelecimento e bronzeamento desta região e a subsequente queda prematura das folhas. $\mathrm{O}$ objetivo deste trabalho foi analisar a distribuição de $C$. heveae em seringueira, selecionar a unidade de amostragem mais representativa e desenvolver um plano de amostragem para o estudo de sua flutuação populacional. O trabalho foi conduzido com os clones PB 260 e IAN 873, respectivamente nos municípios de Itiquira e Pontes e Lacerda, ambos no Estado do Mato Grosso. Em Itiquira, diferenças significativas foram observadas em 4 ocasiões em relação ao número médio de ácaros por folha nos diferentes estratos das plantas. Nas amostragens realizadas em Pontes e Lacerda, nenhuma diferença significativa foi encontrada entre os estratos em relação àquele parâmetro. Apenas em Itiquira, em uma amostragem, foi verificada diferença entre os 3 estratos, em relação à proporção de folhas infestadas. Nenhuma diferença significativa foi verificada em relação ao número médio de ácaros por folha e proporção de folhas infestadas por $C$. heveae a diferentes distâncias da periferia da copa. C. heveae exibe distribuição agregada no campo. Para estimar a densidade de $C$. heveae, um plano numérico e um plano binomial de amostragem foram desenvolvidos. 


\section{SPACIAL DISTRIBUCTION AND SAMPLLING PLAN FOR Calacarus heveae (ACARI: ERIOPHYIDAE) ON RUBBER TREES}

\section{SUMMARY}

Calacarus heveae Feres is an Eriophyidae mite described from specimens collected on rubber tree (Hevea brasiliensis Muell. Arg.) in the northwest region of the State of São Paulo. This mite prefers the adaxial face of the folioles which it can turn dry, yellowish and brownish; it can also cause leaf fall. The aim of this work was to analyse the distribution of $C$. heveae on rubber trees, to select the most representative sampling unit and to develop a sampling plan to determine the population's fluctuation. This study was conducted with clones PB 260 and IAN 873, in Itiquira and Pontes e Lacerda, respectively, both in the State of Mato Grosso. In Itiquira, significant differences were observed in 4 occasions in relation to the average number of mites per leaf in the different plant strata. In the samples conducted in Pontes e Lacerda, no significant differences were observed between strata in relation to that parameter. Only in Itiquira, in a sampling, a significant difference between strata was verified in relation to the proportion of leaves infested. No significant differences were verified in relation to the average number of mites per leaf and proportion of leaves infested by $C$. heveae at different depths in the canopy. $C$. heveae exhibits aggregated distribution in the field. To estimate the density of $C \cdot$ heveae, a numeric plan and a sampling plan were developed. 


\subsection{INTRODUÇÃO}

Calacarus heveae Feres é um eriofideo descrito de espécimes coletados em plantas de seringueira (Hevea brasiliensis Muell. Arg.) na região noroeste do Estado de São Paulo (Feres, 1992). Este ácaro prefere a face adaxial dos folíolos (Vieira \& Gomes, 1999; Capítulo 5), podendo causar a perda do brilho, amarelecimento e bronzeamento desta região, e a subseqüente queda prematura das folhas (Feres, 2000). De acordo com Vieira \& Gomes (1999), que acompanharam a dinâmica populacional de $C$. heveae no município de Reginópolis, no Estado de São Paulo, o maior desenvolvimento populacional aconteceu no primeiro semestre, coincidindo com o período de maior produção de látex. Os mesmos autores concluíram que esta espécie pode provocar níveis de desfolha acima de 75\% no clone RRIM 600. Segundo Feres (2000), alguns produtores afirmam que $C$. heveae pode ocasionar perdas de até $30 \%$ na produção de látex de $H$. brasiliensis.

$\mathrm{O}$ conhecimento da dinâmica populacional da praga é um pré-requisito para a definição de um programa de manejo integrado. Um processo de amostragem simples, rápido e acurado é necessário para estimar a densidade, permitindo o efetivo manejo da praga. Nenhum plano de amostragem para estimar a densidade populacional ou para definir a unidade de amostragem de $C$. heveae em seringueira foi ainda estabelecido.

$O$ objetivo deste trabalho foi analisar a distribuição de $C$. heveae na seringueira, selecionar a unidade de amostragem mais representativa e desenvolver um plano de amostragem para o estudo de sua flutuação populacional.

\subsection{MATERIAL E MÉTODOS}

Este estudo foi conduzido em campos de seringueira das Plantações Edouard Michelin Ltda., no município de Itiquira, e da Triângulo Agro-industrial S/A, no município de Pontes e Lacerda, ambos no Estado do Mato Grosso.

Os campos foram escolhidos nas áreas de variedades suscetíveis ao ácaro. Em Itiquira, foi escolhida a variedade PB 260 e em Pontes e Lacerda, a variedade IAN 873, 
com 10 anos e 12 anos do transplantio, respectivamente. A densidade média destes campos era de cerca de 500 plantas por hectares e a altura aproximada das plantas era de 20 metros. Nenhum tratamento químico foi realizado durante o estudo. A última aplicação de agroquímicos havia sido realizada cerca de 6 meses antes do início do trabalho.

\subsubsection{Distribuição de Calacarus heveae na planta: seleção de uma unidade de amos- tragem}

Dez árvores foram definidas ao acaso em cada campo, a pelo menos 20 metros das bordas do plantio, para a realização das amostragens. As amostragens foram feitas, mensalmente, de setembro de 1998 a agosto de 1999. Para definir a distribuição de $C$. heveae verticalmente na planta, as árvores foram divididas em três estratos: basal, mediano e apical.

Mensalmente, foram coletadas três folhas da periferia de cada um dos estratos de cada planta, sendo uma em cada uma das regiões distal, mediana e proximal dos ramos. Devido à disposição das plantas, as coletas foram feitas entre as linhas no quadrante leste, onde havia maior quantidade de folhas.

O estudo da distribuição de $C$. heveae em relação à distância a partir da periferia da planta foi feita apenas no estrato mediano da altura da copa, nos quadrantes leste e oeste, de onde foram retiradas 3 folhas de cada quadrante. Uma das folhas foi tomada da região média de ramos da periferia da copa, outra na mesma posição de ramos próximos ao caule e outra na mesma posição em ramos da região intermediária em relação à profundidade da copa.

As folhas foram individualizadas em sacos de papel e levadas ao laboratório para contagem das formas móveis. A contagem foi realizada sob microscópio estereoscópico, observando-se as duas faces das folhas.

Nestas áreas nenhum tratamento com agroquímicos foi realizado durante o desenvolvimento do trabalho. A última aplicação de agroquímicos nestas áreas havia sido realizada cerca de 6 meses antes do início do trabalho. 
As densidades de ácaros por folha nos diferentes pontos de amostragem foram comparadas usando a análise de variância (ANOVA), adotando-se o delineamento experimental inteiramente casualizado. Para os cálculos, o número médio de ácaros foi transformado em $\log (x+1)$, enquanto que a proporção de ácaros por estrato foi transformado em arcosen $V_{x}(Z a r, 1984)$. A proporção de folhas infestadas, por extrato, foi comparada usando o teste de $\mathrm{X}^{2}$. O nível de significância foi fixado em $\mathrm{P}<0,05$.

\subsubsection{Distribuição entre plantas}

Para a realização dos cálculos da distribuição de $C$. heveae entre as plantas, foram consideradas as populações observadas nas 3 folhas coletadas na periferia de cada um dos estratos basal, mediano e apical, totalizando 9 folhas por planta.

$\mathrm{O}$ padrão de dispersão de $\mathrm{C}$. heveae no campo foi analisado através da lei de Taylor (Taylor, 1961), onde:

$$
\mathrm{s}^{2}=\mathrm{a} \cdot \mathrm{m}^{\mathrm{b}}
$$

Esta lei relaciona a média da densidade populacional $(\mathrm{m})$ com sua variância $\left(\mathrm{s}^{2}\right)$. O fator "b" se refere ao índice de agregação, com $b>1, b=1$, e b $<1$ indicando agregação, distribuição ao acaso ou distribuição regular, respectivamente. Os coeficientes a e b foram calculados através de regressão não linear da equação da lei de Taylor.

\subsubsection{Correlação entre densidade populacional e proporção de folhas atacadas.}

Para a realização dos cálculos da densidade populacional e a proporção das folhas atacadas por $C$. heveae foram utilizadas as populações observadas nas 3 folhas coletadas na periferia de cada um dos estratos basal, mediano e apical, totalizando 9 folhas por planta.

Wilson \& Room (1983) incorporaram a lei de Taylor num modelo que descreve a relação entre a proporção de unidades de amostragem infestadas $\{\mathrm{P}(\mathrm{I})\}$ e a densidade média de ácaros em cada unidade amostral $(\mathrm{m})$, como segue: 
$\mathrm{P}(\mathrm{I})=1-\exp \left(-\mathrm{m} \cdot\left(\log _{\mathrm{e}}\left(\mathrm{a} \cdot \mathrm{m}^{\mathrm{b}-1}\right) /\left(\mathrm{a} \cdot \mathrm{m}^{\mathrm{b}-1}-1\right)\right)\right.$, onde "a" e "b" são os coeficientes de Taylor. Predições da densidade e de sua variância, usadas no plano binomial de amostragem subseqüente foram transformadas de acordo com Schaalje et al. (1991).

\subsubsection{Plano numérico de amostragem}

Para o desenvolvimento do plano numérico de amostragem de $C$. heveae foram utilizadas as populações observadas, durante o período de estudo, nas 3 folhas coletadas na periferia de cada um dos estratos basal, mediano e apical das plantas amostradas, totalizando 9 folhas.

Wilson \& Room (1983) incorporaram a lei de Taylor à equação geral proposta por Karadinos (1976), para calcular o número mínimo de amostras (N) a serem tomadas para calcular a densidade média $(\mathrm{m})$ a um determinado nível de confiança $\left(\mathrm{D}_{0}\right)$, expresso na seguinte proporção de médias:

$$
\mathrm{N}=\left(\mathrm{Z}_{\mathrm{a} / 2} / \mathrm{D}_{0}\right)^{2} \cdot \mathrm{a} \cdot \mathrm{m}^{\mathrm{b}-2}
$$

com $Z_{\mathrm{a} / 2}$ sendo o padrão normal de desvio de 1,96 e o coeficiente de confiança de 0,9 .

\subsubsection{Plano binomial de amostragem}

Para a realização dos cálculos do plano binomial de amostragem para $C$. heveae foram utilizadas as populações encontradas nas 3 folhas coletadas na periferia de cada um dos estratos basal, mediano e apical, totalizando 9 folhas.

Para o cálculo do número mínimo de amostras com base na observação da presença ou ausência de ácaros em cada amostra, utilizou-se a seguinte equação proposta também por Karandinos (1976):

$$
N=\left(t / D_{p i}\right)^{2} \cdot q / p
$$

onde $\mathrm{N}$ é o número de amostras necessárias para estimar a média, $\mathrm{p}=\mathrm{P}(\mathrm{I}), \mathrm{q}=1$-p e $D_{p i}$ é o nível de confiança que $\mathrm{p}$ obteve usando a equação da Lei Wilson \& Room (1983), apresentada no item 3.2.3 deste Capítulo, para achar limites de $\mathrm{p} \mathrm{em} \mathrm{m} \pm \mathrm{D}_{\mathrm{m}}$, onde $\mathrm{D}_{\mathrm{m}}$ é uma proporção fixa da média. 


\subsection{RESULTADOS}

C. heveae mostrou uma nítida preferência pela face adaxial dos folíolos, pois poucos indivíduos foram encontrados na face abaxial. Somente foram encontrados indivíduos desta espécie na face abaxial dos folíolos quando altas populações foram observadas na face adaxial. Desta forma, para a realização destes estudos foram utilizadas as populações de $C$. heveae observadas na face adaxial.

\subsubsection{Distribuição de Calacarus heveae na planta de seringueira.}

Em Itiquira, diferenças significativas foram observadas em 4 ocasiões em relação ao número médio de ácaros por folha nos diferentes estratos da $\mathrm{s}$ plantas (Figura 1A). Nos meses de novembro e dezembro de 1998, os níveis no estrato basal foram maiores que os níveis encontrados no estrato apical; no mês de janeiro de 1999, o estrato basal apresentou maior número de ácaros que os demais estratos. A população do estrato basal, no início do mês de dezembro de 1998, alcançou cerca de 100 ácaros/folha, enquanto nos demais estratos os níveis populacionais chegaram próximo de 75 ácaros/folha. Apenas em dezembro foram observadas altas populações de $C$. heveae. Nas amostragens realizadas em Pontes e Lacerda, nenhuma diferença significativa foi encontrada entre os estratos com relação ao número médio de ácaros por folha (Figura 1B). Neste local, a densidade populacional esteve sempre baixa, atingindo no máximo 4 ácaros/folha, no estrato apical, no mês de dezembro de 1998.

Em Itiquira, a proporção de ácaros presentes em cada estrato, em relação ao total de ácaros encontrados, foi significativamente maior no estrato basal nas amostras coletadas em novembro de 1998, e janeiro e maio de 1999 (Figura 1C). No mês de dezembro de 1998, a proporção de ácaros foi significativamente menor no estrato basal. Em Pontes e Lacerda, não foi observada diferença significativa entre os estratos em relação à proporção de ácaros encontrados em cada um (Figura 1D). 
Ácaros/estrato - itiquira

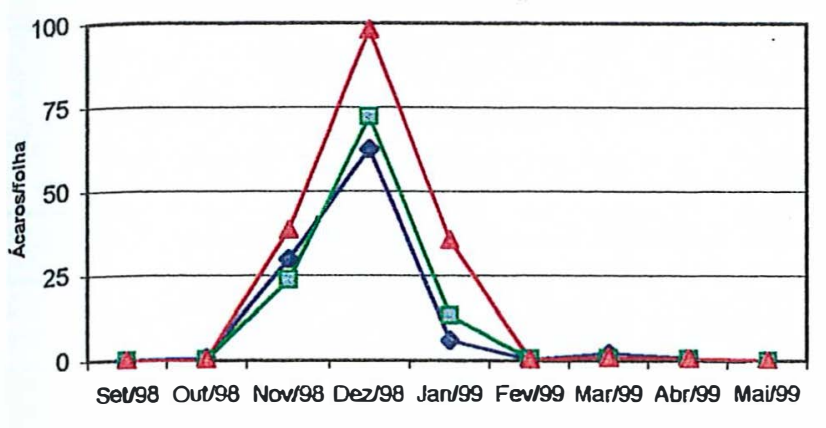

Mês

$\multimap$ Apical $\multimap-$ Mediano $\multimap-8 a s a l$

Itiquira - MT

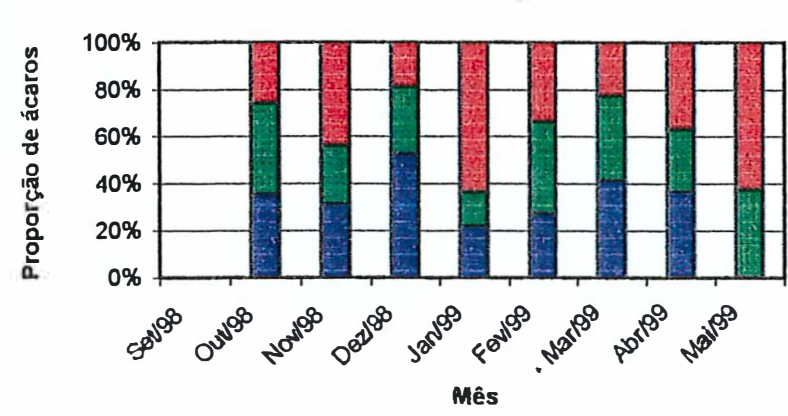

aplcal Medlano aBasal

Itiquira - MT

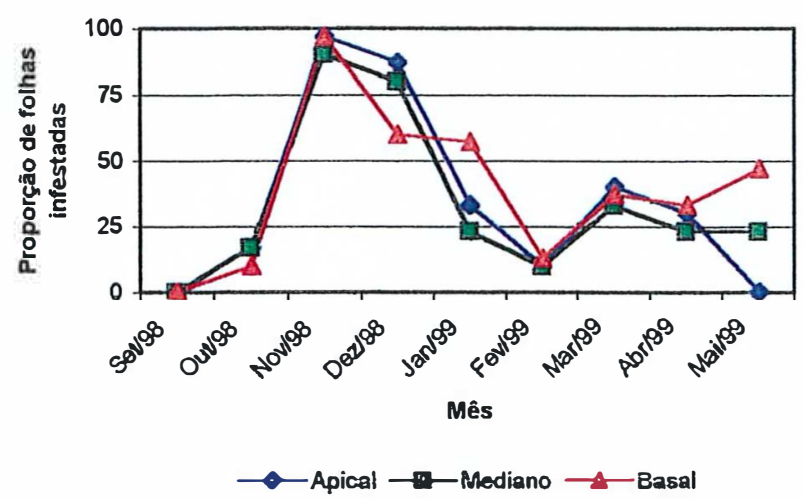

A

C
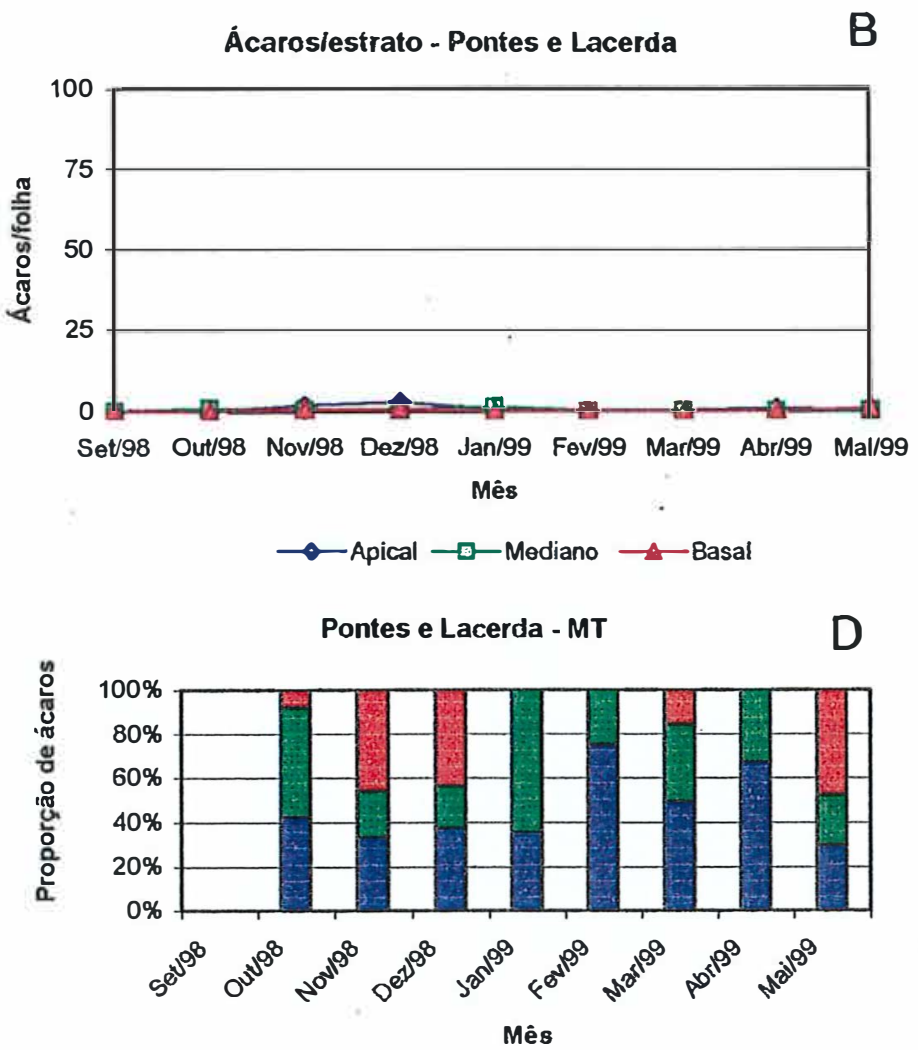

aplcal Dedlano EBasal

Pontes e Lacerda - MT

$\mathrm{F}$

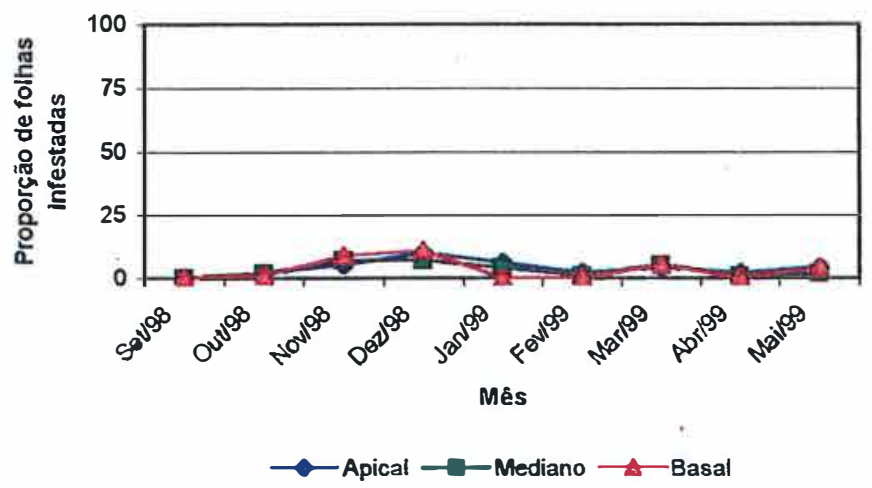

Figura 1 - Número médio (A, B), percentagem de ácaros presentes em cada estrato $(C, D)$ e proporção de folhas infestadas $(\mathrm{E}, \mathrm{F})$, por estrato, em plantas de seringueira nos municipios de Itiquira e Pontes e Lacerda, no Estado do Mato Grosso. 
Com exceção da amostragem feita em maio de 1999 em Itiquira, nenhuma diferença foi verificada em relação à proporção de folhas infestada nos 3 estratos (Figura $1 \mathrm{E}$ e 1F).

\subsubsection{Distribuição de Calacarus heveae de acordo com a distância a partir da peri- feria da copa.}

Apenas nos meses de janeiro e março de 1999, em Itiquira e Pontes e Lacerda, respectivamente, foram encontradas diferenças significativas quanto ao número médio de ácaros e proporção de folhas infestadas por C. heveae em diferentes distâncias da periferia da copa (Tabela 1).

Tabela 1. Diferença entre o número médio de ácaros e proporção de folhas infestadas por C. heveae, em diferentes distâncias da periferia da copa da planta de seringueira, nos clones PB 260 e IAN 873, entre os meses de setembro de 1998 a maio de 1999, em Itiquira e Pontes e Lacerda, no Estado do Mato Grosso.

\begin{tabular}{llllllllll}
\hline \multicolumn{1}{c}{ Itiquira } \\
\hline Mês & $09 / 98$ & $10 / 98$ & $11 / 98$ & $12 / 98$ & $01 / 99$ & $02 / 99$ & $03 / 99$ & $04 / 99$ & $05 / 99$ \\
$\mathrm{~F}$ & 0,3 & 0,9 & 1,1 & 2,6 & 3,7 & 0,05 & 0,3 & 1,6 & 0,08 \\
$\mathrm{p}$ & 0,7 & 0,4 & 0,3 & 0,7 & 0,03 & 0,9 & 0,7 & 0,2 & 0,9 \\
\hline \multicolumn{8}{c}{ Pontes e Lacerda } \\
\hline Mês & $09 / 98$ & $10 / 98$ & $11 / 98$ & $12 / 98$ & $01 / 99$ & $02 / 99$ & $03 / 99$ & $04 / 99$ & $05 / 99$ \\
$\mathrm{~F}$ & 1,4 & 0,8 & 0,2 & 0,3 & 1 & 2,1 & 4,2 & 2,3 & 0,5 \\
$\mathrm{p}$ & 0,2 & 0,4 & 0,7 & 0,6 & 0,3 & 0,1 & 0,01 & 0,1 & 0,6 \\
\hline
\end{tabular}

$\mathrm{F}=$ valor do teste ANOVA de Fisher.

$p=(p<0.05)$ diferença entre as distâncias da periferia da copa da planta de seringueira. 


\subsubsection{Distribuição entre as plantas}

Os parâmetros da lei de Taylor (1961) mostram a relação entre a variância e o número de $C$. heveae observado na folhas do extrato médio para todas as densidades populacionais, dados de amostragens e a disposição da espécie na planta. Os parâmetros são: $a=7,35 ; b=1,44 ; r 2=0,94$ e df $=14$. O parâmetro " $b$ " foi significativamente maior que 1 , indicando que $C$. heveae exibe distribuição agregada no campo (Figura 2).

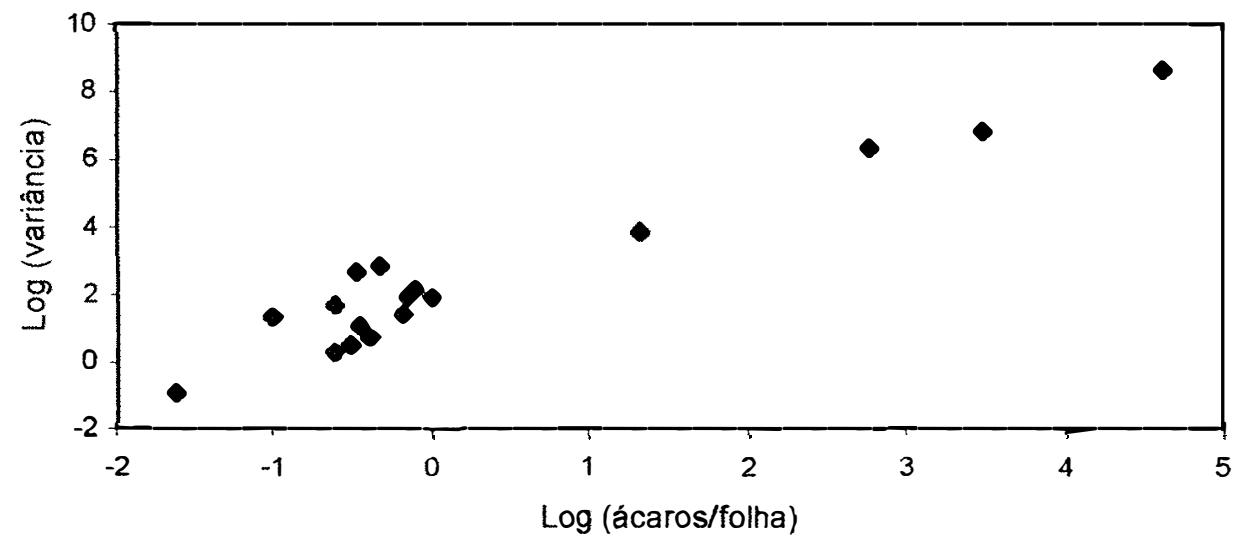

Figura 2 - Relação entre o logaritmo do número de Calacarus heveae por folha e o logaritmo de sua variância nas 180 folhas amostradas mensalmente, entre setembro de 1998 e agosto de 1999, nos clones PB 260 e IAN 873 em Itiquira e Pontes e Lacerda, respectivamente.

\subsubsection{Correlação entre densidade populacional e proporção de folhas atacadas}

A figura 3 mostra a relação entre a densidade média de ácaros por folha e a proporção de folhas infestadas. A curva gerada pela equação de Wilson \& Room (1983), modificada segundo Schallje et al. (1991) representa a relação observada no campo. A relação entre a proporção de folhas infestadas e o número médio de ácaros por folha pode ser usada como uma estimativa preliminar das densidades populacionais de $C$. 
heveae, afim de escolher o tamanho ótimo de amostras. Assim, para facilitar o trabalho de campo observa-se a proporção de folhas com ácaros e, a partir disso, estima-se a média de ácaros por folha, num determinado momento.

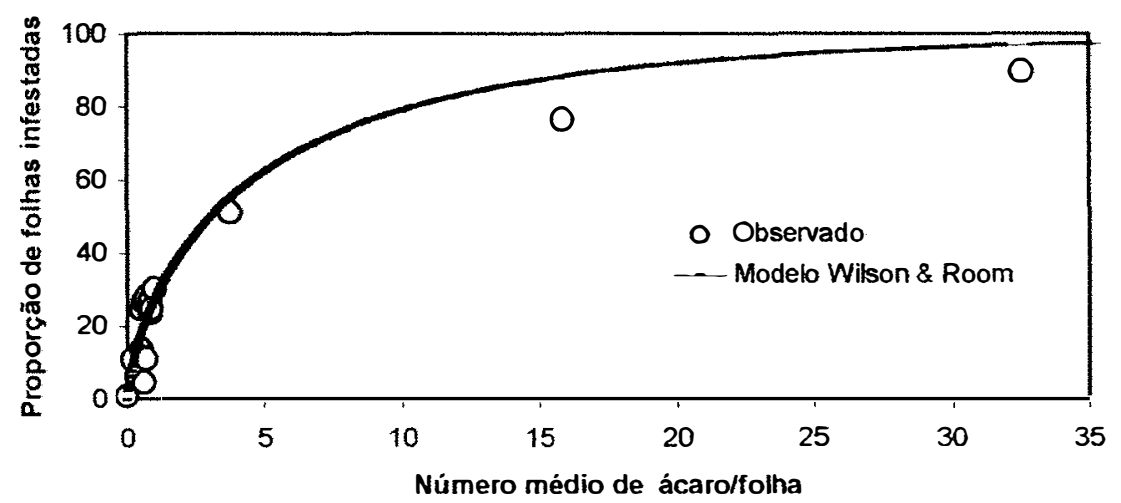

Figura 3 - Relação entre o número médio de ácaros por folha e as folhas infestadas com Calacarus heveae. A curva indica a estimativa desta relação segundo o modelo de Wilson \& Room, modificado segundo Schallje et al. (1991).

\subsubsection{Plano numérico de amostragem}

O número mínimo de amostras exigido para calcular a densidade populacional através do uso de um plano numérico para um determinado nível de precisão $\mathrm{D}_{0}$ é apresentado à figura 4. De acordo com os resultados obtidos, para uma densidade média de 5,0 ácaros por folha, o tamanho mínimo da amostra é de aproximadamente 150 folhas por campo, para um nível de precisão de $\mathrm{D}_{0}$ de 0.3 , e cerca de 300 folhas, para um nível de precisão de 0.2 . 


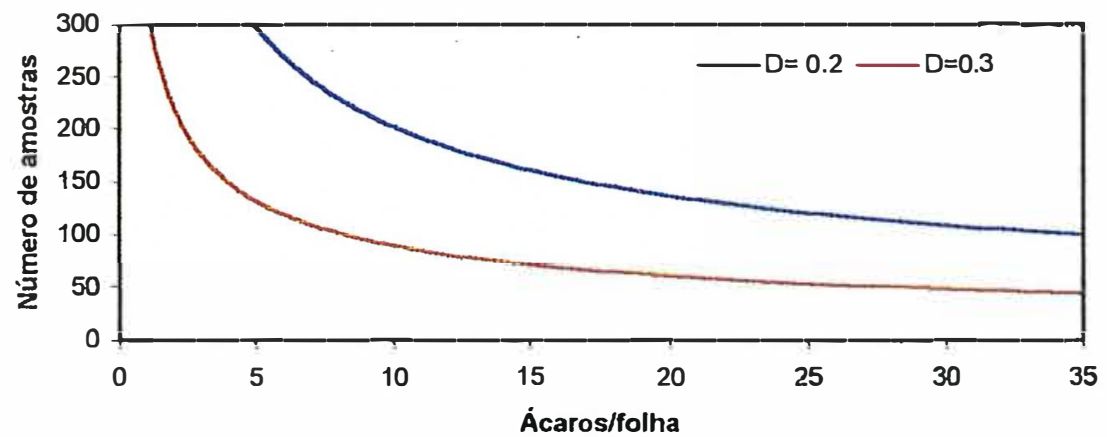

Figura 4 - Número mínimo de amostras necessárias para estimar a densidade de Calacarus heveae, usando o plano de amostragem numérica para um determinado nível de precisão.

\subsubsection{Plano binomial de amostragem}

A figura 5 mostra o número mínimo de amostras a serem tomadas para estimar a densidade populacional de $C$. heveae, com diferentes níveis de confiança, quando se usa a proporção de folhas com ácaros. De acordo com os resultados obtidos, para uma densidade média de 5,0 ácaros por folha, o tamanho mínimo da amostra é de aproximadamente 50 folhas por campo, para um nível de precisão de $D_{0}$ de 0.3 , e cerca de 100 folhas, para um nível de precisão de 0.2 . 


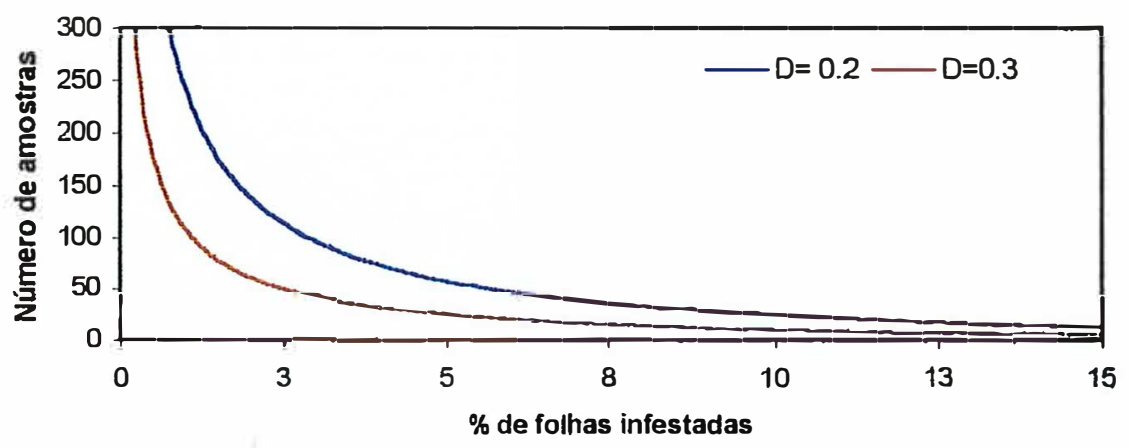

Figura 5 - Número mínimo de amostras necessárias par estimar a densidade de Calacarus heveae, usando a avaliação da presença ao ausência de ácaros nas folhas para um determinado nível de precisão.

\subsection{DISCUSSÃO}

Devido à dificuldade da contagem de todas as folhas de uma árvore, para definir a população de uma determinada espécie, é necessário definir uma unidade de amostragem que possa de forma confiável ser utilizada para estimar aquela população. Neste estudo, o estrato mediano não apresentou diferença significativa quanto à densidade de ácaros e à proporção de folhas infestadas em relação aos demais estratos, demonstrando ser a região da planta mais representativa no estudo da flutuação populacional de $C$. heveae.

Os resultados deste estudo demonstram a alta capacidade de dispersão de $C$. heveae na planta, de vez que uma grande proporção de folhas estiveram infestadas mesmo a níveis populacionais muito baixos. Como exemplo, quando o nível médio de ácaros por folha era de apenas 5 ácaros, cerca de $70 \%$ das folhas dos estratos basal, mediano e apical das plantas apresentavam ácaros. Esta grande capacidade de colonização da planta, indica, provavelmente que esta espécie utilize ramos ou fissuras da epiderme da planta para a estivação. Outra possibilidades seria a presença de estimulo à migração mesmo quando presentes baixos números de ácaros por folha. 
A avaliação apenas da presença ou ausência de ácaros nas folhas demonstrou ser mais adequado do que o numérico, pois com menor número de folhas e em menor tempo é possível avaliar a população de $C$. heveae. Esta forma de amostragem é de fácil aplicação quando é observada apenas uma espécie num determinado ambiente ou no caso da espécie ser reconhecida com facilidade. Entretanto, devido a presença de mais de uma espécie de eriofideo na cultura da seringueira (Capítulos 4 e 5), este plano tornase de dificil aplicação no campo para a cultura da seringueira. As dificuldades observadas para o plano binomial também se aplicam para o plano numérico, pois para a contagem de ácaros é preciso reconhecer e diferenciar os eriofideos presentes nesta cultura.

\subsection{CONCLUSÕES}

1) O estrato mediano é o local mais adequado para a retirada das folhas para conhecer as populações de Calacarus heveae na cultura da seringueira.

2) Calacarus heveae exibe distribuição agregada no campo. 


\section{4 ÁCAROS (ARACHNIDA: ACARI) DA SERINGUEIRA (Hevea brasiliensis Muell. Arg.) NO ESTADO DO MATO GROSSO}

\section{RESUMO}

Os ácaros passaram a ser considerados economicamente importantes na cultura da seringueira a partir dos anos 90 , quando foram responsabilizados por danos causados a esta cultura e pela conseqüente redução de produtividade. $\mathrm{O}$ objetivo deste trabalho foi conhecer os ácaros presentes nesta cultura no Estado do Mato Grosso e elaborar uma chave dicotômica para a separação das espécies encontradas. Este estudo foi conduzido em campos de seringueira das Plantações Edouard Michelin Ltda., no município de Itiquira, e da Triângulo Agro-industrial S/A, no município de Pontes e Lacerda. As coletas foram feitas mensalmente em 6 clones diferentes: PB 260, PR 255, IAN 713, IAN 873, FX 3864 e RRIM 600. Para os clones PB 260 e IAN 873, as coletas foram realizadas de agosto de 1998 a julho de 2000; para os demais clones, as coletas foram realizadas de agosto de 1999 a julho de 2000. Na safra 1998/1999 a amostragem consistiu de 15 folhas dos estratos basal, mediano e apical de cada uma das 10 plantas tomadas ao acaso. Os dados conseguido nesta safra serviram também para estudar a distribuição de Calacarus heveae Feres na planta e definir uma metodologia de amostragem desta, que é considerada uma das principais pragas da seringueira. Com base nos resultados desta safra, foi alterada a metodologia de coleta na safra 1999/2000. Para esta, foram tomadas 5 folhas do estrato mediano de cada uma de 15 plantas tomadas ao acaso. Foi encontrado um total de 4270 ácaros pertencentes a 12 famílias. Cerca de $77,2 \%$ dos ácaros coletados pertenciam às famílias Eriophyidae, Tarsonemidae, Tenuipalpidae e Tetranychidae, compostas por espécies predominantemente fitófagas. 
Phytoseiidae foi a família que apresentou maior diversidade, com 15 espécies, seguida pelas familias Tetranychidae e Eriophyidae, com 5 espécies, e Tydeidae, com 4 espécies.

\section{MITES (ARACHNIDA: ACARI) ON RUBBER TREE (Hevea brasiliensis Muell Arg.) IN THE STATE OF MATO GROSSO}

\section{SUMMARY}

Mites started to be considered economically important on rubber tree since the early 1990's, when they were considered responsible for damages caused to this crop and by the consequent yield reduction. The aim of this work was to determine the mites present on this crop in the State of Mato Grosso and to elaborate a key for the separation of the species found. This study was conducted in fields of Plantações Edouard Michelin Ltda., in Itiquira, and Triângulo Agro-Industrial S/A, in Pontes e Lacerda. Samplings were conducted monthly in 6 different clones: PB 260, PR 255, IAN 713, IAN 873, FX 3864 and RRIM 600. Clones PB 260 and IAN 873 were sampled between August 1998 and July 2000; other clones were sampled between August 1999 and July 2000. In the season 1998/1999 samples consisted of 15 leaves of each of 10 plants taken randomly. The data obtained in this season were also used to study the distribution of Calacarus heveae Feres in the rubber tree, and define a sampling technique for this, which is considered on of the main pests of this plant. Based on those results, the sampling methodology was changed in the season 1999/2000. For that season, 5 leaves of the median stratum of each of 15 plants taken randomly were sampled. A total of 4270 mites were found, belonging to 12 families. Nearly $77,2 \%$ of the mites collected belonged to the families Eriophyidae, Tarsonemidae, Tenuipalpidae and Tetranychidae, composed predominantly by phytophagous species. Phytoseiidae was the most diverse family, with 15 species, followed by the families Tetranychidae and Eriophydae, with 5 species, and Tydeidae, with 4 species. 


\subsection{INTRODUÇÃO}

A seringueira (Hevea brasiliensis Muell. Arg.) é comumente atacada por diversas espécies de insetos e ácaros nas áreas onde é cultivada, sendo que algumas são consideradas pragas de suma importância (Manual Técnico, 1983; Silva, 1972). Os ácaros passaram a ser considerados economicamente importantes nesta cultura a partir dos anos 90, quando foram responsabilizados por danos causados a esta cultura (Feres, 1992; Feres, 2000; Vieira \& Gomes, 1999).

Poucos estudos foram realizados para o reconhecimento de ácaros na cultura da seringueira até os anos 90. Até aquela data, apenas Temuipalpus heveae Baker havia sido descrito por Baker (1945). Poucos trabalhos tinham sido desenvolvidos para conhecer as espécies acarinas presentes nesta cultura, destacando-se os trabalhos de Fazolin \& Pereira (1989), Flechtmann (1989), Flechtmann \& Arleu (1984) e Silva (1972). Devido ao dano e à redução de produtividade dos seringais, atribuídos às altas infestações de ácaros, principalmente por Calacarus heveae Feres, vários estudos foram iniciados, a partir do início da década de 1990, com o intuito de reconhecer as principais espécies e os danos causados por elas nesta cultura, nos estados em que tinha sido introduzida.

O trabalho mais extenso em relação ao conhecimento dos ácaros encontrados nesta cultura foi recentemente realizado por Feres (2000) no qual são relatadas 28 espécies de ácaros pertencentes a 24 gêneros de 11 famílias acarinas presentes na cultura da seringueira nos Estados do Mato Grosso, Mato Grosso do Sul, Minas Gerais e São Paulo.

De acordo com a literatura, os ácaros fitófagos, comumente encontrados em seringueira pertencem às famílias Eriophyidae, Tarsonemidae, Tenuipalpidae e Tetranychidae, enquanto que, entre os predadores, os ácaros mais comuns pertencem às famílias Cunaxidae, Phtyoseiidae e Stigmaeidae (Bergmann, 1991; Fazolin \& Pereira, 1989; Feres, 1992; Feres, 1998; Feres, 2000; Flechtmann, 1989; Flechtmann \& Arleu, 1984; Silva, 1972).

O objetivo deste trabalho foi conhecer os ácaros presentes na cultura da seringueira em 2 regiões do Estado do Mato Grosso e elaborar uma chave dicotômica 
para a separação das espécies encontradas.

\subsection{MATERIAL E MÉTODOS}

Este estudo foi conduzido em campos de seringueira das Plantações Edouard Michelin Ltda., no município de Itiquira, e da Triângulo Agro-industrial S/A, no município de Pontes e Lacerda.

As coletas foram feitas mensalmente em 6 clones suscetíveis aos ácaros. Em Itiquira, foram escolhidos os clones PB 260 (4,5 ha e 12 anos) e PR 255 (6,4 ha e 15 anos), e, em Pontes e Lacerda, os clones IAN 713 (2,6 ha e 15 anos), IAN 873 (17,1 ha e 16 anos), FX 3864 (6,5 ha e 14 anos) e RRIM 600 (3,2 ha e 15 anos). Para os clones PB 260 e IAN 873, as coletas foram realizadas de agosto de 1998 a julho de 2000; para os demais clones as coletas foram realizadas de agosto de 1999 a julho de 2000. Os dados conseguidos na safra 1998/1999 e apresentados no Capítulo 1, serviram para estudar a distribuição de $C$. heveae na planta, definir uma metodologia de coleta e o estrato do qual seriam retiradas as folhas na safra seguinte.

$\mathrm{Na}$ safra 1998/1999, a amostragem consistiu de 15 folhas coletadas de cada uma das 10 plantas escolhidas ao acaso em cada campo, localizadas a pelo menos 20 metros da borda. Foram coletadas folhas da periferia da copa de cada um dos estratos basal, mediano e apical de cada planta, sendo coletada uma folha em cada uma das regiões distal, mediana e proximal de cada ramo, totalizando 9 folhas. Além disso, foram coletadas 3 folhas do estrato mediano de cada um dos quadrantes leste e oeste, totalizando 6 folhas em cada planta. Nestes quadrantes, as folhas foram tomadas na região média de ramos da periferia da copa, outra na mesma posição de ramos próximos ao caule e outra na mesma posição em ramos da região intermediária em relação a profundidade da copa de cada uma das plantas amostradas. As parcelas nas quais foram

realizadas as amostragens apresentavam aproximadamente 500 plantas com altura aproximada de 20 metros. Na segunda safra, entre 1999/2000, 5 folhas de cada uma das 15 plantas escolhidas foram amostradas em ramos da periferia do estrato mediano dos clones IAN 713, IAN 873, FX 3864, PB 260, PR 255 e RRIM 600. 
Nestas áreas nenhum tratamento com agroquímicos foi realizado durante 0 desenvolvimento do trabalho. A última aplicação de agroquímicos nestas áreas havia sido realizada cerca de 6 meses antes do início do trabalho.

Para a identificação das espécies acarinas na safra 1998/1999 foram observadas 40 folhas de cada clone, enquanto que na safra 1999/2000 foram 20 folhas de cada clone. Até 10 ácaros de cada família foram coletados em cada folha amostrada. Para exame ao microscópio, os eriofideos foram montados em meio modificado de Berlese (Amrine \& Manson, 1996) e os demais ácaros coletados foram montados usando meio de Hoyer (Flechtmann, 1975). As lâminas montadas foram mantidas em estufa a 50$60^{\circ} \mathrm{C}$ por cerca de 10 dias para a fixação, distensão e clarificação dos espécimes e secagem do meio. Posteriormente, foi feita a lutagem das bordas das lamínulas.

Para os Typhlodrominae utilizou-se o sistema de classificação genérico proposto por Chant \& Yoshida-Shaul (1983), Chant \& Yoshida-Shaul (1986a e b) e Chant \& McMurtry (1994), enquanto que a classificação genérica adotada para os Amblyseiinae seguiu aquela adotada por Moraes et al. (1986).

Espécimes representantes de cada uma das espécies encontradas foram depositados na Coleção de Referência de Ácaros do Setor de Zoologia do Departamento de Entomologia, Fitopatologia e Zoologia Agrícola da Escola Superior de Agricultura da Universidade de São Paulo (ESALQ-USP), em Piracicaba, São Paulo.

\subsection{RESULTADOS}

Foi encontrado um total de 4270 ácaros pertencentes a 12 famílias nas plantas analisadas. Cerca de $77,2 \%$ dos ácaros coletados pertenciam às famílias Eriophyidae, Tarsonemidae, Tenuipalpidae e Tetranychidae, compostas por espécies predominantemente fitófagas; cerca de 19,8\% pertenciam às famílias Cheyletidae, Cunaxidae, Phytoseiidae e Stigmaeidae, compostas por espécies predominantemente predadoras, e cerca de 2,9\% pertenciam às famílias Tydeidae e Acaridae, de hábitos polífagos.

Os ácaros encontrados pertencem a 41 espécies distintas. Phytoseiidae foi a 
família que apresentou maior diversidade, com 15 espécies, seguida por Tetranychidae e Eriophyidae, com 5 espécies cada, e por Tydeidae, com 4 espécies. As demais famílias foram representadas por 1 ou 2 espécies.

$\underline{\text { Lista dos ácaros encontrados }}$

São apresentados a seguir os grupos de ácaros encontrados e o número de machos e fềmeas em cada clone. Neste estudo não foram encontrados ácaros da ordem Oribatida.

\section{ORDEM MESOSTIGMATA}

\section{PHYTOSEIIDAE Berlese}

\section{Amblyseius acalyphus Denmark \& Muma}

Amblyseius acalyphus Denmark \& Muma, 1973: 243; 1989: 75; Feres \& Moraes, 1998: 125 .

Espécimes examinados: Itiquira: PB 260 V-99, IV-00, V-00, VI-00 (22 क e 4ơ); PR 255 V-00 (1 + ); Pontes e Lacerda: IAN 713 XI-99 (4 + e $\left.10^{\pi}\right)$; FX 3864 X-99 (2 + ).

Registros prévios no Brasil: São Paulo (Feres \& Moraes, 1998).

Observações: As medidas conferem com aquelas relatadas por Denmark \& Muma (1989), exceto pelo comprimento menor de Z5 e macroseta do gênu IV (220 e 86 para o holótipo e 175 e 73, respectivamente, para os espécimes examinados). O comprimento e a largura do escudo dorsal do espécime observado também é menor que o do holótipo (426 e 232 para o holótipo e 351 e 185, respectivamente, para o espécime coletado). É a primeira citação desta espécie nesta cultura.

Amblyseius neochiapensis Lofego, Moraes \& McMurtry Amblyseius neochiapensis Lofego, Moraes \& McMurtry, 2000: 462. 
Espécimes examinados: Itiquira: PB 260 V-00 (1 9); Pontes e Lacerda: IAN 873 XII-98, IV-99, V-99, VIII-99, IX-99 (11 क e 3 б); IAN 713 VIII-99, IX-99, X-99, XI-99 (7 7 e $\left.2 \sigma^{\pi}\right)$; FX 3864 VIII-99, IX-99, X-99, XI-99, XII-99, I-00, VI-00 (10 9 e 4o ); RRIM 600 VIII-99, IX-99 (3ㅇ).

Registros prévios no Brasil: São Paulo (Lofego et al., 2000).

Observação: É a primeira citação desta espécie nesta cultura.

\section{Euseius alatus DeLeon}

Euseius alatus DeLeon, 1966: 87; Denmark \& Muma, 1973: 262; Feres \& Moraes, 1998: 127; Moraes \& McMurtry, 1983: 137.

Euseius paraguayensis, Denmark \& Muma, 1970: 224 (sinonímia de acordo com Moraes \& McMurtry, 1983: 137).

Espécimes examinados: Itiquira: PR 255 I-00 (1 9); Pontes e Lacerda: IAN 873 IX-98, XI-98, VII-99, IX-99, X-99, XI-99, XII-99 (32 ㅇ e 6 67); IAN 713 IX-99, X-99, XI-99, XII-99 (8ำ e 107); FX 3864 IX-99, X-99, XI-99, XII-99 (7\% ); RRIM 600 IX-99, X-99, XII-99 $\left(5+\right.$ e $\left.10^{\pi}\right)$.

Registros prévios no Brasil - Bahia, Ceará, Maranhão, Mato Grosso do Sul, Minas Gerais, Paraíba, Pernambuco e Rio Grande do Sul (Feres \& Moraes, 1998; Ferla \& Moraes, 1998; Moraes et al., 1986).

Observações: Reis et al., (2000) sugerem que esta espécie seja predadora de Phyllocoptruta oleivora (Ashmead) em citros. É a primeira citação de $E$. alatus em seringueira.

\section{Euseius citrifolius Denmark \& Muma}

Euseius citrifolius Denmark \& Muma, 1970: 222; Feres, 2000: 161; Feres \& Moraes, 1998: 125; Moraes \& McMurtry, 1983: 128.

Espécimes Examinados: Itiquira: PB 260 IX-98, II-99, III-99, V-99, XI-99 (19ㅇ e 30 $0^{\pi}$ ); 
PR 255 XI-99, I-00 (4우).

Registros prévios no Brasil - Bahia, Ceará, Maranhão, Mato Grosso do Sul, Minas Gerais, Paraíba, Pernambuco, Piauí, Rio Grande do Sul e São Paulo (Feres, 2000; Feres \& Moraes, 1998; Ferla \& Moraes, 1998; Moraes et al., 1986).

Observações: Sua presença na cultura da seringueira foi relatada por Feres (2000).

\section{Euseius concordis (Chant)}

Typhlodromus (Amblyseius) concordis Chant, 1959: 69.

Ambly seius (Iphiseius) concordis, Muma, 1961: 288.

Amblyseius concordis, Chant \& Baker, 1965: 22; Moraes \& McMurtry, 1983: 138.

Euseius concordis, Denmark \& Muma, 1973: 264; Feres \& Moraes, 1998: 127; Moraes \& McMurtry, 1983: 138; Moraes \& Oliveira, 1982: 317.

Euseius flechtmanni, Denmark \& Muma, 1970: 223; Denmark \& Muma, 1973: 261 (sinonímia de acordo com Moraes et al., 1982: 18).

Espécimes examinados: Itiquira: PB 260 IX-98, XII-98, I-99, III-99, V-99, VIII-99, I-

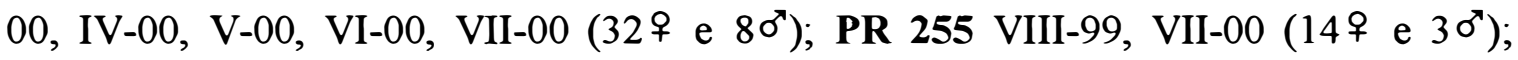
Pontes e Lacerda: IAN 873 IX-98, VII-99, VIII-99, IX-99, X-99, I-00 (469 e $\left.50^{7}\right)$; IAN 713 VIII-99, IX-99, X-99, XI-99, XII-99, I-00, V-00 (84 ๆ e 8б'); FX 3864 VIII-99, IX99, X-99, I-00, V-00 (20 9 e 40'); RRIM 600 VIII-99, IX-99, X-99, XI-99, XII-99, I-00, III-00, V-00 (67우 e 120').

Registros prévios no Brasil - Bahia, Ceará, Maranhão, Mato Grosso do Sul, Paraíba, Pernambuco, Piauí, Rio Grande do Sul e São Paulo (Feres \& Moraes, 1998; Ferla \& Moraes, 1998; Moraes et al., 1986).

Observações: Uma das espécies mais comumente encontradas em plantas no Brasil e em outros países da América do Sul (Moraes, 1991). É uma das espécies mais comuns em citros, sendo estudada para o manejo integrado de pragas nesta cultura (Komatsu, 1988; Gravena, 1994). Foi relatada por Feres (2000) em 
seringueira. No presente estudo, foi o fitoseídeo mais freqüentemente encontrado.

\section{Galendromimus alveolaris (DeLeon)}

Typhlodromus alveolaris DeLeon, 1957: 141.

Typhlodromus (Typhlodromus) alveolaris, Chant, 1959: 52.

Cydnodromella alveolaris, Chant \& Yoshida-Shaul, 1986b: 2821; Moraes \& Mesa, 1988: 80 .

Galendromimus alveolaris, DeLeon, 1962: 175; DeLeon, 1967:13; Muma, 1961: 298; Muma \& Denmark, 1970: 58.

Galendromimus (Galendromimus) alveolaris, Feres \& Moraes, 1998: 128; Moraes et al., 2000: 255 .

Espécimes examinados: Pontes e Lacerda: RRIM 600 VII-00 (2\%).

Registros prévios no Brasil: São Paulo ( Feres \& Moraes, 1998).

Observação: Esta é a primeira constatação desta espécie em seringueira.

\section{Galendromus annectens DeLeon}

Typhlodromus annectens DeLeon, 1958: 75; Chant \& Yoshida-Shaul, 1984: 1868; Feres \& Moraes, 1998: 129; Moraes \& McMurtry, 1983: 142; Moraes \& Mesa, 1988: 82; Moraes et al., 1991: 134.

Galendromus annectens, Denmark \& Muma, 1973: 274; Farias et al., 1981: 316; Moraes et al., 1982: 21; Muma, 1961: 298; Muma \& Denmark, 1970: 135.

Espécimes examinados: Itiquira: PB 260 X-99 (1 9 ); PR 255 X-99 (1 9 ); Pontes e

Lacerda: IAN 713 XI-99, XII-99, I-00 (6ㅇ e $\left.10^{7}\right)$; RRIM 600 IX-99 (1 우).

Registros prévios no Brasil - Pernambuco, São Paulo e Rio Grande do Sul (Feres, 2000; Feres \& Moraes, 1998; Ferla \& Moraes, 1998; Moraes et al., 1986). Observações: Espécie relatada nesta cultura por Feres (2000).

\section{Galendromus sp.}

Espécimes examinados: Pontes e Lacerda: IAN 873 VII-99 (10 $).$ 
Observações: Trata-se possivelmente de uma espécie nova.

Neoseiulus anonymus (Chant \& Baker)

Amblyseius anonymus Chant \& Baker, 1965: 21; McMurtry, 1983: 254; Schicha \& Elshafie, 1980: 32.

Neoseiulus anonymus, Denmark \& Muma, 1972: 27; Kreiter \& Moraes, 1997: 378; Moraes \& Mesa, 1988: 76; Moraes et al., 1991: 126; Moraes et al., 2000: 245.

Espécimes examinados: Itiquira: PB 260 X-98, XI-98, XII-98, XII-99, I-00 (37 우 e $\left.30^{7}\right)$; PR 255 XII-99 ( 13 \% e $\left.20^{\circ}\right)$. Pontes e Lacerda: IAN 873 X-98, XI-98, XII-98, X-99, XI-

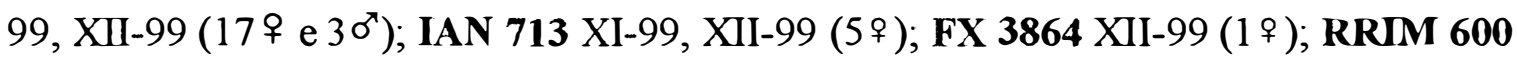
IX-99, X-99, XII-99, II-00 (5\% e $\left.10^{\pi}\right)$.

Registros prévios no Brasil: Alagoas, Bahia, Paraíba, Paraná, Pernambuco, Rio Grande do Sul, Santa Catarina e São Paulo (Moraes et al., 1986).

Observações: É uma das espécies freqüentemente associada a Mononychellus tanajoa (Bondar) no Nordeste do Brasil (Moraes et al., 1988). No presente estudo, foi a segunda espécie mais freqüentemente encontrada.

\section{Neoseiulus tunus (DeLeon)}

Typhlodromips tunus DeLeon, 1967: 29; Denmark \& Muma, 1973: 253.

Amblyseius tunus, Feres \& Moraes, 1998: 126.

Espécimes examinados: Pontes e Lacerda: IAN 713 X-99(1 9 ).

Registros prévios no Brasil - Rio Grande do Sul, Santa Catarina e São Paulo (Feres \& Moraes, 1998; Ferla \& Moraes, 1998; Moraes et al., 1986).

Observações: Esta espécie foi comumente encontrada em pomares não tratados de macieira, no Estado do Rio Grande do Sul (Ferla \& Moraes, 1998). É a primeira constatação desta espécie em seringueira. 


\section{Typhlodromalus aff. horatii}

Espécimes examinados: Pontes e Lacerda: FX 3864 X-99 (1 \&).

Observação: Trata-se possivelmente de uma espécie nova, próxima de horatii.

Typhlodromalus feresi Lofego, Moraes \& McMurtry

Typhlod romalus feresi Lofego, Moraes \& McMurtry, 2000: 466.

Espécimes examinados: Pontes e Lacerda: IAN 873 X-99 (1 \&).

Registros prévios no Brasil: São Paulo (Lofego et al., 2000).

Observações: O espécime encontrado apresentou setas j3, z4, s4, J2, Z1, $\mathrm{Z} 4, \mathrm{Z} 5, \mathrm{~S} 2, \mathrm{~S} 4, \mathrm{r} 3$ menores que o holótipo, enquanto que as macrosetadas do gênu I, II, III e do tarso IV são maiores que as macrosetas do holótipo (j3 = 25, z4 = 31, s4 = 37, J2 $=20, \mathrm{Z} 1=29, \mathrm{Z} 4=39, \mathrm{Z} 5=56, \mathrm{~S} 2=30, \mathrm{~S} 4=22, \mathrm{r} 3=25$ para o holótipo e $\mathrm{j} 3=19, \mathrm{z} 4$ $=21, \mathrm{~s} 4=30, \mathrm{~J} 2=14, \mathrm{Z} 1=19, \mathrm{Z} 4=32, \mathrm{Z} 5=46, \mathrm{~S} 2=24, \mathrm{~S} 4=16, \mathrm{r} 3=16$ para $\mathrm{o}$ espécime examinado; macrosetas do holótipo dos gênus I $=7, \mathrm{II}=10, \mathrm{III}=15$ e tarso IV $=30$, enquanto que no espécime examinado gênu $\mathrm{I}=11, \mathrm{II}=11, \mathrm{III}=17$ e tarso $\mathrm{IV}=$ 43; comprimento do escudo dorsal do holótipo 331, enquanto que no espécime examinado 325). É a primeira citação desta espécie nesta cultura.

\section{Typhlod romips amilus DeLeon}

Typhlod romips amilus DeLeon, 1967: 28.

Espécimes examinados: Pontes e Lacerda: IAN 873 VII-99, VIII-99 (5 9 ); IAN 713 XII99, I-00, IV-00, VI-00 (5 e 10 ); FX 3864 VIII-99, X-99, XI-99, XII-99, I-00, VI-00 (11 9 e $\left.30^{x}\right)$; RRIM 600 VII-99 (1 + ).

Observações: As macrosetas das pernas do exemplar coletado são maiores que as macrosetas do holótipo de T. amilus (holótipo SgeIV 24, StiIV 11, StIV 39 e no espécime examinado SgeIV 38, Sti IV 22, StIV 47); enquanto o cérvix da espermateca é menor que do holótipo de T. amilus (holótipo 28 e o espécime examinado 
16). É a primeira citação desta espécie no Brasil.

\section{Typhlodromips aff. sinensis}

Espécimes examinados: Pontes e Lacerda: IAN 873 IV-99, V-99 (7우 e $\left.2 \sigma^{\circ}\right)$.

Observação: Trata-se possivelmente de uma espécie nova, próxima de sinensis.

\section{Typhlodromus (Anthoseius) transvaalensis (Nesbitt)}

Kampimodromus transvaalensis Nesbitt, 1951: 55.

Typhlodromus transvaalensis, Chant, 1955: 498.

Espécimes examinados: Pontes e Lacerda: IA N 873 V-99 (1 †).

Registros prévios no Brasil: São Paulo e Rio Grande do Sul (Ferla \& Moraes, 1998; Moraes et al., 1986).

Observação: É a primeira constatação desta espécie em seringueira.

\section{ORDEM PROSTIGMATA}

\section{CHEYLETIDAE Leach}

Hemicheyletia sp.

Espécimes examinados: Itiquira: PB 260 III-99 (1 + ); Pontes e Lacerda: IAN 873 II-99 (19).

Observações: Feres (2000) relatou a presença de Hemicheyletia wellsi (Baker) em seringueira.

CUNAXIDAE Thor

\section{Pseudobonzia sp.}

Espécimes examinados: Itiquira: PB 260 II-00 (1 9 ); PR 255 II-00 (1 9 ); Pontes e 
Lacerda: IAN 873 X-98, XII-98, II-99, III-99, IV-99, V-99, VII-99, VIII-99, I-00 (45 9 e 150 ); IAN 713 VIII-99, I-00, VI-00 (4 ㅇ); FX 3864 VIII-99, XI-99, XII-99, I-00, II-00,

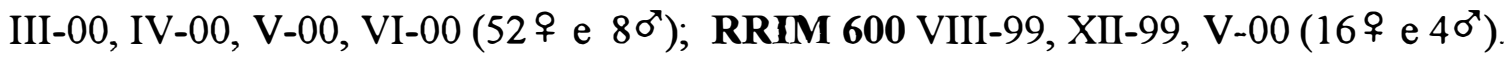
Observações: Pseudobonzia sp. foi relatado por Feres (2000) em seringueira.

\section{ERIOPHYIDAE Nalepa}

\section{Aff. Acaphyllisa sp.}

Espécimes examinados: Itiquira: PB 260 XII-99 (1 우).

Observação: De acordo com comunicação pessoal de Reinaldo J. F. Feres, este espécime provavelmente pertença a um novo gênero, próximo de Acaphyllisa Keifer.

\section{Aff. Chakrabartiella sp.}

Espécimes examinados: Pontes e Lacerda: FX 3864 V-00, VI-00 (4 ㅇ).

Observações: Segundo comunicação pessoal de Reinaldo J. F. Feres, os espécimes pertencem possivelmente a um novo gênero, próximo de Chakrabartiella Amrine \& Stasny.

\section{Calacarus heveae Feres}

Calacarus heveae Feres, 1992: 61; Feres, 2000: 167; Feres, 2001: 343.

Espécimes examinados: Itiquira: PB 260 XII-98, I-99, II-99, III-99, V-99, VIII-99, XI99, XII-99, I-00, II-00, V-00 (260 9 e 1507); PR 255 VIII-99, XI-99, XII-99, I-00, II-00, V-00, VI-00 (26ㅇ e 40'); Pontes e Lacerda: IAN 873 X-98, XI-98, XII-98, II-99, III-99,

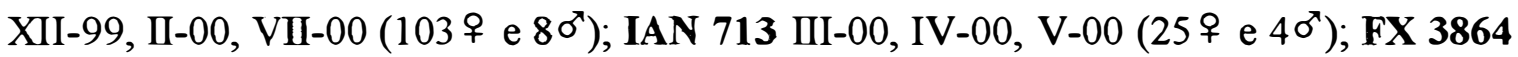
IV-00, V-00 (9 ) ); RRIM 600 I-00, II-00, III-00, V-00 (78 9 e $\left.9 \sigma^{7}\right)$.

Registros prévios no Brasil: Amazonas, Mato Grosso, Mato Grosso do Sul, Minas Gerais e São Paulo (Feres, 1992; Feres, 2000; Feres, 2001). 
Observações: Espécie descrita de material coletado da região noroeste do Estado de São Paulo. Esta espécie, juntamente com $T$. heveae, são consideradas as espécies-praga mais importantes da seringueira.

\section{Phyllocoptruta seringueirae Feres}

Phyllocoptruta seringueirae Feres, 1998: 71; Feres, 2000: 168.

Espécimes examinados: Itiquira: PB 260 VIII-99, XI-99, I-00, II-00, VII-00 (10우 e $\left.10^{\pi}\right)$ ); PR 255 VIII-99, XI-99, II-00, IV-00, V-00, VII-00 (9우 e 20 ); Pontes e Lacerda: IAN 873 XI-98, XII-98, III-99, IV-99, V-99, VIII-99, IX-99, XI-99, XII-99, I-00, II-00, III-00, IV-00, V-00, VI-00, VII-00 (280 9 e $\left.25 \sigma^{\pi}\right)$; IAN 713 VIII-99, IX-99, X-99, XI99, XII-99, I-00, II-00, III-00, IV-00, V-00, VI-00, VII-00 (192ㅇ e $\left.180^{\text {* }}\right)$; FX 3864 VIII-99, IX-99, X-99, XII-99, I-00, II-00, IV-00, V-00 (285 e 15 07); RRIM 600 VIII99, IX-99, X-99, XI-99, XII-99, I-00, II-00, III-00, IV-00, V-00 (180 ㅇ e $\left.17 \sigma^{\pi}\right)$.

Registros prévios no Brasil: Amazonas, Mato Grosso, Mato Grosso do Sul e São Paulo (Feres, 1998; Feres, 2000; Feres, 2001).

Observações: Espécie de cor alaranjada, que ocorre na face adaxial e abaxial do folíolo (Feres, 2000).

\section{Shevtchenkella petiolula Feres}

Shevtchenkella petiolula Feres, 1998: 69; Feres, 2000: 168.

Espécimes examinados: Itiquira: PB 260 X-99, XI-99 (4 \%); PR 255 X-99 (2 $)$ ); Pontes

e Lacerda: IAN 873 X-98, XI-98, XII-98, V-99, XI-99, V-00, VII-00 (20 9 e $\left.30^{\pi}\right)$; IAN 713 XII-99, II-00 (3 9 ); FX 3864 IX-99, X-99, XII-99, I-00, II-00, IV-00, V-00 (20 9 e $\left.10^{\pi}\right)$; RRIM 600 IX-99, X-99, XII-99 (11 9 e $\left.2 \sigma^{6}\right)$.

Registros prévios no Brasil: Amazonas, Mato Grosso, Mato Grosso do Sul e São Paulo (Feres, 1998; Feres, 2000; Feres, 2001).

Observações: Espécie de cor alaranjada, encontrada preponderantemente 
em pecíolos e peciólulos das folhas de seringueira (Feres, 2000) ), diferentemente de outros ácaros citados neste trabalho, que ocorrem no limbo foliar.

\section{TARSONEMIDAE Kramer}

\section{Polyphagotarsonemus latus (Banks)}

Tarsonemus latus Banks, 1904: 1553.

Hemitarsonemus latus, Ewing, 1939: 54.

Neotarsonemus latus, Smiley, 1967: 137.

Espécimes examinados: Itiquira: PB 260 X-99 (1 9); Pontes e Lacerda: IAN 873 X-99 (2ㅇ); FX 3864 IX-99 (2 )); RRIM 600 IX-99 (1 $\left.\sigma^{7}\right)$.

Observações: A primeira citação desta espécie na cultura da seringueira foi feita por Flechtmann \& Arleu (1984). Segundo os mesmos autores, o ataque desta espécie restringe-se aos brotos das plantas, causando deformação e bronzeamento das folhas. Provavelmente, o baixo número de ácaros desta espécie, encontrado neste estudo, se deve ao fato de apenas folhas já desenvolvidas terem sido examinadas.

\section{Tarsonemus sp.}

Espécimes examinados: Itiquira: PB 260 I-99, XI-99, I-00, II-00 (17 9 e $\left.10^{\pi}\right)$; PR 255 XI-99, I-00, II-00 (12 9 ); Pontes e Lacerda: IAN 873 IV-99, V-99 (10 ); RRIM 600 II00 (1 ㅇ).

\section{TENUIPALPIDAE Berlese}

\section{Brevipalpus phoenicis (Geijskes)}

Tenuipalpus phoenicis Geijskes, 1939: 23.

Brevipalpus phoenicis Sayed, 1946: 99; Pritchard \& Baker, 1958: 223; DeLeon, 1961: 48; Gonzales, 1975: 82; Baker et al., 1975: 18; Meyer, 1979: 87; Baker \& Tuttle, 1987: 98; Feres, 2000: 164.

Espécimes examinados: Itiquira: PB 260 II-00 (2 +); Pontes e Lacerda: IAN 873 
II-99(1 우), FX 3864 VIII-99(1 우).

Registros prévios no Brasil: Alagoas, Bahia, Ceará, Minas Gerais, Pará, Paraná, Pernambuco, Rio de Janeiro e São Paulo (Feres, 2000; Flechtmann, 1976; Flechtmann \& Arleu, 1984).

Observações: No Brasil, foi registrado pela primeira vez em seringueira por Flechtmann \& Arleu (1984)

\section{Tenuipalpus heveae Baker}

Tenuipalpus heveae Baker, 1945: 36; Baker \& Pritchard, 1953: 320; Feres, 2000: 165. Espécimes examinados: Itiquira: PB 260 IX-98, XII-98, I-99, II-99, III-99, IV-99, V-99, X-99, XI-99, XII-99, I-00, II-00, IV-00, V-00, VI-00 (350 우 e 170 ); PR 255 X-99, XI99, XII-99, I-00, II-00, IV-00, V-00 (55 क e 40 ); Pontes e Lacerda: IAN 873 IX-98, X98, XI-98, XII-98, II-99, III-99, IV-99, V-99, VIII-99, IX-99, X-99, XI-99, XII-99, I-00,

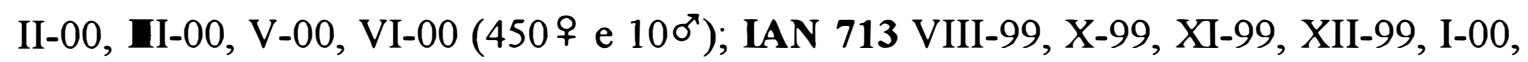
II-00, III-00, IV-00, V-00, VI-00 (85 क e $\left.80^{\pi}\right)$; FX 3864 VIII-99, IX-99, X-99, XI-99, XII-99, I-00, II-00, III-00, IV-00, V-00 (110 e 60 ); RRIM 600 VIII-99, IX-99, X-99, XI-99, XII-99, I-00, II-00, III-00, IV-00, V-00 (85 क e $\left.60^{\circ}\right)$.

Observações: Esta é uma das espécies consideradas pragas mais importantes da seringueira. Ocorre preponderantemente na face abaxial dos folíolos, sendo que em grandes populações pode ser encontrada também na face adaxial (Feres, 2000).

TETRANYCHIDAE Donnadieu

Mononychellus sp.

Espécimes examinados: Itiquira: PB 260 XII-98, X-99 (3ㅇ); PR 255 X-99, I-00 (3우 e 10 $0^{\pi}$ ); Pontes e Lacerda: IAN 873 XI-98, VIII-99, XII-99 (3 9 e $10^{7}$ ); IAN 713 VIII-99, 
X-99, XII-99 (4 9); FX 3864 VIII-99, XII-99 (6\%); RRIM 600 VIII-99, IX-99, X-99, XII-99 $\left(9+\right.$ e $\left.10^{\pi}\right)$

Observações: Esta é a primeira constatação de uma espécie deste gênero nos seringais do Brasil.

\section{Eutetranychus banksi (McGregor)}

Tetranychus banksi McGregor, 1914: 358.

Anychus banksi, McGregor, 1919 : 644 .

Eutetranychus banksi, Flechtmann \& Baker, 1970: 156; Flechtmann \& Baker, 1975: 112; McGregor, 1950: 268; Pritchard \& Baker, 1955: 115.

Espécimes examinados: Itiquira: PB 260 VIII-99 (1 9 ); PR 255 IX-99 (1 $0^{\text {* })}$.

Registros prévios no Brasil: Bahia, Mato Grosso, Minas Gerais e São Paulo (Feres, 2000; Flechtmann \& Abreu, 1973; Silva, 1972)

Observações: Nos Estados Unidos da América do Norte esta espécie é considerada séria praga dos citros. No Brasil, ocorre sobre grande número de plantas, sem que se tenha registrado danos de importância na cultura da seringueira (Feres, 2000) ou em outras culturas.

\section{Oligonychus coffeae (Nietner)}

Acarus coffeae Nietner, 1861: 845.

Oligonychus coffeae, Baker \& Pritchard, 1960: 505; Feres, 2000: 166; Gutierrez, 1968: 446; Meyer, 1974: 251; Meyer, 1987: 146; Meyer \& Rodrigues, 1965: 12; Pritchard \& Baker, 1955: 315; Rodrigues, 1968: 220.

Espécimes examinados: Itiquira: PB 260 II-00 (2 9 ); PR 255 II-00 ( 2 e e $\left.1 \sigma^{\top}\right)$; Pontes e Lacerda: IAN 873 IX-98, III-99, II-00 (3 9 e 10); IAN 713 XI-99 (1 9 ); FX 3864 IX99, I-00 (2ㅇ e $\left.10^{r}\right)$.

Registros prévios no Brasil: Espírito Santo e Mato Grosso (Feres, 2000; Flechtmann \& Arleu, 1984). 


\section{Oligonychus gossypii (Zacher)}

Paratetranychus gossypii Zacher, 1921: 183.

Oligonychus gossypii, Baker \& Pritchard, 1960: 508; Feres, 2000: 166; Meyer, 1974: 263; Meyer, 1987: 152.

Espécimes examinados: Itiquira: PB 260 XII-98, I-99, II-99, V-99, VIII-99, XII-99, I00, II-00, IV-00, V-00, VII-00 (35 e 60 ); PR 255 VIII-99, XII-99, II-00, V-00, VII00 (7 ); Pontes e Lacerda: IAN 873 IX-98, X-98, XI-98, XII-98, II-99, VIII-99, IX-99, X-99, XI-99, XII-99, II-00, IV-00, VI-00 (85 \% e 40 ); IAN 713 VIII-99, IX-99, X-99, XI-99, XII-99, I-00, II-00, III-00, IV-00, V-00 (30 e 10 $\left.0^{\pi}\right)$; FX 3864 VIII-99, IX-99, XI-99, XII-99, I-00, II-00, VI-00 (45 \&); RRIM 600 VIII-99, IX-99, X-99, XI-99, XII99, I-00, IV-00 $\left(25\right.$ \% e $\left.20^{\pi}\right)$.

Registros prévios no Brasil: Acre, Amazonas, Mato Grosso e São Paulo (Fazolin \& Pereira, 1989; Feres, 2000; Flechtmann, 1989).

Observações: Registrada em vários países da África e nas Américas Central e do Sul, em várias espécies de plantas (Feres 2000).

\section{Tetranychus mexicanus (McGregor)}

Septanychus mexicanus McGregor, $1950: 323$.

Tetranychus mexicanus, Flechtmann \& Baker, 1970: 162; Flechtmann \& Baker, 1975: 120; Pritchard \& Baker, 1955: 411.

Espécimes examinados: Itiquira: PB 260 IX-98, XII-98, I-99, II-99, V-99, VI-99, VIII99, X-99, XI-99, XII-99, II-00, IV-00, V-00, VII-00 (45 ㅇ e $30^{\text {T }}$ ); PR 255 VIII-99, X-99, XI-99, XII-99, I-00, II-00, VII-00 (13ㅇ e $\left.10^{\pi}\right)$; Pontes e Lacerda: IAN 873 IX-98, X-98, XII-98, III-99, V-99, VII-99, VIII-99, IX-99, XI-99 (28ㅇ e 307); IAN 713 VIII-99, IX-

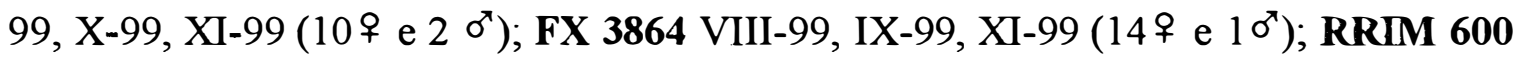
VIII-99, IX-99, X-99, I-00, VII-00 (16 9 e 10'); IAN 713 VIII-99, IX-99, X-99, XI-99 
$\left(14+\right.$ e $\left.20^{7}\right)$

Registros prévios no Brasil: Bahia, Mato Grosso, Minas Gerais, Pernambuco e São Paulo (Feres, 2000; Flechtmann \& Baker, 1970; Paschoal, 1971).

Observações: Espécie de ampla distribuição geográfica, ocorrendo em grande número de plantas hospedeiras. Ácaros encontrados em grande número logo após o enfolhamento, nos meses de julho e agosto, sendo encontrado até o início das chuvas em Itiquira e Pontes e Lacerda. Segundo comunicação pessoal de Reinaldo J. F. Feres, o edéago dos espécimes coletados, embora semelhante na forma, é menor que o descrito para a espécie.

\section{TYDEIDAE Kramer \\ Lorryia formosa Cooreman}

Lorryia formosa Cooreman, 1958:6; Baker, 1968:995.

Espécimes examinados: Itiquira: PB 260 IX-98, I-99, II-00 (17 9 e 20 $)$; $\underline{\text { Pontes e }}$ Lacerda: IAN 873 IV-99 (1 9 ).

\section{Lorryia sp.}

Espécimes examinados: Itiquira: PB 260 II-99 (13 9 e $\left.2 \sigma^{7}\right)$; Pontes e Lacerda: IAN 873 IX-98, VII-00 (5).

\section{Parapronematus sp.}

Espécimes examinados: Itiquira: PB 260 XII-98, VIII-99 (2‡ e 10 ); PR 255 VIII-99 (1 $)$ ); Pontes e Lacerda: IAN 873 X-98, XII-98, VIII-99, IX-99, X-99, XI-99 (149 e 60'); IAN 713 VIII-99, X-99, VI-00 (3 9 e $\left.10^{\pi}\right)$; FX 3864 VIII-99, IX-99, X-99, XI-99, XII-99, IV-00 ( 11 \% e $\left.30^{\circ}\right)$; RRIM 600 VIII-99, I-00 (2 9 ). 


\section{Pronematus sp.}

Espécimes examinados: Itiquira: PB 260 XII-98 (1 1 )ㅜㄹ Pontes e Lacerda: IAN 873 X-98,

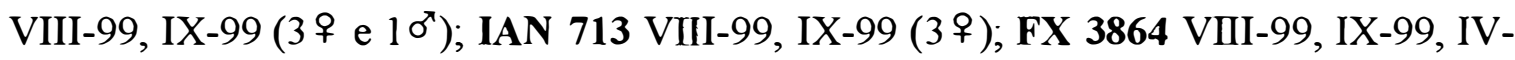
00 (4오 e 1 or$^{\pi}$; RRIM 600 VIII-99, IX-99, I-00, IV-00 (3 ㅇ e $\left.2 \sigma^{\pi}\right)$.

STIGMAEIDAE Oudemans, 1931

\section{Agistemus floridanus Gonzalez}

Agistemus floridanus Gonzalez, 1965: 38.

Espécimes examinados: Itiquira: PB 260 XII-98, I-99, II-99, X-99, XII-99, I-00, II-00, V-00, VI-00, VII-00 (32 + e 4 $\sigma^{\pi}$ ); PR 255 X-99, XII-99, I-00, II-00, IV-00, V-00, VI-00, VII-00 (24 $\uparrow$ e $\left.60^{\top}\right)$; Pontes e Lacerda: IAN 873 XII-98, III-99, IX-99 (3 $\left.\uparrow\right)$; IAN 713 IX-99, II-00, III-00, IV-00, V-00, VI-00 (7 क ); FX 3864 IX-99 (1 9); RRIM 600 IX-99, V-00, VII-00 (5 9 ).

Observações: É a primeira constatação desta espécie no Brasil.

Zetzellia aff. yusti

Espécimes examinados: Itiquira: PB 260 II-00 (1 + ); Pontes e Lacerda: IAN 713 I-00 (1 +); RRIM 600 II-00 (2 +).

\section{ORDEM ASTIGMATA}

ACARIDAE Ewing \& Nesbitt

Tyrophagus sp.

Espécimes examinados: Itiquira: PB 260 V-99, V-00 (3 \&); PR 255 V-00 (1 9 ). 


\section{Neotropacarus $\mathrm{sp}$.}

Espécimes examinados: Itiquira: PB 260 V-00, VI-00, VП-00 (10 ๆ).

\section{WINTERSCHMIDTIIDAE Oudemans}

\section{Oulenzia sp}

Espécimes examinados: Itiquira: PB 260 II-99, V-99, I-00 (4 ㅇ); PR 255 IV-00, V-00, VI-00 (3 9 ).

\section{Separação das espécies:}

A chave dicotômica baseada, em parte, na de Feres (2000) que se segue auxilia na separação dos taxa de ácaros encontrados neste estudo. Não foram incluídos os gêneros de Eriophyidae que não puderam ser categoricamente identificados.

1. Tarso do palpo com apotele; tritosterno presente; estigmas localizados lateralmente entre as coxas III e IV Superordem Anactinotrichida.

1' Tarso do palpo sem apotele; tritosterno ausente; sem estigmas entre as coxas III e IV. Superordem Actinotrichida. 16

2. Região podonotal do escudo dorsal com 4 pares de setas "laterais" $(j 3, z 2, z 4$ e $s 4)$ AMBLYSEIINAE 3

2' Região podonotal do escudo dorsal com 6 pares de setas "laterais" ( $j 3, z 2, z 3, z 4, s 4$ e s6) TYPHLODROMINAE

3. Seta $J V I$ afastada da margem anterior do escudo ventrianal; peritrema normalmente curto, raramente estendendo-se além da base da seta $z 2$.......Euseius Wainstein......4

3' Seta $J V 1$ inserida próxima à margem anterior do escudo ventrianal; peritrema normalmente estendendo-se até a base da seta $j l$. 
4. Escudo dorsal com poucas estrias na região antero-lateral; seta $z 2$ menor que $z 4$, que por sua vez é menor que $s 4$. Euseius concordis (Chant)

4' Escudo dorsal totalmente reticulado; comprimentos relativos das setas $z 2, z 4$ e $s 4$ diferentes dos citados acima. 5

5. Macrosetas da perna IV com extremidade distal dilatada. Euseius alatus DeLeon

5' Macrosetas da perna IV com extremidade distal afilada.

Euseius citrifolius Denmark \& Muma

6. Macrosetas presentes apenas na perna IV Neoseiulus Hughes. 7

6' Macrosetas presentes também em outras pernas. 8

7. Maioria das setas do escudo dorsal curtas, não alcançando as bases das setas imediatamente posteriores; cálice da espermateca em forma de copo; macroseta do tarso IV com $29 \mu \mathrm{m}$ de comprimento. Neoseiulus tunus (Denmark \& Muma).

7' Maioria das setas do escudo dorsal longas, geralmente ultrapassando as bases das setas imediatamente posteriores; cálice da espermateca alongado; macroseta do tarso IV com $44 \mu \mathrm{m}$. ..Neoseiulus anonymus (Chant \& Baker)

8. Tarso I com seta proximal ereta; setas $Z 5$ consideravelmente maiores que a distância entre suas bases. Amblyseius Berlese .9

8' Tarso I sem seta proximal ereta; setas $Z 5$, relativamente curta, usualmente mais curta ou apenas pouco mais longas que a distância entre suas bases. 10

9. Cálice da espermateca em forma de taça rasa.

Amblyseius neochiapensis Lofego, Moraes \& McMurtry

9' Cérvix da espermateca cilíndrico, com um alargamento no meio assemelhando-se a um anel, que divide o cérvix em uma metade mais larga, próxima à vesícula, e a outra metade mais estreita, próxima ao átrio. 
10.Margem posterior do escudo esternal trilobada, freqüentemente pouco visível; escudo ventrianal com constrição lateral. Typhlodromalus Muma..........11

10'Margem posterior do escudo esternal reta ou côncava, sempre bem visível; escudo ventrianal aproximadamente pentagonal. Typhlodromips DeLeon. 12

11.Escudo dorsal liso; setas do escudo dorsal afilando-se progressivamente da base ao ápice. Typhlodromalus aff. horatii

11 'Escudo dorsal estriado antero-lateralmente; setas do escudo dorsal capitadas e lisas, exceto $S 5$ e $J 5$ que são setiformes.

Typhlodromalus feresi Lofego, Moraes \& McMurtry

12.Escudo dorsal liso; setas do escudo dorsal lisas; setas $Z 4$ e $Z 5$ afilando-se progressivamente da base ao ápice; macrosetas com pontas afiladas

Typhlodromips aff. sinensis

12 'Escudo dorsal reticulado; setas $Z 4$ e $Z 5$ grossas e serreadas; macrosetas com pontas dilatadas. Typhlodromips amilus DeLeon

13. Seta $R I$ presente; setas $J V 3$ ausente; seta $S 4$ presente; quase todas as setas do escudo dorsal longas, serreadas e com pontas dilatadas.

Typhlodromus (Anthoseius) transvaalensis Nesbitt

13 'Seta $R 1$ ausente; setas JV3 presente ou ausente; seta $S 4$ ausente; setas do escudo dorsal afilando-se progressivamente da base para a ponta 14

14. Seta $S 5$ diminuta; bases das setas $S 5$ e $Z 5$ próximas; apenas as setas $Z 4$ e $Z 5$ serreadas; seta $Z 1$ presente.

Galendromimus (Galendromimus) alveolaris (DeLeon).

14 'Seta $S 5$ longa; bases das setas $S 5$ e $Z 5$ distantes; todas as setas do escudo dorsal serreadas; seta $Z 1$ ausente. 
15.Peritrema curto, estendendo-se até pouco além da base da seta $r 3$; setas do escudo dorsal longas; seta $R I$ ausente

Galendromus (Galendromus) annectens De Leon

15 'Peritrema longo, estendendo-se à base da seta $j l$; setas do escudo dorsal curtas; seta $R I$ presente Galendromus sp.

16.Empódio pode estar ausente; se presente, de formas variadas; sistema traqueal geralmente presente, com estigmas abrindo-se entre as bases das quelíceras ou na base do gnatossoma ou anteriormente no propodossoma; quelíceras estiletiformes, raramente queladas; abertura genital de diversas formas.

Ordem Prostigmata.

16'Empódio unciforme, situado em um distinto pré-tarso ou carúncula; unhas verdadeiras ausentes; sistema traqueal ausente; quelíceras em forma de pinças; abertura genital em forma de $\mathrm{V}$ invertido..........Ordem Astigmata............................36

17. Gnatossoma em forma de cápsula ovóide; palpos diminutos; perna IV da fềmea com duas setas distais flageliformes TARSONEMIDAE .....18

17 'Gnatossoma sem a forma de cápsula; palpos distintos, se não distintos o corpo é vermiforme e o ácaro apresenta dois pares de pernas em todos os estágios; em alguns grupos pode apresentar palpo com seta dorso-distal da tíbia modificada em esporão, que desloca o tarso lateral ou ventralmente (complexo "unha-dedão"); perna IV sem setas distais flageliformes

18. Tarso IV do macho terminando em um robusto esporão; escudo prodorsal da fêmea cobrindo os estigmas dorsolaterais; setas dorsais de diferentes tamanhos.

Tarsonemus Canestrini \& Fanzago

18'Tarso IV do macho terminando numa estrutura arredondada; escudo prodorsal da fêmea não cobrindo os estigmas dorsolaterais; setas dorsais curtas. 
19. Corpo vermiforme; com dois pares de pernas.

ERIOPHYIDAE. 20

19'Corpo ovalado, com mais de 2 pares de pernas

20.Escudo dorsal sem setas, com margem anterior e laterais reticuladas; empódio dividido em 4 ramos. Calacarus heveae Feres

20 'Escudo dorsal com setas; margens do escudo não reticuladas; empódio dividido em 4 ou 5 ramos.

21. Tubérculos dorsais localizados anteriormente à margem posterior do escudo dorsal; empódio com 4 ramos; opistossoma com um sulco dorso-mediano largo

Phyllocoptruta seringueirae Feres

$21^{\prime}$ Tubérculos dorsais localizados junto à margem posterior do escudo dorsal; empódio dividido em 5 ramos; opistossoma sem sulco dorso-mediano

Shevtchenkella petiolula Feres

22.Palpo com seta dorso-distal da tíbia modificada em esporão, que desloca o tarso lateral ou ventralmente (complexo "unha-dedão").

22'Palpo sem o complexo "unha dedão". 30

23. Quelíceras com estiletes longos e recurvados, implantados em um estilóforo; tarsos I e II com setas dúplices ou associadas; região ao redor da abertura genital pregueada TETRANYCHIDAE 24

23' Quelíceras curtas e afiladas, não implantadas em estilóforo; tarsos sem setas dúplices ou associadas; região ao redor da abertura genital da fềmea não pregueada

24.Empódio ausente ou distalmente dividido; dois pares de setas paranais .25

24'Empódio presente; um par de setas paranais. 26 
25.Tarso I sem setas dúplices, mas com setas associadas; empódio ausente Eutetranychus banksi (McGregor)

25’Tarso I com setas dúplices distais e próximas; empódio fendido distalmente.

Mononychellus sp.

26.Empódio fendido distalmente; tarso I com setas dúplices bem separadas no segmento

Tetranychus mexicanus Mcgregor

26'Empódio unciforme; tarso I com setas dúplices distais e próximas; empódio com cerdas próximo-ventrais

Oligonychus Berlese 27

27. Tibia I da fêmea com sete setas táteis; edeágo dirigido ventralmente terminando em ponta. Oligonychus coffeae (Nietner)

27’Tíbia I da fềmea com nove setas táteis; edéago dirigido dorsalmente, com cabeça sigmóide Oligonychus gossypii (Zacher)

28. Bases das quelíceras fundidas com o restante do gnatossoma; tarso do palpo com setas modificadas e em forma de foice e com duas setas pectinadas; segmentos do palpo mais robustos que os das pernas

CHEYLETIDAE Hemicheyletia Volgin

28'Bases das quelíceras totalmente separadas ou fundidas na base, porém sempre independentes do restante do gnatossoma; tarso do palpo sem setas modificadas em forma de foice ou pectinadas; segmentos do palpo de diâmetro semelhante ao das pernas STIGMAEIDAE 29

29.Escudo central do histerossoma com 5 pares de setas na fêmea e 6 no macho Agistemus floridamus

29'Escudo central do histerossoma da fềmea e do macho com 4 pares de setas Zetzellia aff yusti. 
30.Bases das quelíceras não fundidas; com 2 pares de órgãos pseudo-estigmáticos no dorso do propodossoma CUNAXIDAE Pseudobonzia sp. Smiley

30'Bases das quelíceras fundidas podendo formar um estilóforo; somente um par de setas sensoriais no dorso do propodossoma ou sem essas setas.

31. Corpo achatado dorso-ventralmente; dígitos móveis das quelíceras modificados em estiletes longos e recurvados; setas sensoriais propodossomais ausentes

TENUIPALPIDAE 32

31 'Corpo não achatado; dígitos móveis das quelíceras modificados em estiletes curtos e retos; com um par de setas sensoriais no dorso do propodossoma.

TYDEIDAE

32.Palpo com 3 segmentos; podossoma tipicamente mais largo que o opistossoma; setas L5 (=h2) flageliforme Tenuipalpus heveae Baker

32'Palpo com 4 segmentos; podossoma não distintamente mais largo que o opistossoma; setas L5 (=h2) semelhantes às demais. Brevipalpus phoenicis (Geijskes)

33.Estrias dorsais do tegumento formando padrão reticulado na totalidade ou parte do idiossoma. 34

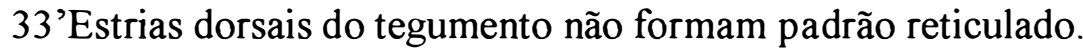
35

34. Setas dorsais lanceoladas e lisas. Lorryia formosa Cooreman 34 'Setas dorsais fortemente serrilhadas Lorryia sp. Oudemans

35. Setas anais ausentes; fêmures III e IV apresentando, cada um, uma proeminente seta bifurcada. Parapronematus sp. Baker 35'Setas anais presentes; fêmures III e IV sem setas proeminentes bifurcadas Pronematus sp. Canestrini 
36.Empódio ligado à extremidade do tarso por um delicado tendão. WINTERSCHMIDTIIDAE. Oulenzia sp. Radford 36’Empódio ligado à extremidade do tarso por um par de estruturas em forma de bastão ACARIDAE. 37

37. Setas ve pequenas e finas, implantadas próximo da altura mediana do bordo lateral do escudo dorsopropodossomal; setas sce mais longas que sci.

Neotropacarus sp. Baker

37'Setas ve longas e implantadas quase à mesma altura que as setas $v i$; setas sce mais curtas do que sci. Tyrophagus sp. Oudemans

\subsection{DISCUSSÃO}

Uma grande diversidade de ácaros foi constatada na cultura da seringueira no Estado do Mato Grosso. A diversidade de espécies foi semelhante nos dois locais pesquisados, sendo que Pontes e Lacerda apresentou 32 espécies e Itiquira, 28 espécies acarinas.

Neste estudo, os ácaros mais freqüentemente encontrados pertenceram à ordem Prostigmata, sendo mais comuns aqueles das famílias Eriophyidae, Tenuipalpidae e Tetranychidae.

Dentre as espécies de eriofideos encontradas, $C$. heveae e $P$. seringueirae foram as mais freqüentes. $C$. heveae foi mais comum em Itiquira, e $P$. seringueirae, em Pontes e Lacerda. As duas espécies foram coletadas durante todo o ano nos diferentes clones avaliados. Possivelmente, a diferença de freqüência se deva aos clones cultivados e às condições climáticas distintas nos dois locais. Devido à baixa freqüência, S. petiolula parece ser de pouca importância econômica para a cultura da seringueira no Mato Grosso.

Entre os tetraniquídeos, T. mexicanus e $O$. gossypii foram as espécies mais freqüentemente encontradas nos dois locais. Pela primeira vez é relatada a presença de uma espécie do gênero Mononychellus nesta cultura. 
T. heveae e B. phoenicis foram as únicas espécies da família Tenuipalpidae encontradas. A freqüência de $T$. heveae foi alta durante todo o ano, enquanto que $B$. phoenicis apresentou baixa freqüência nos dois locais. Devido à sua alta freqüência, $T$. heveae foi o tenuipalpídeo mais importante encontrado. Esta espécie tem sido encontrada em níveis elevados em São Paulo (Feres, 2000) e em Goiás (G. J. Moraes, comunicação pessoal)

Dentre os predadores da ordem Prostigmata, foram encontrados ácaros das famílias Cunaxidae, Tydeidae (Subfamília Pronematinae) e Stigmaeidae. Os estigmeídeos A. floridanus e Zetzellia aff. yusti foram encontrados nos dois locais amostrados, sendo a primeira a espécie mais freqüente. Este ácaro foi mais freqüente em Itiquira. De acordo com os resultados apresentados no Capítulo 8, esta espécie apresenta maior oviposição quando alimentada com $C$. heveae e $T$. heveae do que quando alimentada com $O$. gossypii, P. latus, T. mexicanus ou pólen de Typha angustifolia $\mathrm{L}$. Isto indica que a maior freqüência em Itiquira se deva à maior abundância de $C$. heveae e T. heveae naquele local. Os ácaros da família Cunaxidae foram comuns em Pontes e Lacerda, sendo que a única espécie encontrada pertence ao gênero Pseudobonzia. Estudos preliminares em laboratório mostraram que este ácaro se alimenta de $T$. heveae.

A família Tydeidae apresentou grande diversidade, embora poucos indivíduos tenham sido encontrados. A maior freqüência foi constatada em Pontes e Lacerda, onde predominaram o tideídeos dos gêneros Pronematus e Parapronematus, da subamília Pronematinae. Espécies destes grupos tem sido referidas por Laing \& Knop (1982) e Perrin \& McMurtry (1996) como predadoras de eriofideos.

$\mathrm{Na}$ ordem Mesostigmata, foram coletados apenas ácaros da família Phytoseiidae. Até o momento, apenas 3 espécies de fitoseídeos haviam sido relatadas nos seringais do Estado do Mato Grosso (Feres, 2000). O presente trabalho relata mais 12 espécies. O número de espécies encontradas em Pontes e Lacerda (14) foi o dobro daquelas encontradas em Itiquira (7). Possivelmente, as condições climáticas de Pontes e Lacerda, ambiente próximo da Amazônia, local de onde é originária a seringueira, tenham possibilitado a presença de um maior diversidade de fitoseídeos. É possível também, que essa diferença possa estar ligada aos diferentes clones estudados em cada 
um destes locais.

Os Astigmata das famílias Acaridae e Winterschmidtiidae estiveram presentes apenas em Itiquira e com baixa freqüência. Suas presenças estão restritas aos meses de janeiro a julho, sendo sua maior freqüência observada entre abril e junho, época em que as folhas estão velhas, com maior concentração de fungos, liquens e matéria orgânica. Segundo Flechtmann (1986), a presença de fungos, liquens e matéria orgânica propicia o desenvolvimento de populações destas famílias.

\subsection{CONCLUSÕES}

1) Os ácaros fitófagos mais freqüentemente encontrados em seringueira no Estado do Mato Grosso pertencem às famílias Eriophyidae, Tenuipalpidae e Tetranychidae.

2) C. heveae e $P$. seringueirae são os ácaros mais freqüentemente encontrados em seringueira no Estado do Mato Grosso.

3) A maior diversidade de ácaros fitófagos em seringueira no Estado do Mato Grosso pertence às famílias Eriophyidae e Tetranychidae.

4) T. heveae é o tenuipalpídeo mais importante em seringueira no Estado do Mato Grosso.

5) Pela primeira vez é relatada a presença de uma espécie do gênero Mononychellus em seringueira.

6) Phytoseiidae é o grupo de ácaros predadores mais diverso em seringueira nos dois locais estudados. 


\section{FLUTUAÇÃO POPULACIONAL E EVOLUÇÃO dOS SINTOMAS DE DANO CAUSADOS POR ÁCAROS (ACARI) EM SERINGUEIRA, NO ESTADO DO MATO GROSSO.}

\section{RESUMO}

Apesar da grande importância da cultura da seringueira (Hevea brasiliensis Muell. Arg.) em várias regiões do Brasil, pouco se conhece sobre a flutuação populacional dos ácaros considerados importantes nesta cultura. Os ácaros Calacarus heveae Feres e Tenuipalpus heveae Baker são citados como pragas da seringueira no Brasil. O objetivo deste trabalho foi estudar a flutuação populacional das espécies acarinas presentes na cultura de seringueira no Estado do Mato Grosso e observar a evolução dos sintomas de ataque dos ácaros nesta cultura. Este estudo foi conduzido em campos de seringueira de Itiquira e de Pontes e Lacerda, no Estado do Mato Grosso. Seis clones foram estudados: FX 3864, RRIM 600, IAN 873, IAN 713, PB 260 e PR 255. As coletas foram realizadas de agosto de 1998 a julho de 2000 , sendo que os dados conseguidos na safra 1998/1999 serviram também para estudar a distribuição de $C$. heveae na planta e definir uma metodologia de amostragem a ser utilizada para acompanhar a dinâmica populacional na safra seguinte. Na safra 1998/1999 a amostragem consistiu de 15 folhas dos estratos basal, mediano e apical de cada uma das 10 plantas tomadas ao acaso. Com base nos resultados desta safra, foi alterada a metodologia de coleta na safra 1999/2000. Para esta, foram tomadas 5 folhas do estrato mediano de cada uma de 15 plantas tomadas ao acaso. Em Itiquira, a espécie mais freqüente foi $C$. heveae e em Pontes e Lacerda, foi Phyllocoptruta serigueirae Feres. Apenas em Itiquira foi observada a queda prematura das folhas de plantas de seringueira. 


\section{FLUCTUATION OF THE POPULATION OF MITES (ACARI) ON RUBBER TREES AND EVOLUTION OF THE SYMPTOMS OF THEIR DAMAGE IN THE STATE OF MATO GROSSO}

\section{SUMMARY}

In spite of the importance of rubber trees (Hevea brasiliensis Muell. Arg.) in several regions of Brazil, little is known about the fluctuation of the population of mite species on this crop. The mites Calacarus heveae Feres and Tenuipalpus heveae Baker have been mentioned as pests of this crop in Brazil. The aim of this work to study the fluctuation of the population of mite species on rubber trees in the State of Mato Grosso and to observe the evolution of the symptoms of their attack. This study was conducted at Itiquira and Pontes e Lacerda, State of Mato Grosso. Six clones were studied: FX 3864, RRIM 600, IAN 873, IAN 713, PB 260 and PR 255. Samplings were conducted between August 1998 and July 2000, and the data obtained in the 1998/1999 season were also used to study the distribution of $C$. heveae in the rubber tree plant as well as to define a sampling technique of $C$. heveae in the next season. In the season 1998/1999 samples consisted of 15 leaves of each of 10 plants taken randomly. Based on those results, the sampling methodology was changed in the season 1999/2000. For that season, 5 leaves of the median stratum of each of 15 plants taken randomly when sampled. In Itiquira, $C$. heveae was the most frequent specie and, in Pontes e Lacerda, the most frequent species was Phyllocoptruta serigueirae Feres. Only in Itiquira premature leaf drop was observed. 


\subsection{INTRODUÇÃO}

Apesar da grande importância da cultura da seringueira (Hevea brasiliensis Muell. Arg.) para várias regiões do Brasil, pouco se conhece sobre a dinâmica populacional dos ácaros considerados praga nesta cultura. Apenas nos Estados do Acre, Amazonas e São Paulo foram realizados alguns estudos sobre a flutuação populacional de ácaros presentes na cultura da seringueira (Fazolin \& Pereira, 1989; Furquim, 1994; Vieira \& Gomes, 1999).

Entre os ácaros fitófagos, Calacarus heveae Feres e Tenuipalpus heveae Baker são consideradas as espécies acarinas mais importantes na cultura da seringueira (Feres, 1992; Feres 2000). C. heveae prefere a face adaxial dos folíolos (Vieira \& Gomes, 1999), causa a perda do brilho, amarelecimento e bronzeamento e conseqüente queda prematura dos mesmos (Feres, 2000). Segundo Vieira \& Gomes (1999) o ataque de $C$. heveae pode provocar níveis de desfolha acima de 75\% no clone RRIM 600. Segundo Feres (2000), alguns produtores afirmam que $C$. heveae ocasiona perdas de até $30 \%$ na produção de látex em variedades de $H$. brasiliensis. T. heveae predomina na face abaxial dos folíolos, embora, quando em altas infestações, seja também encontrado na face adaxial (Feres, 2000). Causa amarelecimento das folhas atacadas, também contribuindo para a queda prematura das folhas.

Fazolin \& Pereira (1989) relataram os sintomas de ataque e os níveis populacionais de Oligonychus gossypii (Zacher) nos Estados do Acre e do Amazonas, no período seco do ano, entre os meses de outubro a dezembro. Furquim (1994) estudou a flutuação das espécies de ácaros fitófagos em 10 variedades de seringueira no norte do Estado de São Paulo, constatando que $C$. heveae foi a espécie mais abundante, cujos picos populacionais ocorreram entre março e maio. Apenas Vieira \& Gomes (1999) estudaram os sintomas dos danos provocados por $C$. heveae em Reginópolis, Estado de São Paulo. Estes autores relataram a presença de maiores populações deste ácaro no primeiro semestre, coincidindo com o período de maior produção de látex .

O objetivo deste trabalho foi estudar a flutuação populacional das espécies acarinas presentes na cultura de seringueira no Estado do Mato Grosso e a evolução dos 
sintomas de ataque dos ácaros à cultura.

\subsection{MATERIAIS E MÉTODOS}

Este estudo foi conduzido nos seringais das Plantações Edouard Michelin Ltda., no município de Itiquira, e da Triângulo Agro-industrial S/A, no município de Pontes e Lacerda, ambos no Estado do Mato Grosso.

As coletas foram feitas mensalmente em 6 clones diferentes. Em Itiquira, foram escolhidos os clones PB 260 (4,5 ha e 12 anos) e PR 255 (6,4 ha e 15 anos), e em Pontes e Lacerda, os clones IAN 713 (2,6 ha e 15 anos), IAN 873 (17,1 ha e 16 anos), FX 3864 (6,5 ha e 14 anos) e RRIM 600 (3,2 ha e 15 anos). Nos clones PB 260 e IAN 873, as coletas foram realizadas de agosto de 1998 a julho de 2000; nos demais clones, as coletas foram realizadas de agosto de 1999 a julho de 2000.

Os dados conseguidos na safra 1998/1999 e apresentados no Capítulo 1, serviram para estudar a distribuição de $C$. heveae na planta e definir uma metodologia de coleta a ser utilizada para acompanhar a dinâmica populacional deste ácaro na safra seguinte. Na safra 1998/1999, a amostragem consistiu de 15 folhas coletadas de cada uma das 10 plantas escolhidas ao acaso em cada campo, localizadas a pelo menos 20 metros da borda. Foram coletadas 3 folhas de cada um dos estratos basal, mediano e apical de cada planta, sendo coletada, em cada estrato, uma folha em cada uma das regiões distal, mediana e proximal de cada ramo, totalizando 9 folhas. Além disso, foram coletadas 3 folhas do estrato mediano de cada um dos quadrantes leste e oeste, totalizando 6 folhas em cada planta. Nestes quadrantes, as folhas foram tomadas na região média de ramos da periferia da copa, outra na mesma posição de ramos próximos ao caule e outra na mesma posição em ramos da região intermediária em relação a profundidade da copa de cada uma das plantas amostradas. As parcelas nas quais foram realizadas as amostragens apresentavam aproximadamente 500 plantas com altura aproximada de 20 metros. Na segunda safra, entre 1999/2000, 5 folhas de cada uma das 15 plantas escolhidas foram amostradas em ramos da periferia do estrato mediano dos clones IAN 713, IAN 873, FX 3864, PB 260, PR 255 e RRIM 600. 
Nestas áreas nenhum tratamento com agroquímicos foi realizado durante o desenvolvimento do trabalho. A última aplicação de agroquímicos nestas áreas havia sido realizada cerca de 6 meses antes do início do trabalho.

As folhas coletadas foram acondicionadas em sacos de papel e levadas ao laboratório para a contagem das formas móveis, identificando-os até o nível de família. A contagem foi realizada sob microscópio estereoscópio, observando-se as duas faces dos folíolos.

Para a identificação das espécies acarinas na safra 1998/1999 foram observadas 40 folhas de cada clone, enquanto que na safra 1999/2000 foram 20 folhas de cada clone. Até 10 ácaros de cada família foram coletados em cada folha amostrada. Para exame ao microscópio, os eriofideos foram montados em meio modificado de Berlese (Amrine \& Manson, 1996) e os demais ácaros foram montados em meio de Hoyer (Jeppson et al., 1975). As lâminas montadas foram mantidas em estufa a $50-60^{\circ} \mathrm{C}$ por cerca de 10 dias para a fixação, distensão e clarificação dos espécimes, e secagem do meio. Posteriormente, foi feita a lutagem das bordas das lamínulas.

A relação das espécies e a freqüência com que foram encontradas foi relatada no Capítulo 4.

A evolução dos sintomas de ataque dos ácaros à seringueira foi estudada através de uma escala de notas variando de 1 a 5 . Pertenciam ao nível 1 as folhas sem nenhum dano e ao nível 5 as folhas com toda a face superior amarelada. Os níveis 2,3 e 4 corresponderam a danos crescentes e intermediários (Figura 6). 

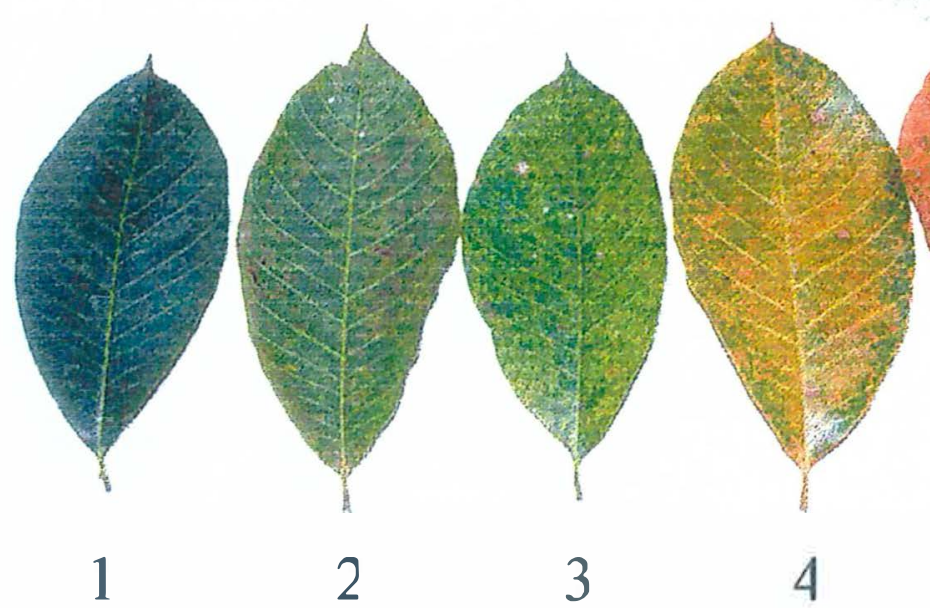

4

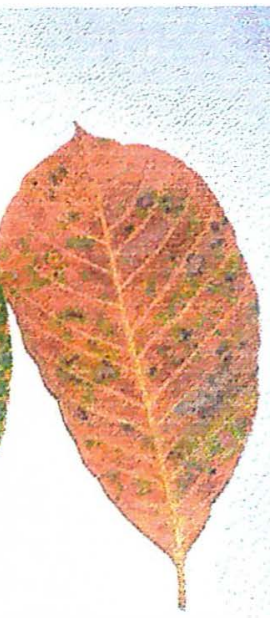

Figura 6 - Níveis de dano causado por ácaros nos clones avaliados nos municípios de Itiquira e Pontes e Lacerda (nível 1 : folhas sem dano; níveis 2, 3 e 4 : danos crescentes e intermediários; nível 5 : toda a face adaxial amarelada).

\subsection{RESULTADOS}

\subsubsection{Dinâmica populacional das famílias encontradas}

No clone FX 3864, em Pontes e Lacerda, as maiores populações de ácaros foram observadas na face abaxial e pertenceram à família Eriophyidae (Figura 7). Neste clone, o pico populacional dos eriofideos da face adaxial foi observado quando ocorreu o aumento da umidade relativa. No mês de março, quando foi observada a maior precipitação, houve uma diminuição na população de eriofideos nas duas faces dos folíolos. Os ácaros das famílias Cunaxidae e Phytoseiidae foram os predadores mais comumente encontrados.

No clone RRIM 600, em Pontes e Lacerda, os ácaros da família Eriophyidae também alcançaram as maiores populações, sendo as densidades semelhantes nas duas faces dos folíolos. Na face adaxial o pico populacional ocorreu no mês de março e na face abaxial no mês de abril (Figura 8). O pico populacional dos eriofideos da face adaxial foi observado no mês de maior precipitação, quando a umidade relativa também 
Face Adaxial

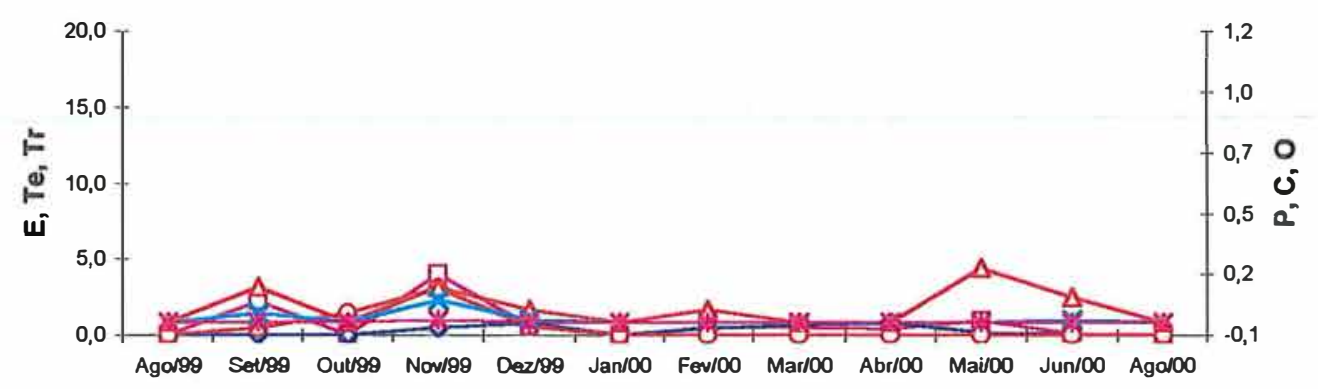

Face Abaxial

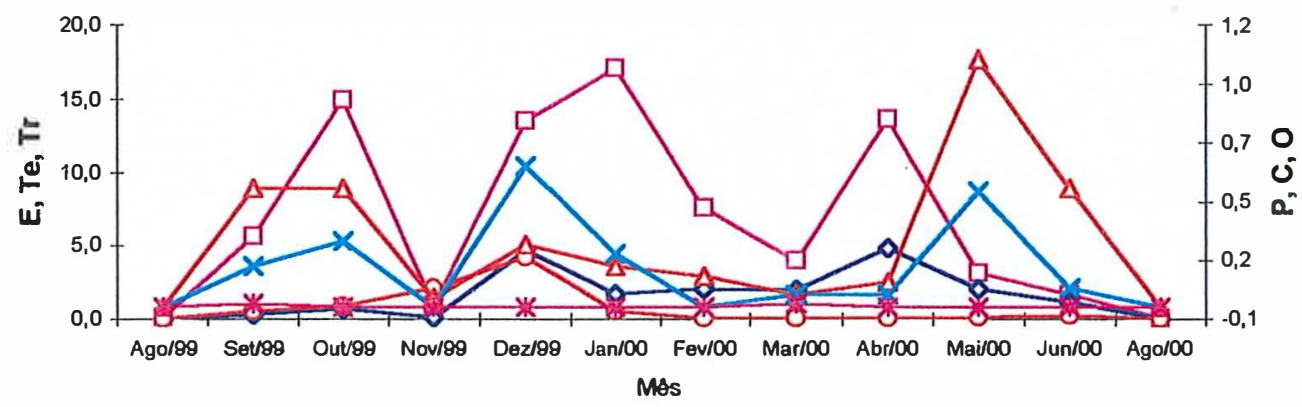

$\rightarrow-E \multimap T e-\infty \mathrm{Tr} \rightarrow \mathrm{P} \rightarrow \mathrm{T}-\mathrm{C} \rightarrow \mathrm{O}$

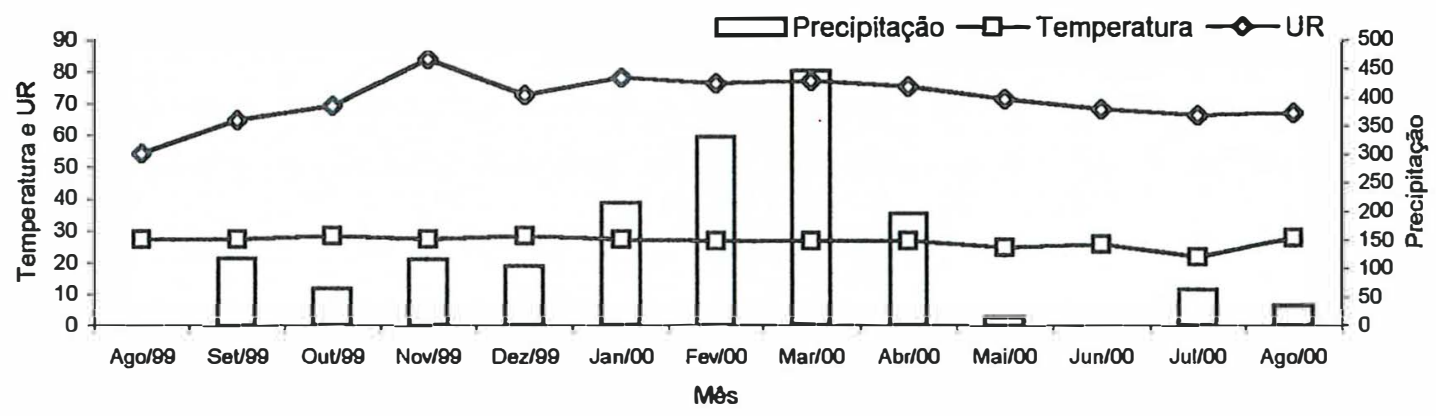

Figura 7 - Flutuação populacional (ácaros/folha) dos ácaros encontrados no clone FX 3864 de seringueira em Pontes e Lacerda, Mato Grosso ( $E=$ Eriophyidae; $T e=$ Tenuipalpidae; $T r=$ Tetranychidae; $P=$ Phytoseiidae; $\mathrm{C}=$ Cunaxidae; $\mathrm{O}=$ Acaridae, Cheyletidae, Tarsonemidae, Tydeidae, Stigmaeidae, Winterschmidtiidae). 
Face Adaxial

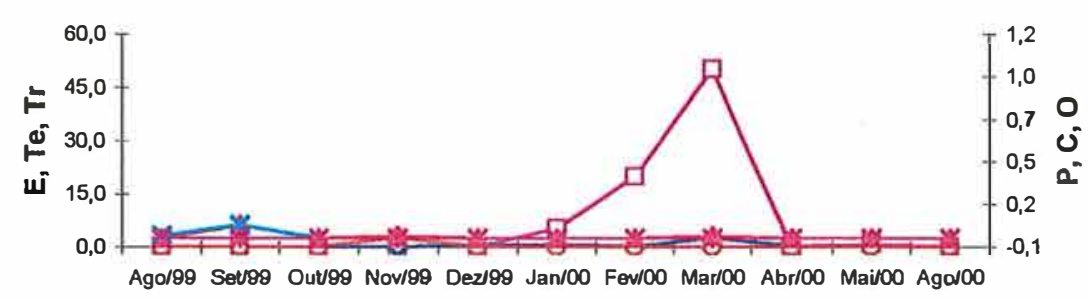

Face Abaxial

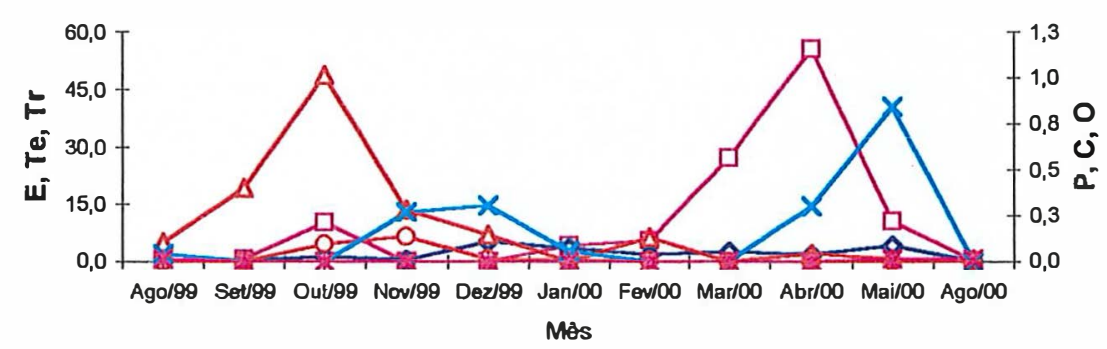

$\neg-E \multimap T e \multimap-T r \rightarrow P \rightarrow C \rightarrow-O$

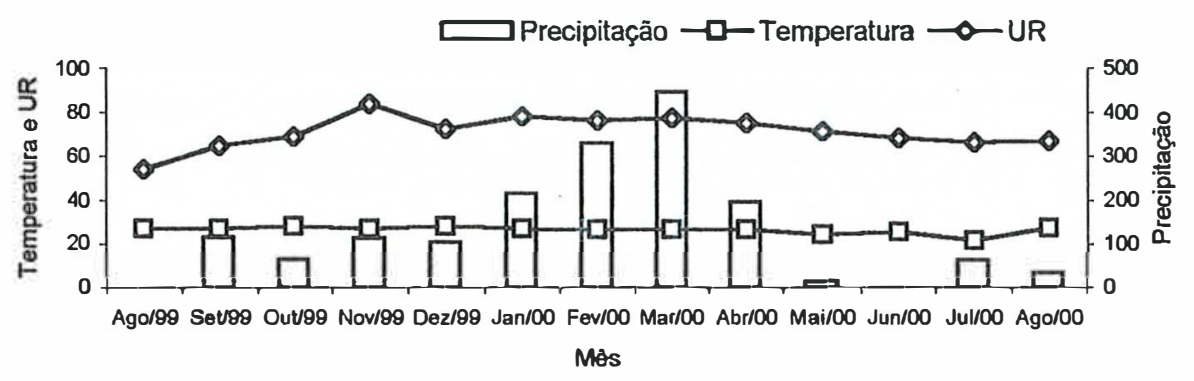

Figura 8 - Flutuação populacional (ácaros/folha) dos ácaros encontrados no clone RRIM 600 de seringueira em Pontes e Lacerda, Mato Grosso (E = Eriophyidae; $\mathrm{Te}=$ Tenuipalpidae; $\mathrm{Tr}=$ Tetranychidae; $\mathbf{P}=$ Phytoseiidae; $\mathbf{C}=$ Cunaxidae; $\mathrm{O}=$ Acaridae, Cheyletidae, Tarsonemidae, Tydeidae, Stigmaeidae, Wintershmidtiidae). 
foi alta, enquanto que o pico populacional dos eriofídeos da face abaxial aconteceu no mês imediatamente posterior ao mês de maior precipitação. Semelhantemente ao que se observou no clone FX 3864, os ácaros predadores das famílias Cunaxidae e Phytoseiidae apresentaram maiores populações.

No clone IAN 873, em Pontes e Lacerda, os eriofideos foram os ácaros que apresentaram maiores populações na face abaxial, a partir de setembro de 1999 (Figura 9). Em março e abril de 2000, quando ocorreu a maior precipitação, houve uma diminuição das populações de eriofídeos na face abaxial. A população de T. heveae aumentou muito neste período, e provavelmente, afetou o crescimento das populações de eriofideos. Os fitoseídeos foram os ácaros predadores mais comuns. Entretanto, em outubro de 1998 os tideídeos dos gêneros Pronematus e Parapronematus foram os ácaros predadores mais comuns, enquanto que em maio de 1999, Pseudobonzia sp. e Agistemus floridamus apresentaram altas populações.

No clone IAN 713, em Pontes e Lacerda, os eriofideos alcançaram maior população na face abaxial, enquanto que os tetraniquideos apresentaram populações semelhante nas duas faces da folha (Figura 10). No mês de março foi observada a maior precipitação e as maiores populações de eriofídeos da face abaxial. O pico populacional dos tetraniquídeos aconteceu no mês de novembro, quando foi observada a maior umidade relativa. Os fitoseídoes e os cunaxídeos foram os ácaros predadores mais comuns, alcançando níveis mais elevados entre outubro e dezembro de 1999, quando também os tetraniquídeos foram encontrados em níveis mais elevados.

Diferentemente do que se observou nos clones até agora citados, no clone PB 260, localizado em Itiquira, as populações de eriofideos foram maiores na face adaxial. Os tenuipalpídeos ocorreram em maiores populações na face abaxial (Figura 11). Nos dois anos de observação, as maiores populações de eriofideos e tenuipalpídeos aconteceram em presença de alta umidade relativa e alta precipitação. Neste clone, os estigmeídeos e os fitoseídeos foram os ácaros predadores mais comuns. $\mathrm{O}$ aumento das populações de Stigmaeidae aconteceu entre os meses de novembro de 1998 e janeiro de 1999 e novembro de 1999 e janeiro de 2000, quando foram observadas altas populações de $C$. heveae na face adaxial e $T$. heveae na face abaxial. 
Face Adaxial

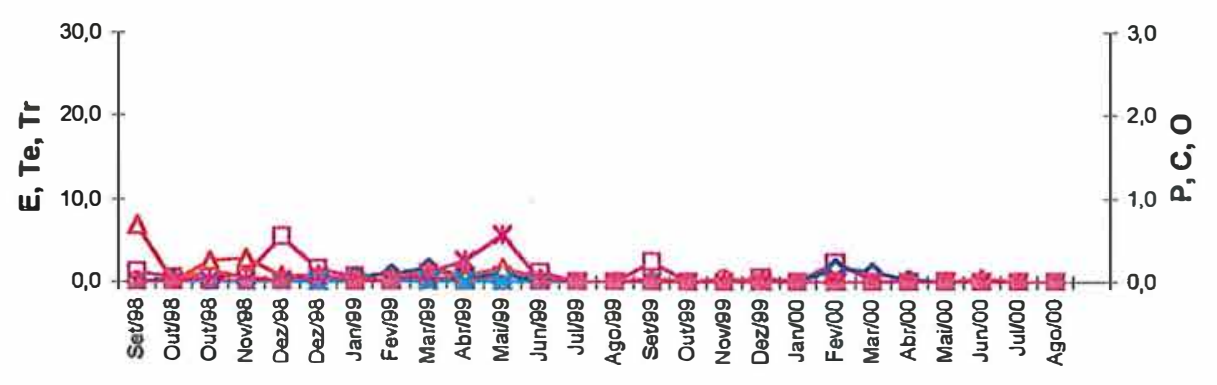

Face Abaxial

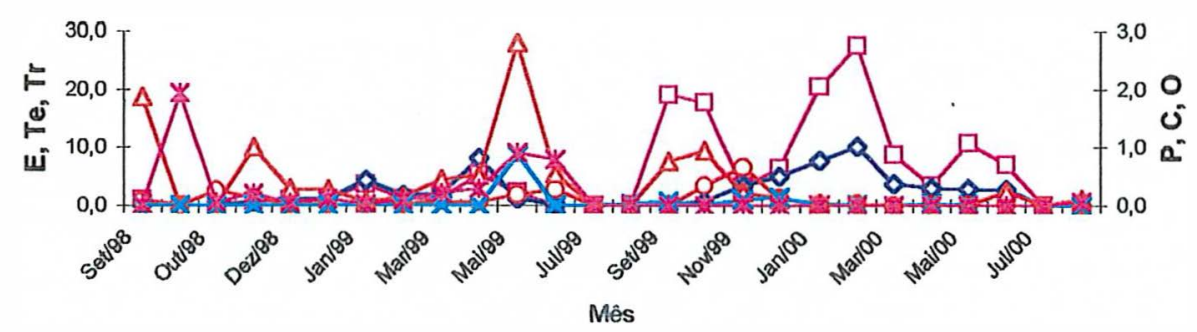

$\rightarrow-E \multimap T e \multimap T r \rightarrow P \rightarrow C \rightarrow O$

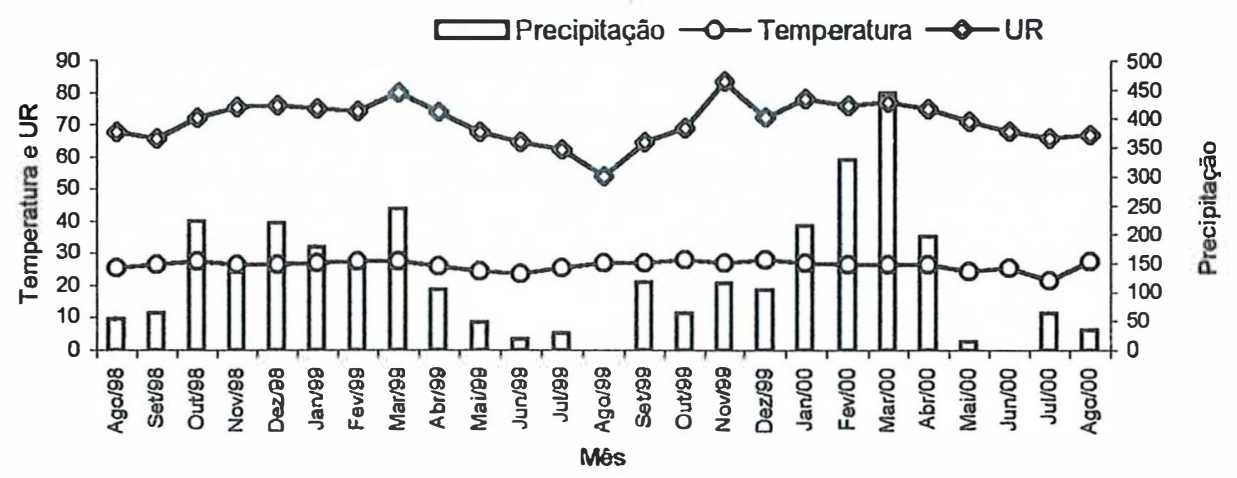

igura 9 - Flutuação populacional (ácaros/folha) dos ácaros encontrados no clone IAN 873 de eringueira em Pontes e Lacerda, Mato Grosso ( $E=$ Eriophyidae; $\mathrm{Te}=$ Tenuipalpidae; $\mathrm{Tr}=$ 'etranychidae; $P$ = Phytoseiidae; $C=$ Cunaxidae; $O=$ Acaridae, Cheyletidae, Tarsonemidae, ydeidae, Stigmaeidae, Winterschmidtiidae). 


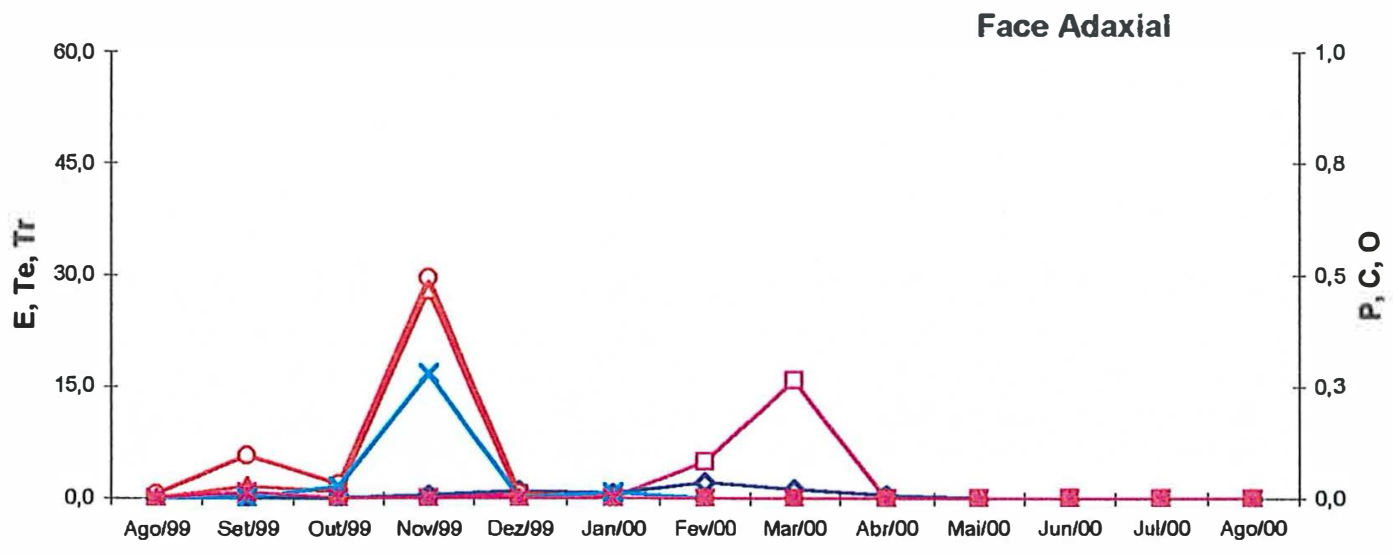

Face Abaxial

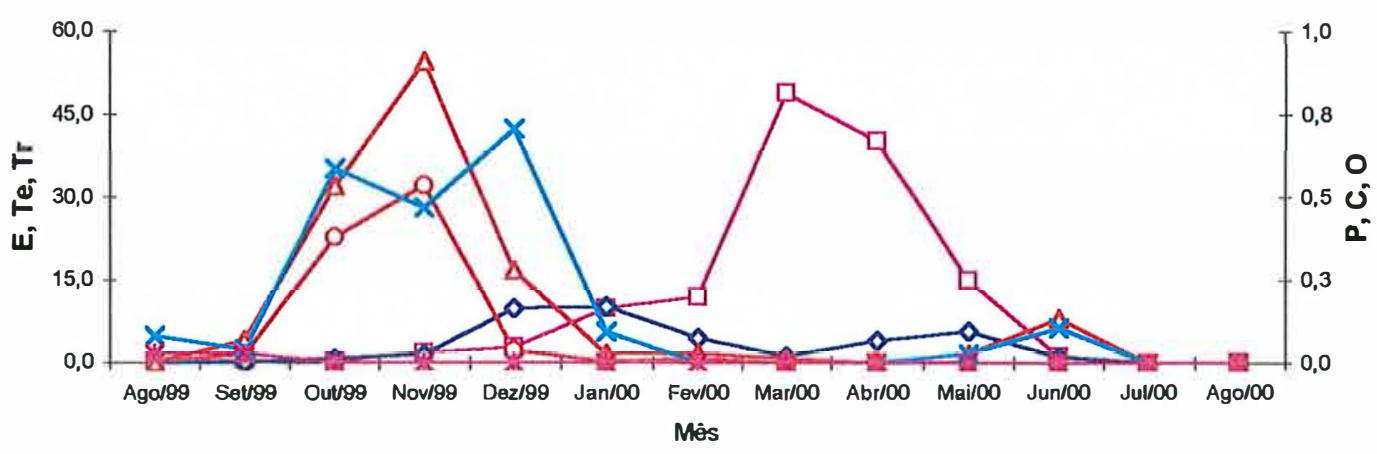

$\rightarrow-E \multimap T e \multimap-T r \rightarrow P \rightarrow C \rightarrow-O$

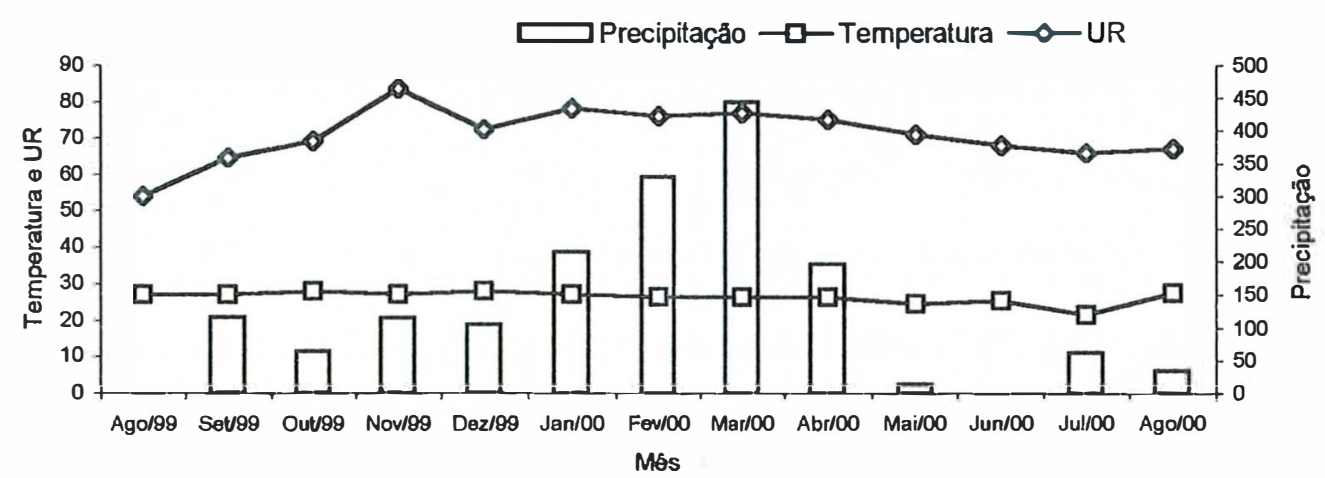

Figura 10 - Flutuação populacional (ácaros/folha) dos ácaros encontrados no clone IAN 713 de seringueira em Pontes e Lacerda, Mato Grosso (E = Eriophyidae; $\mathrm{Te}=$ Tenuipalpidae; $\mathrm{Tr}=$ Tetranychidae; $P$ = Phytoseiidae; $\mathbf{C}=$ Cunaxidae; $O=$ Acaridae, Cheyletidae, Tarsonemidae, 

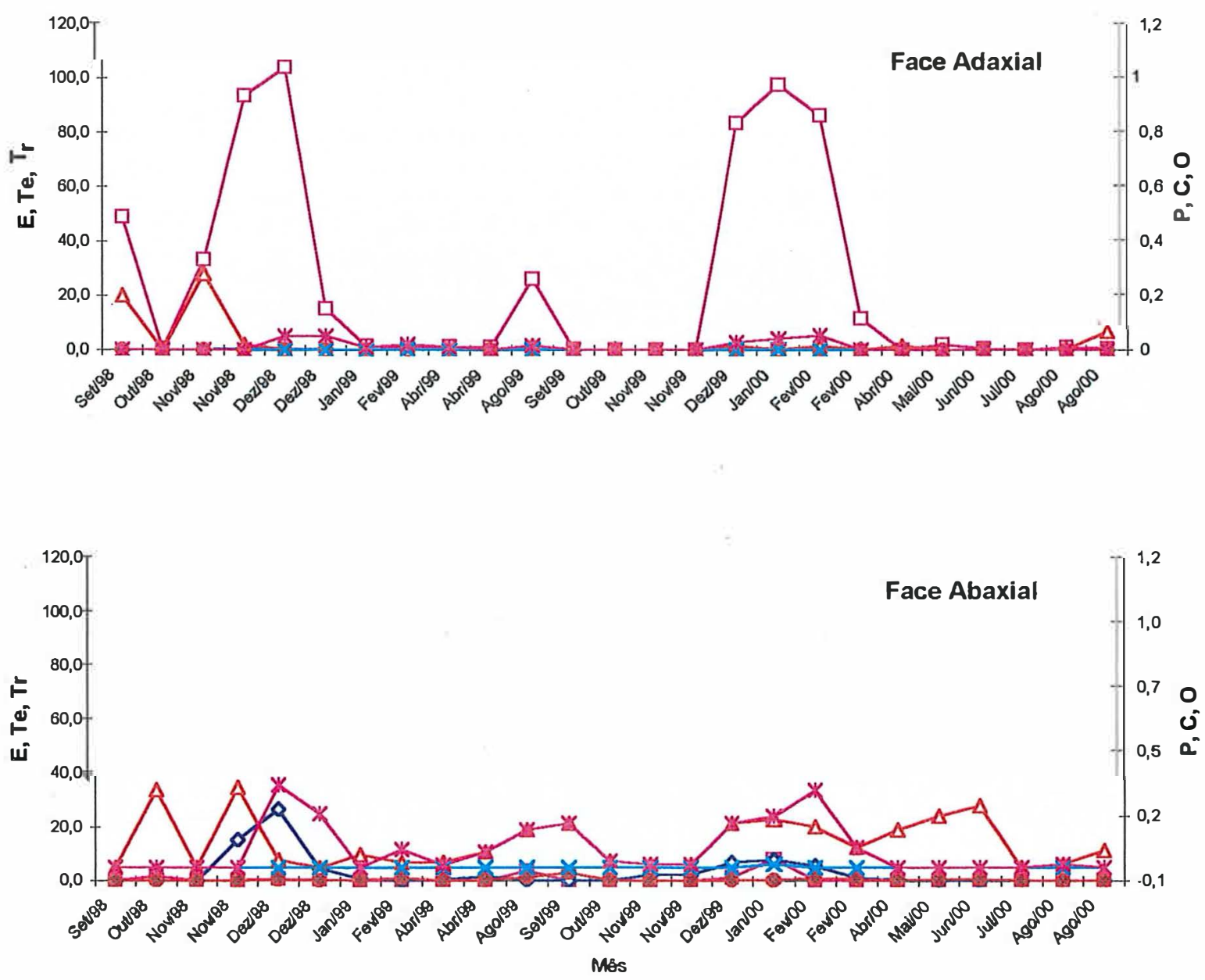

$\rightarrow-E \multimap T e \multimap T r \rightarrow P \rightarrow C \rightarrow-O$

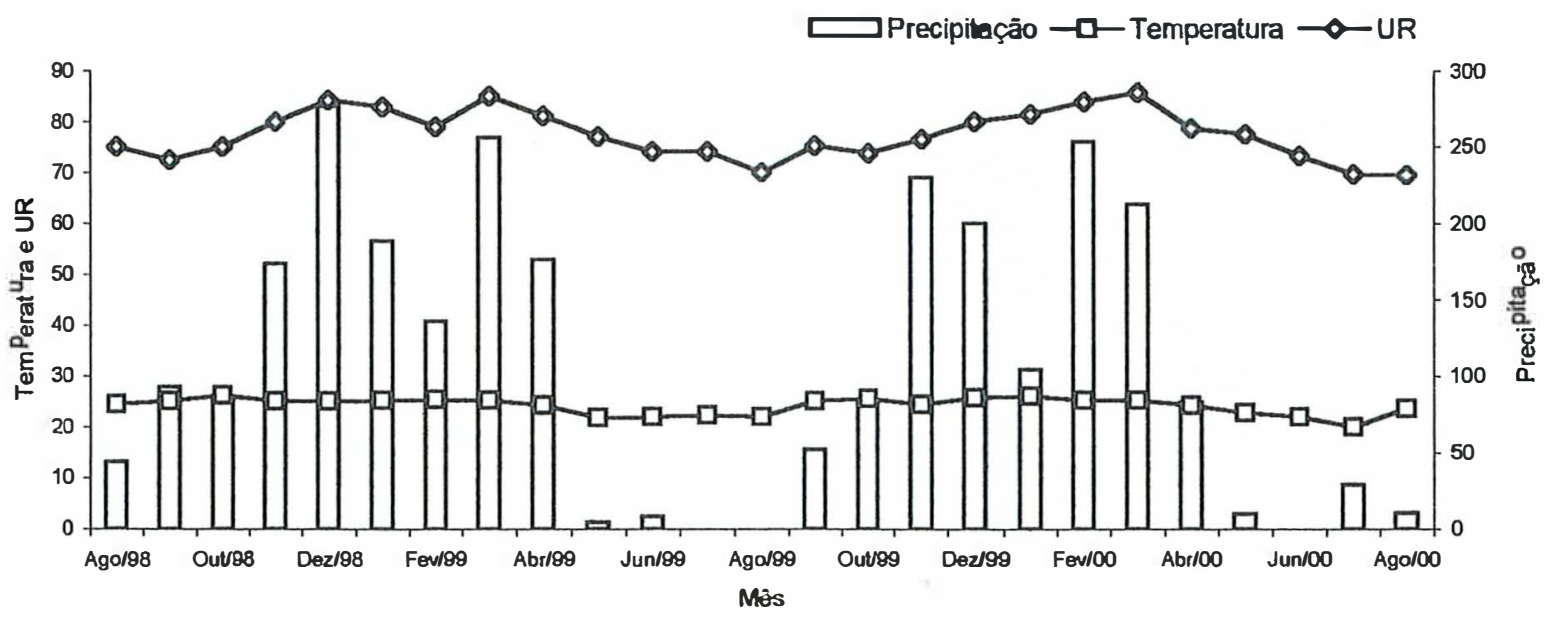

Figura 11 - Flutuação populacional (ácaros/folha) dos ácaros encontrados no clone PB 260 de seringueira em Itiquira, Mato Grosso (E = Eriophyidae; $\mathrm{Te}=$ Tenuipalpidae; $\mathrm{Tr}=$ Tetranychidae; $\mathrm{P}=$ Phytoseiidae; $C$ = Cunaxidae; $O=$ Acaridae, Cheyletidae, Tarsonemidae, Tydeidae, Stigmaeidae, Winterschmidtiidae). 
Da mesma forma que para o clone PB 260, os eriofideos alcançaram maiores populações no clone PR 255 na face adaxial em Itiquira (Figura 12). As maiores populações de eriofideos foram observadas no mês de maior precipitação e alta umidade relativa. Neste clone, os estigmeídeos foram os ácaros predadores mais comuns.

Devido à pouca alteração na temperatura, não foi possível observar sua influência sobre as populações acarinas nos clones avaliados.

\subsubsection{Espécies acarinas mais comuns}

A Tabela 2 apresenta a proporção de cada espécie encontrada neste estudo.

Dentre os eriofideos, Phyllocoptruta seringueirae Feres foi coletada em maior freqüência em Pontes e Lacerda (33\%), enquanto que $C$. heveae foi encontrado em maior freqüência em Itiquira $(25,7 \%)$. T. heveae apresentou número maior de indivíduos em Pontes e Lacerda $(35,1 \%)$ que em Itiquira $(24,8 \%)$. Entre os tetraniquídeos, $O$. gossypii e Teytranychus mexicamus (McGregor) foram as espécies com maior número de indivíduos. O. gossypii foi mais freqüente em Pontes e Lacerda (6,2\%), enquanto que $T$. mexicanus teve freqüência maior em Itiquira $(5,1 \%)$.

$\mathrm{Na}$ família Phytoseiidae, Euseius concordis (Chant) e Neoseiulus anonymus (Chant \& Baker) foram as espécies mais abundantes. E. concordis foi mais abundante em Pontes e Lacerda $(8,0 \%)$ que em Itiquira $(4,6 \%)$. $N$. anonymus foi mais abundante em Itiquira $(4,5 \%)$ que em Pontes e Lacerda $(1,0 \%)$. Pseudobonzia sp. foi mais abundante em Pontes e Lacerda (4,7\%). A freqüência de Agistemus aff. congolensis foi maior em Itiquira $(5,4 \%)$ que em Pontes e Lacerda $(0,5 \%)$.

Uma listagem pormenorizada das espécies encontradas, incluindo informações sobre a taxonomia, distribuição e números absolutos das espécies encontradas, foi apresentada no Capítulo 4. 

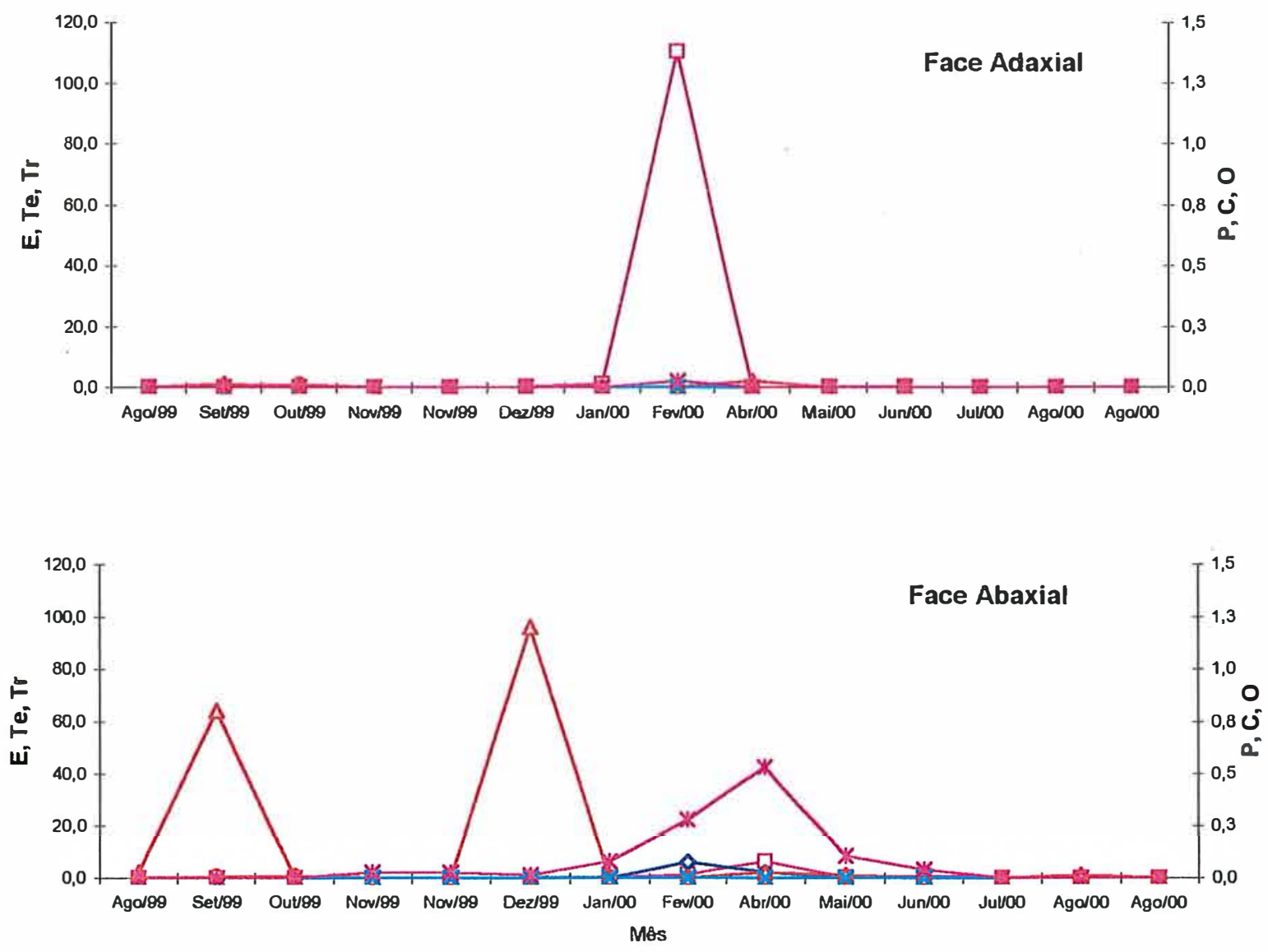

$\rightarrow-\mathrm{E} \multimap \mathrm{Te} \multimap \mathrm{OT} \rightarrow \mathrm{T} \rightarrow \mathrm{P} \rightarrow \mathrm{C} \rightarrow \mathrm{O}$

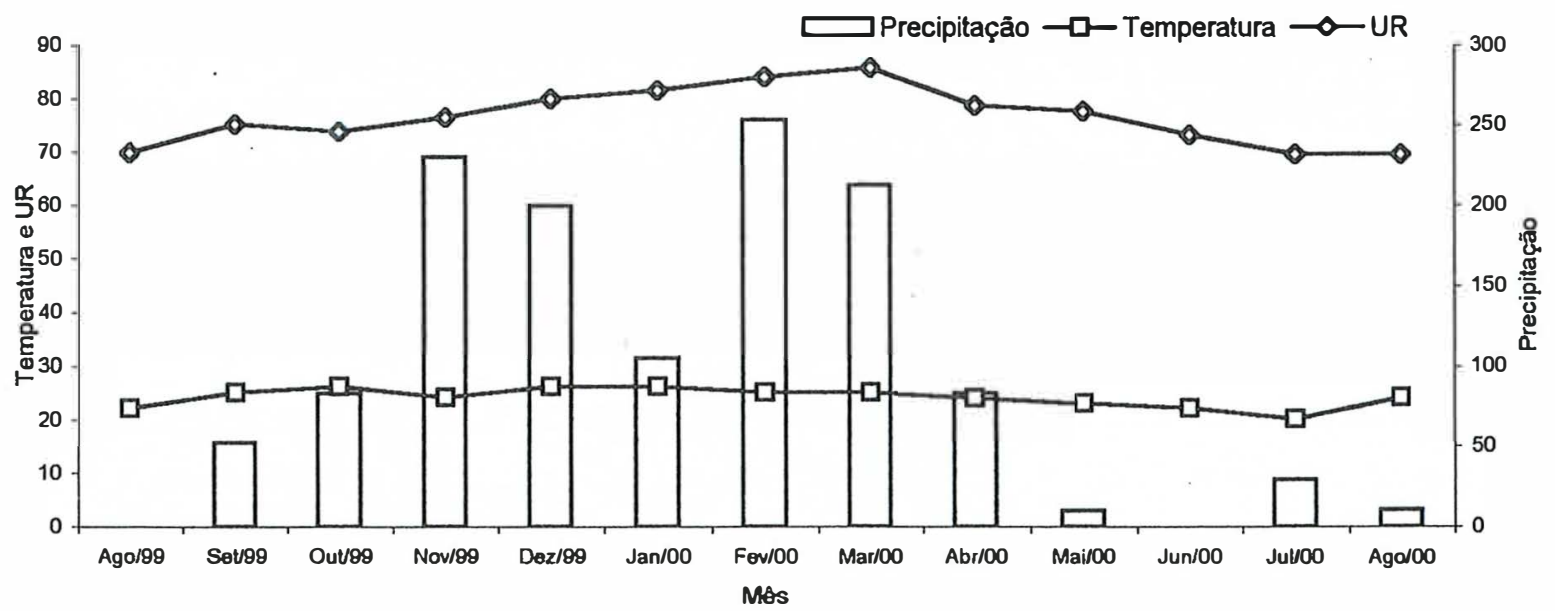

Figura 12 - Flutuação populacional (ácaros/folha) dos ácaros encontrados no clone PR 255 de seringueira em Itiquira, Mato Grosso (E = Eriophyidae; $\mathrm{Te}=$ Tenuipalpidae; $\mathrm{Tr}=$ Tetranychidae; $\mathrm{P}=$ Phytoseiidae; $\mathrm{C}=$ Cunaxidae; $\mathrm{O}=$ Acaridae, Cheyletidae, Tarsonemidae, Tydeidae, Stigmaeidae, Winterschmidtiidae). 
Tabela 2. Proporção (\%) das espécies acarinas encontradas em plantações de seringueira, nos municípios de Itiquira e Pontes e Lacerda, Mato Grosso, entre setembro de 1998 a julho de 2000 .

\begin{tabular}{|c|c|c|c|c|}
\hline \multirow[t]{2}{*}{ Ordem } & \multirow[t]{2}{*}{ Família } & \multirow[t]{2}{*}{ Espécie } & \multicolumn{2}{|c|}{ Itiquira Pontes e } \\
\hline & & & & Lacerda \\
\hline \multirow{18}{*}{\multicolumn{2}{|c|}{ MESOSTIGMATA Phytoseiidae }} & Amblyseius acalyphus Denmark \& & 2,2 & 0,2 \\
\hline & & Muma & & \\
\hline & & Amblyseius neochiapensis Lofego, & 0,08 & 1,3 \\
\hline & & Moraes \& McMurtry & & \\
\hline & & Euseius alatus DeLeon & 0,08 & 1,9 \\
\hline & & Euseius citrifolius Denmark \& Muma & 2,1 & 0,0 \\
\hline & & Euseius concordis (Chant) & 4,6 & 8,0 \\
\hline & & Galendromimus alveolaris (DeLeon) & 0,0 & 0,06 \\
\hline & & Galendromus annectens DeLeon & 0,1 & 0,2 \\
\hline & & Galendromus sp. & 0,0 & 0,3 \\
\hline & & Neoseiulus anonymus (Chant \& Baker) & 1,0 & 4,5 \\
\hline & & Neoseiulus tunus (DeLeon) & 0,0 & 0,03 \\
\hline & & Typhlodromalus aff. horatii & 0,0 & 0,03 \\
\hline & & Typhlodromalus feresi Lofego, Moraes & 0,0 & 0,03 \\
\hline & & \& McMurtry & & \\
\hline & & Typhlodromips amilus DeLeon & 0,0 & 0,8 \\
\hline & & Typhlodromips aff. sinensis & 0,0 & 0,2 \\
\hline & & Typhlodromus transvaalensis (Nesbitt) & 0,0 & 0,03 \\
\hline \multirow[t]{9}{*}{ PROSTIGMATA } & Cheyletidae & Hemicheyletia sp. & 0,08 & 0,03 \\
\hline & Cunaxidae & Pseudobonzia sp. & 0,1 & 4,7 \\
\hline & Eriophyidae & Aff. Acaphyllisa sp. & 0,08 & 0,0 \\
\hline & & Aff. Chakrabartiella sp. & 0,0 & 0,1 \\
\hline & & Calacarus heveae Feres & 25,1 & 7,7 \\
\hline & & Phyllocoptruta seringueirae Feres & 1,8 & 33,0 \\
\hline & & Shevtchenkella petiolula Feres & 0,4 & 1,9 \\
\hline & Stigmaeidae & Agistemus floridanus Gonzalez & 5,4 & 0,5 \\
\hline & & Zetzellia aff. yusti & 0,08 & 0,09 \\
\hline
\end{tabular}


Tabela 2. Proporção (\%) das espécies acarinas encontradas em plantações de seringueira, nos municípios de Itiquira e Pontes e Lacerda, Mato Grosso, entre setembro de 1998 a julho de 2000.

\begin{tabular}{|c|c|c|c|c|}
\hline \multirow[t]{2}{*}{ Ordem } & \multirow[t]{2}{*}{ Família } & \multirow[t]{2}{*}{ Espécie } & \multicolumn{2}{|c|}{ Itiquira Pontes e } \\
\hline & & & \multicolumn{2}{|r|}{ Lacerda } \\
\hline & \multirow[t]{2}{*}{ Tarsonemidae } & Polyphagotarsonemus latus (Banks) & 0,08 & 0,1 \\
\hline & & Tarsonemus sp. & 2,4 & 0,06 \\
\hline & \multirow[t]{2}{*}{ Tenuipalpidae } & Brevipalpus phoenicis (Geijskes) & 0,1 & 0,06 \\
\hline & & Tenuipalpus heveae Baker & 35,1 & 24,8 \\
\hline & \multirow[t]{5}{*}{ Tetranychidae } & Eutetranychus banksi (McGregor) & 0,1 & 0,0 \\
\hline & & Mononychellus sp. & 0,5 & 0,7 \\
\hline & & Oligonychus coffeae (Nietner) & 0,4 & 0,7 \\
\hline & & Oligonychus gossypii (Zacher) & 3,9 & 6,2 \\
\hline & & Tetranychus mexicanus (McGregor) & 5,1 & 2,5 \\
\hline & \multirow[t]{4}{*}{ Tydeidae } & Lorryia formosa Cooreman & 1,5 & 0,03 \\
\hline & & Lorryia sp. & 1,2 & 0,7 \\
\hline & & Parapronematus sp. & 0,3 & 1,3 \\
\hline & & Pronematus sp. & 0,08 & 0,5 \\
\hline \multirow[t]{3}{*}{ ASTIGMATA } & \multirow[t]{2}{*}{ Acaridae } & Tyrophagus sp. & 0,3 & 0,0 \\
\hline & & Neotropacarus sp. & 0,8 & 0,0 \\
\hline & \multicolumn{2}{|c|}{ Wintershmidtiidae Oulenzia sp. } & 0,3 & 0,09 \\
\hline
\end{tabular}




\subsubsection{Prevalência de espécies de Eriophyidae e Phytoseiidae}

Em relação aos eriofideos, em Pontes e Lacerda, $P$. seringueirae foi de maneira geral a espécie dominante durante todo o estudo, sendo a dominância nos clones FX 3864 e IAN 713 (Figura 13). A segunda espécie mais numerosa foi $C$. heveae, cuja abundância foi maior nos clones IAN 873, entre novembro de 1998 a março de 1999, e RRM 600, entre os meses de dezembro de 1999 e março de 2000. S. petiolula foi a espécie encontrada em menor freqüência.

Em Itiquira a espécie dominante foi $C$. heveae, enquanto que $P$. seringueirae e S. petiolula foram espécies pouco freqüentes, exceto em algumas coletas (Figura 13).

Em Pontes e Lacerda, E concordis foi a espécie dominante nos clones FX 3864 , RRIM 600 e IAN 713 (Figura 14). Sua freqüência foi maior entre os meses de agosto e dezembro. $N$. anonymus foi mais freqüente no clone RRIM 600 e IAN 873 entre os meses de setembro a fevereiro. A somatória dos exemplares de outros fitoseídeos encontrados foi maior que o número de E: concordis e $N$. anonymus no clone FX 3864 entre os meses de setembro e fevereiro.

Em Itiquira, a freqüência de $N$. anonymus foi maior no clone PR 255 entre os meses de outubro e fevereiro, enquanto que no clone PB 260 as freqüências de $E$. concordis e $N$. anonymus foram semelhantes (Figura 14). Neste clone, N. anonymus foi mais freqüente nos meses de novembro e janeiro, enquanto que $E$. concordis foi mais freqüente nos demais meses. 

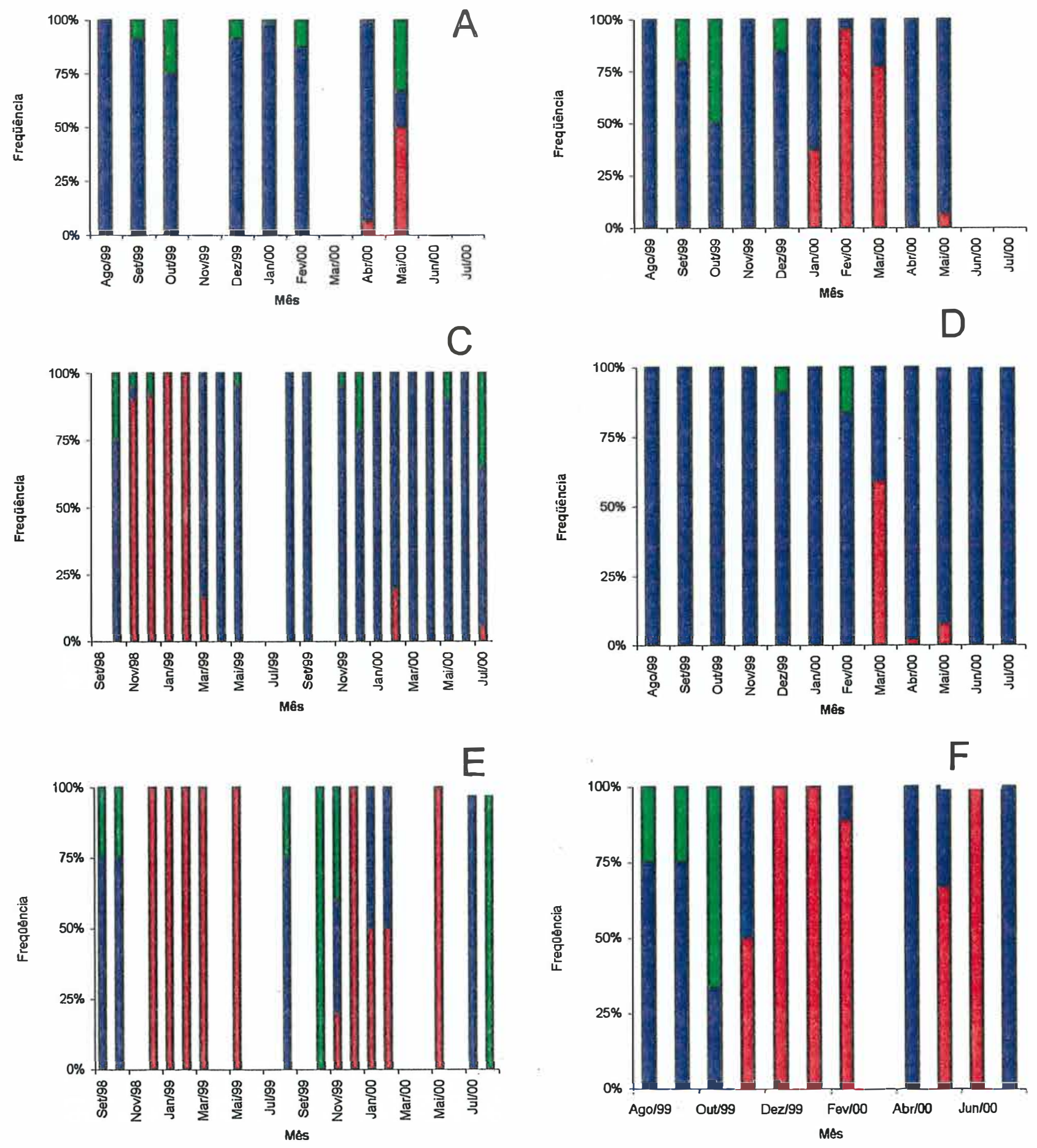

Schevtchenkella petiolula
Phyllocoptruta seringueirae
Calacarus heveae

Figura 13 - Freqüência da ocorrência das principais espécies de Eriophyidae nos clones de seringueira avaliados nos municípios de Pontes e Lacerda ( $\mathrm{A}=$ clone FX 3864; $\mathrm{B}=$ clone RRIM 600; $\mathrm{C}=\mathrm{IAN} 873 ; \mathrm{D}=$ clone IAN 713) e Itiquira ( $\mathrm{E}=$ clone PB 260; $\mathrm{F}=$ clone PR 255). 
A
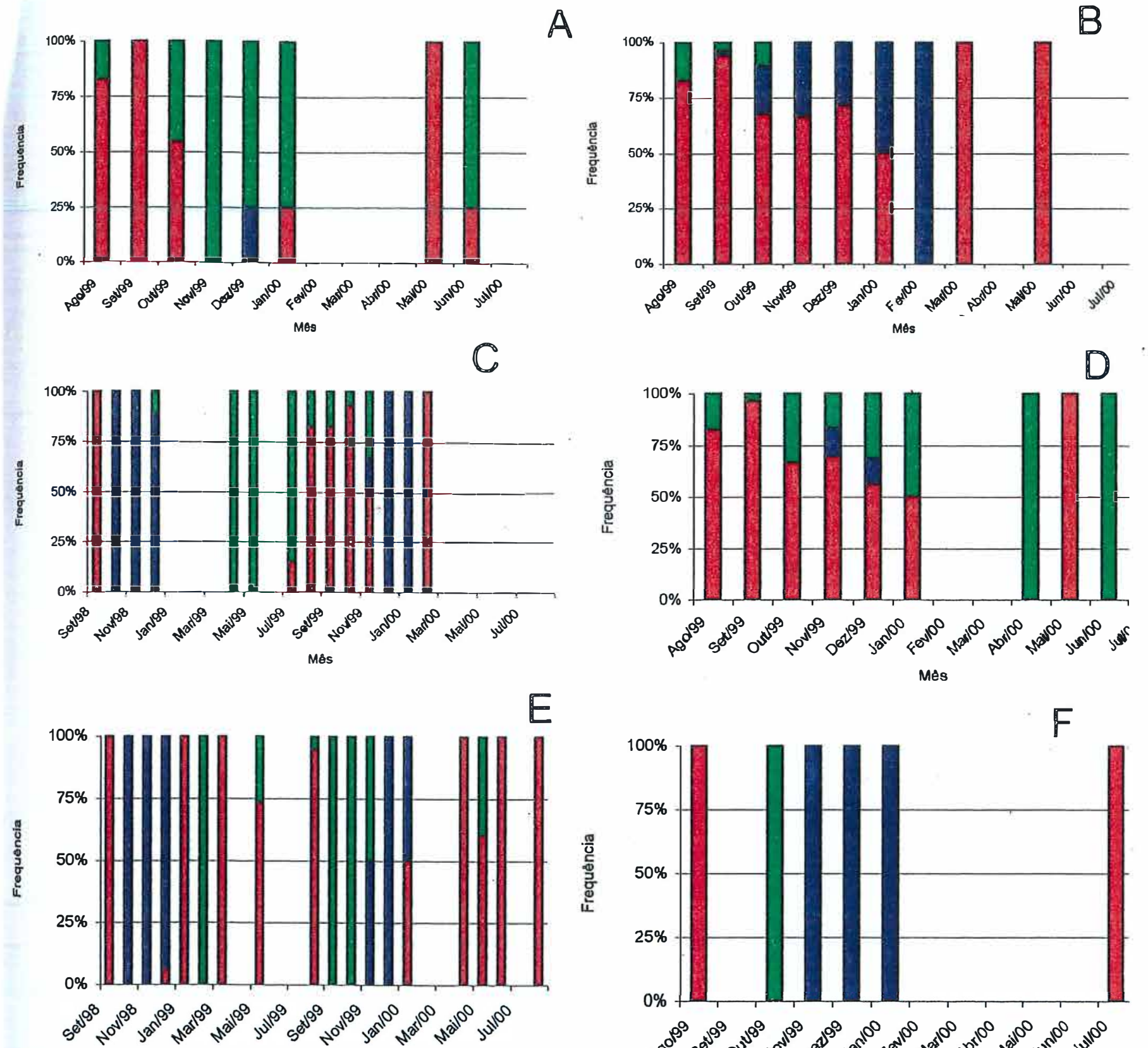

DEuseius concordis

Neoseiulus anonymus

\section{Dutros}

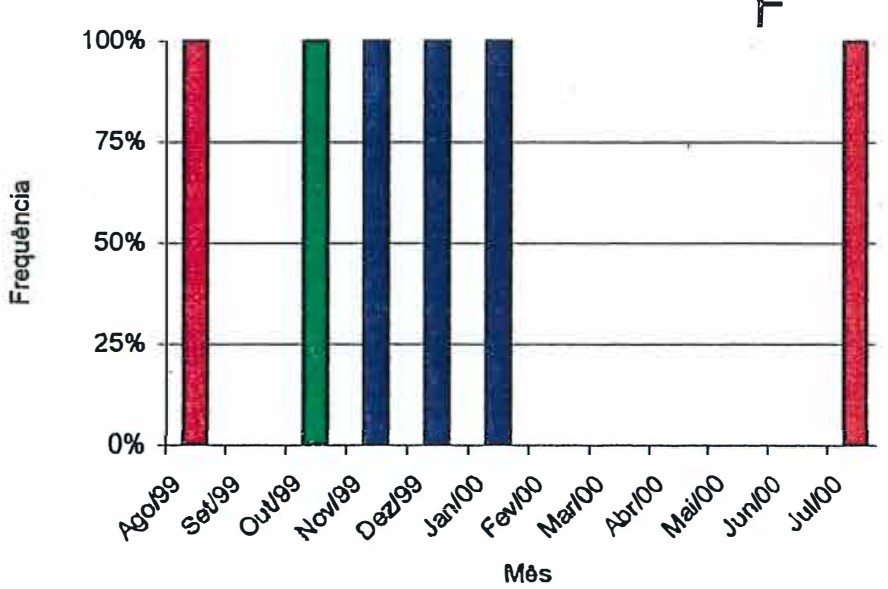

Figura 14 - Frequência da ocorrência das principais espécies de fitoseideos presentes nos clones de seringueira avaliados nos municipios de Pontes e Lacerda(A = clone FX 3864; $B=$ clone RRIM 600; $C=I A N$ 873; $D=$ clone IAN 713) e Itiquira ( $E$ = clone PB 260; $F=$ clone PR 255), no Estado do Mato Grosso. "Outros"= 13 outras espécies de fitoseídeos encontradas neste estudo 


\subsubsection{Dano causado e sintomas de ataque}

Em Itiquira, o nível máximo de dano observado foi de 4,5 entre os meses de maio e junho no clone PB 260, e nível 4, para o clone PR 255 (Figura 15), sendo observada queda prematura de folhas a partir do mês de abril. Em Pontes e Lacerda, o nível máximo observado foi 2 , nos meses de maio e junho, não se observando queda prematura de folhas nos clones avaliados.

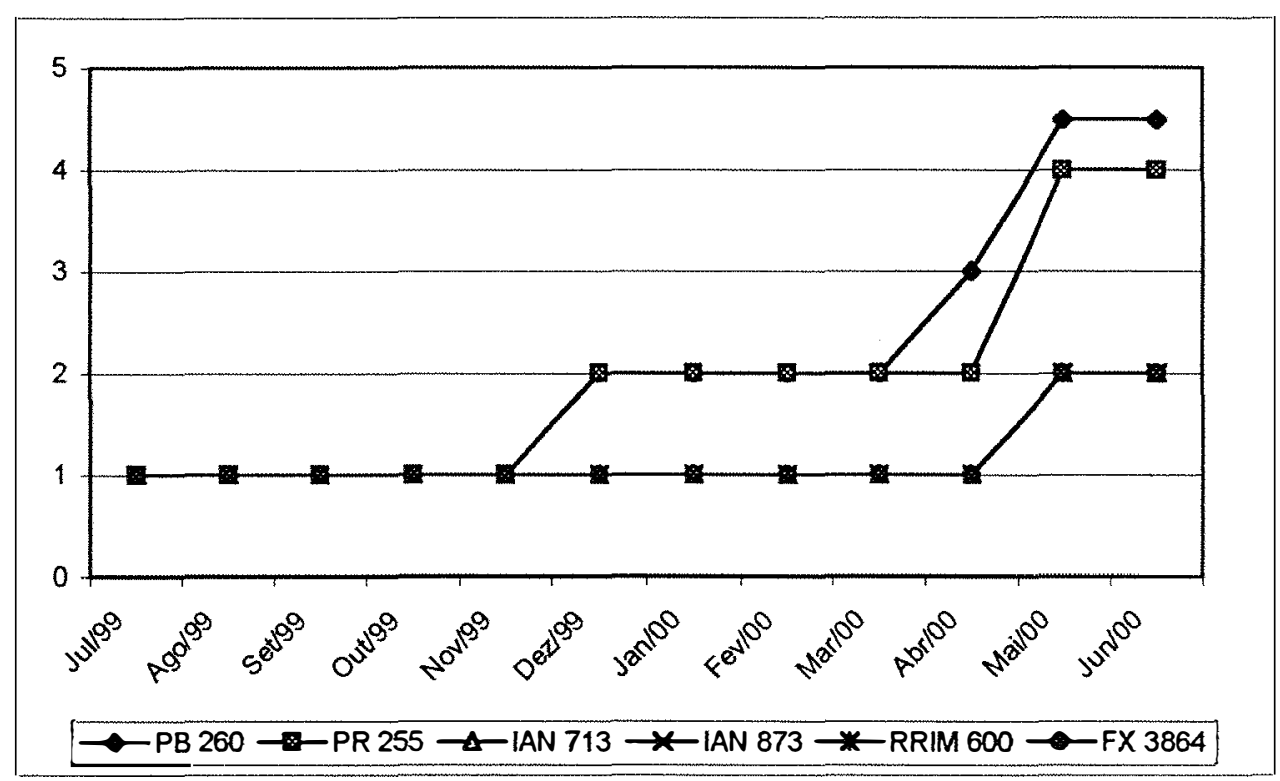

Figura 15 - Danos provocados por ácaros em folhas de seringueira entre agosto de 1999 a julho de 2000, nos clones PB 260 e PR 255 em Itiquira, e nos clones IAN 713, IAN 873, RRIM 600 e FX 3864 em Pontes e Lacerda, no Estado do Mato Grosso.

\subsection{DISCUSSÃO}

As possiveis razões pelas quais os eriofideos foram mais abundantes na face adaxial em Itiquira e na face abaxial em Pontes e Lacerda foram as condições ambientais diferentes entre os dois locais amostrados. Em Itiquira, onde $C$. heveae foi a espécie mais abundante, a umidade relativa e a precipitação foram pouco maiores que no 
município de Pontes e Lacerda, onde $P$. seringueirae foi mais abundante. Entretanto, a umidade relativa e a precipitação não podem por si só explicar os picos populacionais das espécies, pois nos diferentes clones os picos populacionais ocorreram em momentos distintos, principalmente com relação a P. seringueirae em Pontes e Lacerda. Quanto a C. heveae, também não é possível correlacionar seus picos populacionais com as condições ambientais, pois em Itiquira foram observados dois momentos de alta precipitação e somente num dos picos de precipitação foram observadas altas populações desta espécie. Além disso, devido aos diferentes clones avaliados nos dois locais, é possível que a resistência diferenciada apresentada pelos clones possa ter influenciado os picos populacionais destas espécies.

Ácaros predadores da famílias Cunaxidae, Phytoseiidae e Stigmaeidae estiveram presentes quando da diminuição dos níveis populacionais de $C$. heveae em alguns clones observados. Como a presença das populações destes ácaros predadores não foi observada em todos os clones, não é possível formular hipótese consistente para explicar o motivo da diminuição das populações de C. heveae.

O fungo patogênico Hirsutella thompsonii Fisher foi encontrado muito comumente infectando $C$. heveae, quando este ácaro alcançou altos níveis populacionais no campo. Várias tentativas foram feitas, sem sucesso, no período novembro de 1998 a fevereiro de 1999 para se estabelecer uma colônia de manutenção de $C$. heveae no laboratório; em função de estarem praticamente os ácaros coletados em Itiquira e levados ao laboratório, infectados por $H$. thompsonii. Tanzini et al. (2000) relataram e descreveram a ação deste patógeno sobre $C$. heveae em plantações de seringueira no Estado do Mato Grosso, relatando a ocorrência de um grande número de ninfas e adultos de $C$. heveae mortos pela ação deste fungo. É possível que no trabalho de campo realizado neste estudo este patógeno tenha sido pelo menos um dos responsáveis pelas quedas abruptas das populações de $C$. heveae observadas em várias ocasiões em Pontes e Lacerda. Entretanto, aparentemente o efeito sobre $C$. heveae não foi suficientemente significativo em Itiquira em 2000, de vez que a queda da população de $C$. heveae naquela estação, nos 2 clones avaliados, se deveu aparentemente às condições inadequadas das folhas para um aumento ainda maior da população do ácaro. 
Por apresentar maior freqüência quando os tetraniquídeos estiveram presentes, $N$. anonymus possivelmente tenha suas populações relacionadas com as populações de tetraniquídeos. Esta hipótese é suportada pelos resultados apresentados no Capítulo 8, no qual se observou uma maior oviposição de $N$. anonymus quando este foi alimentado com tetraniquídeos do que com outros grupos de ácaros. Segundo classificação proposta por McMurtry \& Croft (1997), esta espécie pertence ao grupo de predadores seletivos, que se alimentam preponderantemente de ácaros da família Tetranychidae.

E. concordis esteve presente durante todo o ano, não tendo sido possível correlacionar sua ocorrência com a ocorrência de nenhuma presa específica. Entretanto, conforme dados apresentados no Capítulo 8 , esta espécie apresentou maior oviposição quando alimentada com pólen de taboa (Typha angustifolia L.) do que com diferentes espécies de ácaros que ocorrem na seringueira. Segundo a classificação estabelecida por McMurtry \& Croft (1997), os fitoseídeos do gênero Euseius pertencem a um grupo que de maneira geral apresenta preferência por diferentes tipos de pólen como alimento. De acordo com aqueles autores, fitoseídeos deste grupo são responsáveis pela manutenção de populações de tetraniquídeos em baixos níveis, principalmente em plantas perenes, sendo importantes em estratégias de conservação. Sua ação se dá usualmente de maneira a evitar o aumento de uma população de ácaros fitófagos em estágio inicial de crescimento.

Nas variedades PB 260 e PR 255, juntamente com o aumento populacional de $C$. heveae e $T$. heveae, houve um aumento populacional de $A$. floridanus. Segundo estudos relatados no Capítulo 8, A. floridanus apresenta oviposição relativamente alta quando alimentado $\operatorname{com} C$. heveae e $T$. heveae. A introdução inoculativa ou a utilização de práticas que preservem esta espécie no campo seriam estratégias recomendáveis para manter este predador no campo.

Segundo os resultados observados neste estudo, não é possível concluir quanto ao tipo de presa preferida por Pseudobonzia sp. Entretanto, observações preliminares de laboratório mostraram que esta espécie se alimenta de $T$. heveae.

A queda das folhas das plantas de seringueira acontece naturalmente no início do inverno nos clones observados, no Estado do Mato Grosso. Neste estudo, a ausência 
de um clone que servisse de controle para comparar com os demais clones estudados, fez com o que o dano observado em Itiquira fosse dificil de diferenciar da queda natural das folhas. De qualquer forma, independentemente da queda prematura, os danos observados nos clones PB 260 e PR 255 são bastante significativos, o que indica a importância de $C$. heveae e $T$. heveae, pois as populações destas espécies foram maiores em Itiquira. Entretanto, como em Pontes e Lacerda foram observadas apenas altas populações de $P$. seringueirae, e os danos às folhas tenham sido relativamente pequenos naquela região, é possível que esta espécie não provoque maiores danos nos clones estudados. As populações de eriofideos encontrados neste estudo foram menores do que as encontradas por Vieira \& Gomes (1999), que estudaram os sintomas e os danos provocados por $C$. heveae neste clone no município de Reginópolis, Estado de São Paulo. A desfolha provocada por $C$. heveae no Estado de São Paulo no clone RRIM 600 foi acima de 75\%, enquanto que em Pontes e Lacerda a queda não foi significativa.

\subsection{CONCLUSÕES}

1) C. heveae e $P$. seringueirae são os ácaros fitófagos mais comuns na cultura da seringueira no Estado do Mato Grosso.

2) E. concordis e N. anonymus são as espécies de ácaros predadores mais comuns em seringueira no Estado do Mato Grosso. 


\section{CICLO BIOLÓGICO DE Calacarus heveae FERES (ACARI: ERIOPHYIDAE)}

\section{RESUMO}

Calacarus heveae Feres é um eriofideo descrito com base em espécimes coletados em plantas de seringueira (Hevea brasiliensis Muell. Arg.) na região noroeste do Estado de São Paulo. Este ácaro prefere a face adaxial dos folíolos e pode causar a perda do brilho, amarelecimento e bronzeamento destes, assim como sua conseqüente queda prematura. Este trabalho teve como objetivo estudar a biologia de $C$. heveae em condições de laboratório, sobre folíolos destacados de seringueira. $\mathrm{O}$ estudo foi iniciado com um total de 59 ovos. $\mathrm{O}$ estudo foi realizado a $28^{\circ} \mathrm{C}$ na fotofase $(12 \mathrm{~h})$ e $25^{\circ} \mathrm{C}$ na escotofase (12h), a $90 \pm 5 \%$ de umidade relativa. A duração média dos estádios de ovo, ninfa II I e ninfa II II foi de 5,8, 2,0 e 1,4 dias, respectivamente. O período de ovo a adulto durou, em média, 9,3 dias. Os períodos de pré-oviposição, oviposição e pósoviposição duraram, em média, 1,8, 6,1 e 1,2 dias, respectivamente. A longevidade média do macho adulto foi cerca de 4,0 dias, enquanto a da fềmea adulta foi cerca de 8,4 dias. A oviposição média diária foi de 2,3 ovos por fêmea e a fecundidade média foi de 16,2 ovos/fêmea. 


\section{BIOLOGICAL CYCLE OF Calacarus heveae FERES (ACARI: ERIOPHYIDAE)}

SUMMARY

Calacarus heveae Feres is an Eriophyidae mite described from specimens collected on rubber tree (Hevea brasiliensis Muell. Arg.) in the northwest region of the State of São Paulo. This mite prefers the adaxial face of the folioles and it can reduce the brightness of the leaves, turning then progressively yellow and brownish, causing consequent premature fall. The aim of this work was to study the biology of $C$. heveae in laboratory, on detached rubber tree folioles. The study was conducted at $28 \pm 1^{\circ} \mathrm{C}$ in the phtotophase (12h), $25 \pm 1^{\circ} \mathrm{C}$ in the dark phase (12h), and $90 \pm 5 \%$ relative humidity. The study was initiated with a total of 59 eggs. The average duration of egg, ninfa $\mathrm{Il}$ and nymphal stages was 5,8,2,0 and 1,4 days, respectively. The period from egg to adult lasted 9,3 days. The average periods of pre-oviposition, oviposition and post-oviposition lasted, $1,8,6,1$ and 1,2 days, respectively. The average longevity of the adult male was ca. 4,0 days, while the longevity adult female was ca. 8,4 days. The average daily oviposition rate was 2,3 egg per female while the average fecundity was 16,2 eggs per female. 


\subsection{INTRODUÇÃO}

Calacarus heveae Feres é um eriofideo descrito de espécimes coletados em plantas de seringueira (Hevea brasiliensis Muell. Arg.) na região noroeste do Estado de São Paulo (Feres, 1992). Esta espécie prefere a face adaxial dos folíolos, mas ocorre também na face abaxial, quando em altas populações (Capítulo 5). C. heveae pode causar perda do brilho, amarelecimento e bronzeamento dos folíolos e sua conseqüente queda prematura (Feres, 2000; Capítulo 5). De acordo com Vieira \& Gomes (1999), que acompanharam a dinâmica populacional de $C$. heveae em Reginópolis, Estado de São Paulo, as maiores populações foram observadas no primeiro semestre do ano, coincidindo com o período de maior produção de látex. Os mesmos autores relataram que o ataque desta espécie pode provocar níveis de desfolha acima de $75 \%$. Segundo Feres (2000), alguns produtores de seringueira estimam que $C$. heveae ocasione perdas de até $30 \%$ na produção de látex de alguns clones de $H$. brasiliensis.

Este trabalho teve como objetivo conhecer a biologia de $C$. heveae em condições de laboratório.

\subsection{MATERIAL E MÉTODOS}

Inicialmente estabeleceu-se uma criação de manutenção de $C \cdot$ heveae com espécimes coletados em folhas de seringueira da Estação Experimental de Pindorama, do Instituto Agronômico de Campinas - IAC, no Estado de São Paulo. Para tanto, foram preparadas unidades de criação com folíolos do clone PB 260 coletados das plantações da Escola Superior de Agricultura "Luiz de Queiroz"/Universidade de São Paulo, Piracicaba - São Paulo. Os folíolos foram lavados em água destilada e postos com a face abaxial sobre um pedaço de esponja de náilon umedecida em bandejas de alumínio de 5 x $7 \times 25 \mathrm{~cm}$, recobrindo as bordas dos folíolos com tiras de algodão hidrófilo. Para manter alta a umidade relativa, cada bandeja foi coberta com uma placa de vidro, deixando-se aberta uma fresta lateral de cerca de $1 \mathrm{~cm}$ para evitar a condensação de água sobre os folíolos. Diariamente, adicionava-se água destilada à bandeja, para manter a 
esponja sempre úmida. Os ácaros foram transferidos com um pincel para novas unidades de criação quando os folíolos em que se encontravam começavam a amarelar. As bandejas foram mantidas em uma câmara climatizada a $25,5 \pm 1{ }^{\circ} \mathrm{C}$, fotofase de 12 horas e umidade relativa de $90 \pm 5 \%$.

$\mathrm{O}$ estudo da biologia foi realizado com unidades de criação preparadas como descrito no parágrafo anterior, utilizando-se o mesmo clone de seringueira. Cada unidade foi então dividida em quadrados de aproximadamente $2 \mathrm{~cm}^{2}$ com o uso de tiras de lenço de papel, estabelecendo-se assim as unidades de criação para o estudo da biologia.

O estudo foi iniciado com ovos obtidos da seguinte forma. Inicialmente, 10 fêmeas foram transferidas da criação de manutenção para cada unidade de criação para o estudo da biologia. Após um período de 12 horas, as unidades foram examinadas retirando-se as fêmeas daquelas unidades onde havia ocorrido a oviposição, assim como os ovos excedentes, deixando apenas 1 ovo por unidade. O restante das arenas foi examinado novamente após outro período de 12 horas, repetindo-se o processo até que se obtivesse um total de 59 ovos. Cada unidade de criação foi examinada diariamente às 7, 12 e 17 horas, até que os ácaros atingissem o estádio adulto, quando foram então transferidos para novas unidades. Em cada exame, verificou-se o estádio de desenvolvimento em que o ácaro se encontrava. Na fase adulta, observações foram realizadas diariamente às 14 horas, para se verificar o número de ovos postos e a sobrevivência dos ácaros. $\mathrm{O}$ estudo foi feito apenas com fêmeas não fecundadas.

As unidades de criação foram mantidas em câmara climatizada com fotoperíodo de 12 horas e umidade relativa de $90 \pm 5 \%$. Na tentativa de imitar as condições ambientais do campo, a temperatura foi mantida a $28 \pm 1{ }^{\circ} \mathrm{C}$ na fotofase e $23 \pm 1^{\circ} \mathrm{C}$ na escotofase.

Após a morte, todos os adultos foram montados em meio modificado de Berlese (Amrine \& Manson, 1996) para sexagem ao microscópio.

Os espermatóforos utilizados para observação foram conseguidos nas colônias de manutenção de $C$. heveae. Para tanto, os folíolos com ácaros foram fixados por uma semana no fixador Karnovsky modificado (Glutaraldeído 2,5\%, formaldeído 2,5\% em 
tampão, cacodilato de sódio $0,05 \mathrm{M}, \mathrm{Ph} 7,2$ ). Em seguida, foi feita a pós-fixação em tetróxido de ósmio ( $1 \%$ em tampão cacodilato de sódio $0,05 \mathrm{M}, \mathrm{Ph} 7,2)$ por 2 horas, seguida da secagem ao ponto crítico para posterior metalização com ouro (210 segundos). Para determinar a forma dos espermatóforos de $C$. heveae, foram feitas observações ao microscópio eletrônico de varredura (Zeiss DSM 940).

\subsection{RESULTADOS}

\subsubsection{Características biológicas dos estádios imaturos.}

A duração das diferentes fases e a viabilidade de $C$. heveae são apresentadas à Tabela 3.

O período médio de incubação do ovo foi de 5,8 dias e a viabilidade deste estádio foi de $95 \%$. Os ovos são esbranquiçados quando recém postos, passando a translúcidos após algumas horas. Arredondados (ca. $75 \mu \mathrm{m}$ de diâmetro) e achatados, ficam aderidos ao substrato, sendo muito difícil manuseá-los.

Horas antes da eclosão, é possível visualizar movimentos da ninfa I através do córion translúcido. A eclosão ocorreu, na maioria das vezes, na parte da manhã, logo após haver a passagem da temperatura de $23^{\circ} \mathrm{C}$ para $28^{\circ} \mathrm{C}$. A emergência durou cerca de 20 minutos.

A duração do estádio de ninfa I foi de 2,0 dias, enquanto que o estádio de ninfa II durou 1,4 dias. A viabilidade conseguida nos estádios de ninfa I e ninfa II foi $96 \%$ e $98 \%$, respectivamente.

As ninfas I, que apresentam comprimento de 90-110 $\mu \mathrm{m}$, iniciam a alimentação na região próxima ao córion do ovo do qual emergiu. Após algumas horas, começa a se formar um friso de cera longitudinal na parte mediana do dorso do opistossoma. A mobilidade é normal até pouco antes da próxima ecdise. Para a ecdise, o ácaro fixa o telossoma no substrato, rompendo o exoesqueleto na região mediana do escudo prodorsal (Figura 16). A ecdise dura cerca de 15 minutos. 
Tabela 3. Duração e viabilidade (machos e fềmeas) das diferentes fases imaturas de Calacarus heveae, em dias, criados em folíolos de seringueira da variedade PB 260 a $28 \pm 1^{\circ} \mathrm{C}$ na fotofase e $25 \pm 1^{\circ} \mathrm{C}$ na escotofase, fotofase de 12 horas e umidade relativa de $90 \pm 5 \%$.

\begin{tabular}{lccc}
\hline Estádio de desenvolvimento & Média \pm EPM & Viabilidade (\%) & N \\
\hline Ovo & $5,8 \pm 0,1$ & 95 & 57 \\
Ninfa I & $2,0 \pm 0,001$ & 96 & 55 \\
Ninfa II & $1,4 \pm 0,05$ & 98 & 54 \\
Ovo-adulto (Fêmeas e Machos) & $9,3 \pm 0,09$ & 91,5 & 54 \\
Ovo-adulto (Fêmeas) & $9,7 \pm 0,02$ & - & 26 \\
Ovo-adulto (Machos) & $9,0 \pm 0,02$ & - & 14 \\
\hline
\end{tabular}

EPM: Erro padrão da média.

$\mathrm{N}$ : Número de indivíduos observados.

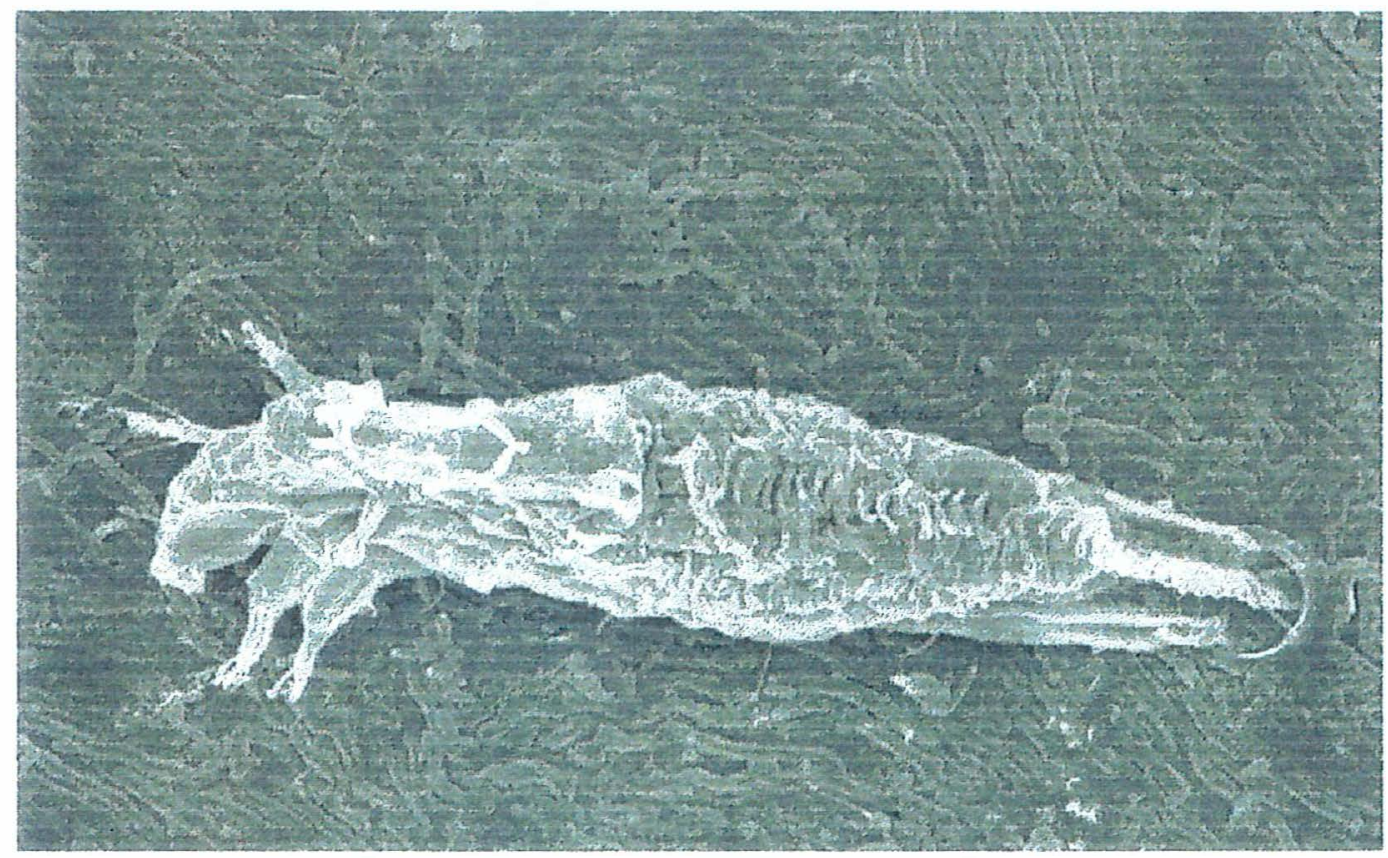

Figura 16 - Espécime de Calacarus heveae fazendo a ecdise. 
As ninfas II medem 140-160 $\mu \mathrm{m}$. Neste estádio, três frisos de cera percorrem longitudinalmente o dorso do opistossoma (Figura 17). Em relação à ecdise, a ninfa II se comporta de forma semelhante à ninfa I. O processo de ecdise demora cerca de 25 minutos.

O período de ovo a adulto durou cerca de 9,7 dias para as fêmeas e 9,0 dias para os machos

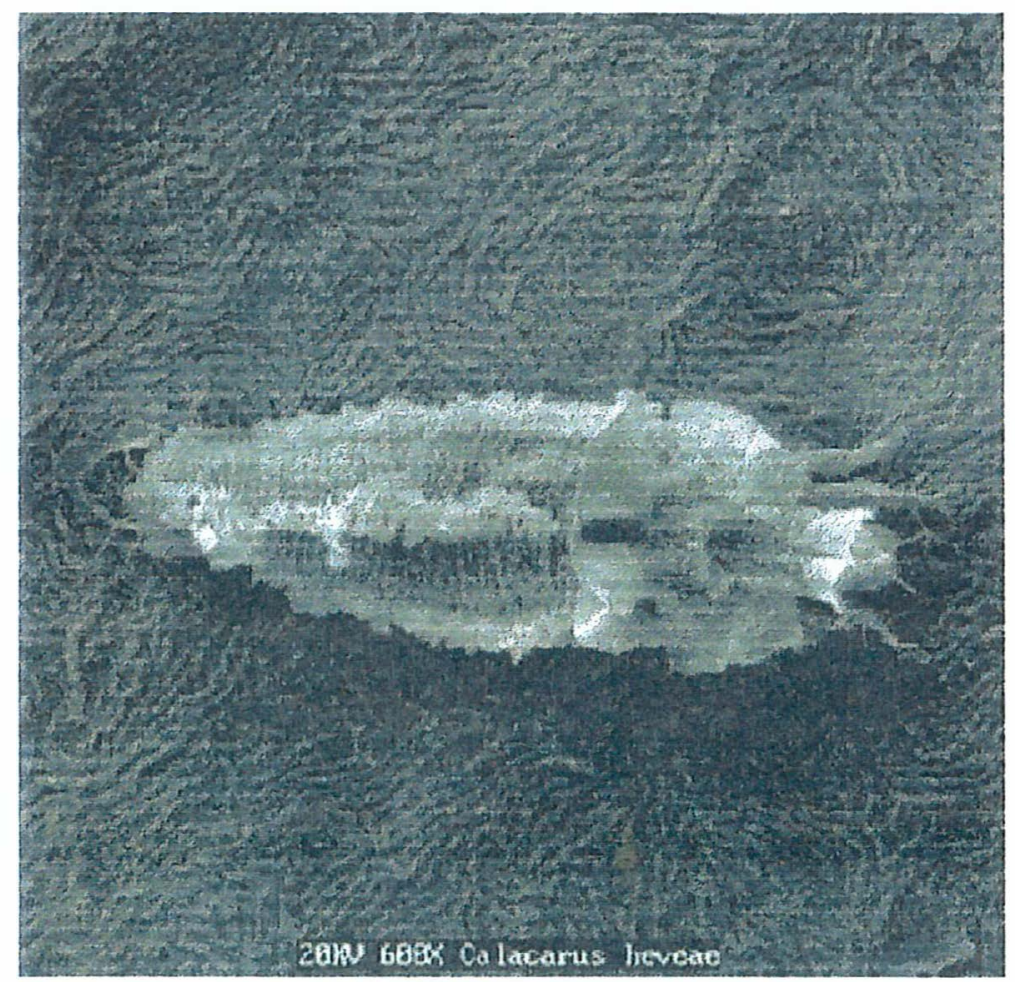

Figura 17 - Ninfa II de Calacarus heveae.

\subsubsection{Características biológicas do estádio adulto.}

Dos ovos postos pela geração estudada, foram obtidos 274 adultos, todos machos. Isso indica a ocorrência de partenogênese arrenótoca, de vez que as fềmeas da geração estudada foram mantidas em arenas sem presença de machos.

$\mathrm{O}$ adulto recém emergido é cinza brilhante, passando a cinza opaco com o passar do tempo. Inicialmente movimenta-se intensamente, mas ao iniciar a alimentação 
diminui o deslocamento, permanecendo por longo tempo numa determinada área. Os adultos medem entre 190-230 $\mu \mathrm{m}$.

Os adultos apresentam deposição de cera sobre o escudo prodorsal e em 3 linhas dorso-longitudinais do opistossoma (Figura 18).

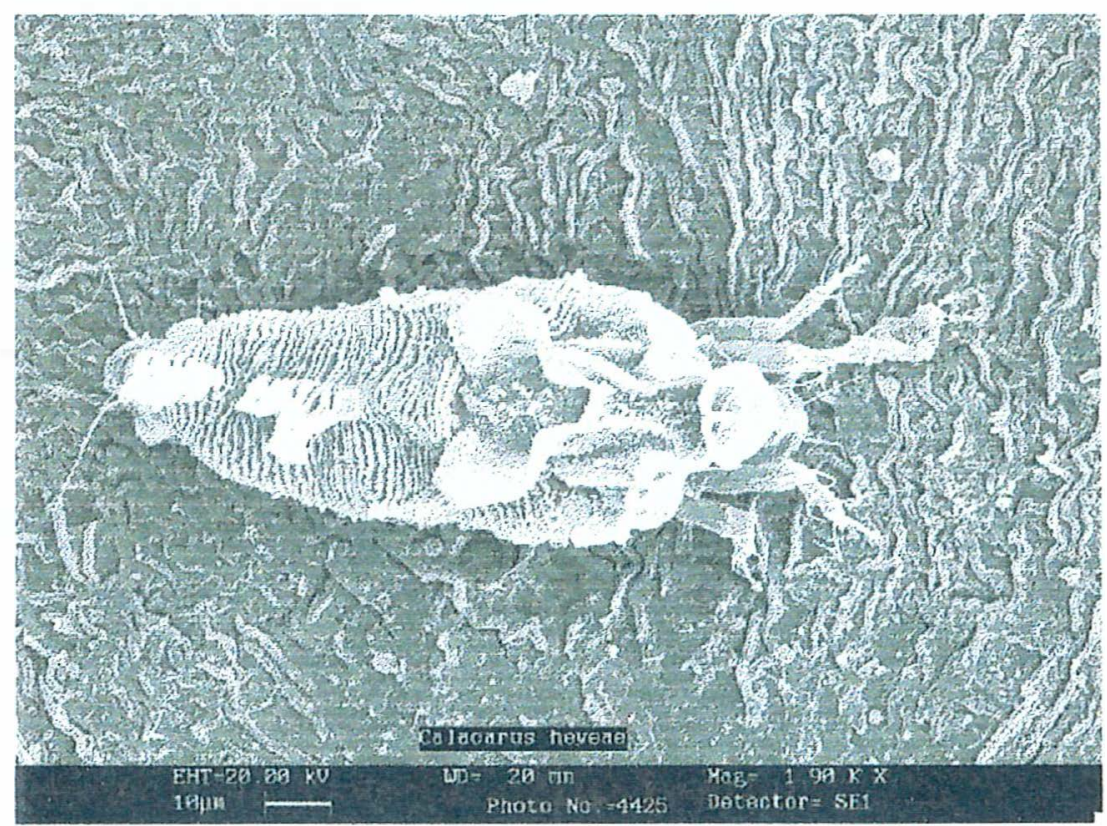

Figura 18 - Adulto de Calacarts heveae

O período de pré-oviposição de $C$. heveae durou cerca de 1,8 dias; a oviposição, 6,1 e a pós-oviposição, 1,2 dias (Tabela 4).

A longevidade média do macho adulto foi de aproximadamente 4,0 dias, enquanto a da fêmea adulta foi de cerca de 8,4 dias.

A oviposição média diária foi de 2,3 ovos por fêmea. A fecundidade média foi de 16,2 ovos por fêmea. Não se constatou nenhuma preferência por sítios determinados de oviposição sobre a superficie da folha.

A duração total de ovo até a morte dos indivíduos foi de aproximadamente 16 dias, sendo que os machos duraram, em média, cerca de 13,0 dias e as fềmeas, 17,8 dias. A razão sexual obtida foi de $65 \%$ de fềmeas. 
Tabela 4. Longevidade e reprodução de Calacarus heveae, a $28 \pm 1^{\circ} \mathrm{C}$ (12h) na fotofase e $25 \pm 1^{\circ} \mathrm{C}(12 \mathrm{~h})$ na escotofase e umidade relativa de $90 \pm 5 \%$ em folíolos de seringueira da variedade PB 260.

\begin{tabular}{lcl}
\hline \multicolumn{1}{c}{ Estádio de desenvolvimento } & Média \pm EPM & N \\
\hline Pré-oviposição & $1,8 \pm 0,16$ & 26 \\
Oviposição & $6,1 \pm 0,9$ & 26 \\
Pós-oviposição & $1,2 \pm 0,2$ & 26 \\
Longevidade da fềmea adulta & $8,4 \pm 0,9$ & 26 \\
Longevidade do macho adulto & $4,0 \pm 0,3$ & 14 \\
Longevidade total da fềmea & $17,8 \pm 1,0$ & 26 \\
Longevidade total do macho & $13,0 \pm 0,32$ & 14 \\
Ovos/fêmea/dia & $2,3 \pm 0,18$ & 26 \\
Ovos/fêmea & $16,2 \pm 3,2$ & 26 \\
\hline
\end{tabular}

EPM: Erro padrão da média.

$\mathrm{N}$ : Número de indivíduos observados.

A Figura 19 mostra a variação de oviposição média diária de $C$. heveae. Observou-se que esta variou ao longo de um patamar nos primeiros 12 dias de oviposição, decrescendo a partir de então.

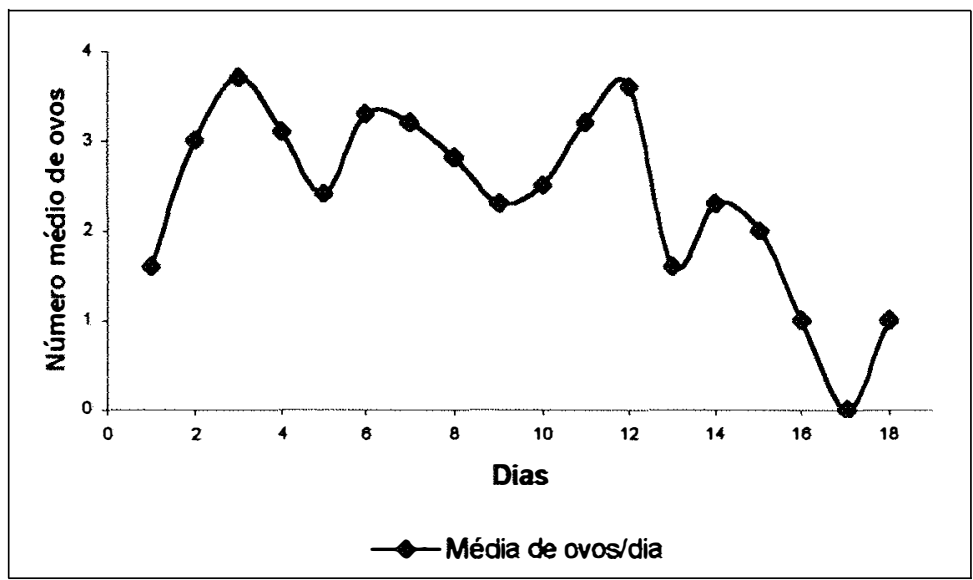

Figura 19 - Oviposição média diária de fềmeas não fecundadas de Calacarus heveae, a $28 \pm 1^{\circ} \mathrm{C}(12 \mathrm{~h})$ na fotofase e $25 \pm 1^{\circ} \mathrm{C}(12 \mathrm{~h})$ na escotofase e umidade relativa de $90 \pm 5^{\circ} \mathrm{C}$ em folíolos de seringueira da variedade PB $260(\mathrm{~N}=16)$. 
O espermatóforo de $C$. heveae foi visualizado através de microscopia eletrônica, apresentando a cabeça em forma de taça, medindo aproximadamente $12 \mu \mathrm{m}$ de lado na extremidade mais dilatada. Esta é presa a um pedúnculo, medindo aproximadamente $8 \mu \mathrm{m}$ de comprimento, cuja base é fixada no folíolo (Figura 20). Não foi possível visualizar o endoespermatóforo.

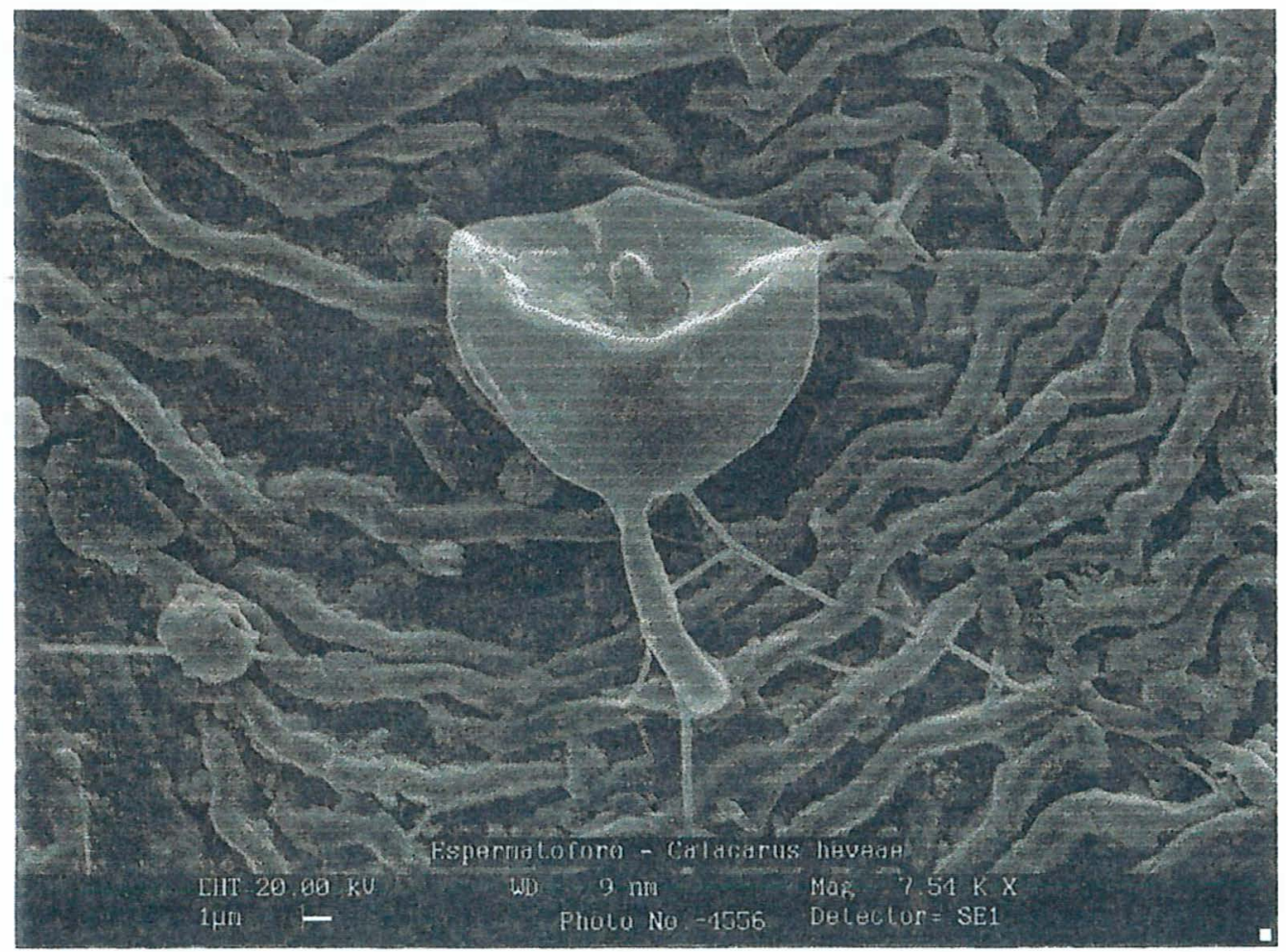

Figura 20 - Espermatóforo de Calacarıs heveae obtidos em colônias de laboratório.

\subsection{DISCUSSÃO}

As únicas informações sobre a morfologia de $C$. heveae até hoje disponíveis foram apresentadas na descrição original da espécie (Feres, 1992), que trata apenas da fase adulta. Os dados aqui apresentados sobre a morfologia deste ácaro complementam aquelas informações, especialmente no que se refere aos estádios imaturos e à forma do espermatóforo. $\mathrm{O}$ espermatóforo de $C$. heveae apresenta tamanho e forma muito semelhantes ao que se conhece até agora para outros eriofideos (Oldfield et al., 1970; 
Oldfield \& Michalska, 1996).

Informações sobre o ciclo biológico de espécies de Calacarus são escassas na literatura. O único estudo até hoje realizado refere-se a Calacarus citrifolii (Ewing), espécie conhecida de citros na África do Sul (Van Der Merwe \& Coates, 1965).

Diversas foram as tentativas iniciais até se conseguir estabelecer uma colônia de manutenção de $C$. heveae no laboratório. Inicialmente, as maiores dificuldades se relacionaram ao fato de estarem, praticamente todos os ácaros coletados em Itiquira e levados ao laboratório, infectados pelo fungo Hirsutella thompsonii Fisher. Tanzini et al. (2000) haviam relatado a ação deste patógeno sobre $C$. heveae. Desta forma, foi necessário buscar populações de outras localidades (Pindorama, Estado de São Paulo), na época não infectadas, para poder manter uma colônia de manutenção deste ácaro. Posteriormente, verificou-se que a colônia só podia ser mantida adequadamente após se promover o aumento da umidade relativa, cobrindo-se quase que totalmente a bandeja que continha as unidades de criação com uma placa de vidro. Outro desafio foi o reconhecimento do ovo de $C$. heveae que, por ser bastante achatado e relativamente grande em relação ao tamanho da fềmea, passou despercebido nas observações iniciais.

As informações das fases imaturas conseguidas com $C$. heveae são semelhantes àquelas encontradas por Van Der Merwe \& Coates, (1965) que estudaram a biologia $C$. citrifolii, exceto para o estádio de ninfa II que foi 2 a 3 vezes mais longo para $C$. citrifolii. Os mesmos autores relataram oviposição média diária de 1,1 ovos por fềmea e longevidade média de 10 dias para fêmeas adultas.

\subsection{CONCLUSÕES}

1) C. heveae apresentou ciclo biológico e fecundidade comparável à outras espécies de Eriophyidae. 


\section{EFEITO DE DIFERENTES CONCENTRAÇÕES DE AGROQUÍMICOS EM Calacarus heveae FERES E Tenuipalpus heveae BAKER (ACARI: ERIOPHYIDAE E TENUIPALPIDAE)}

\section{RESUMO}

Calacarus heveae Feres e Tenuipalpus heveae Baker tem sido considerados os ácaros fitófagos mais importantes da seringueira (Hevea brasiliensis Muell. Arg.) no sudoeste e sudeste do Brasil. C. heveae é um eriofideo que pode causar a perda do brilho, amarelecimento e bronzeamento das folhas de seringueira, e ocasionalmente a conseqüente queda prematura destas. $T$. heveae é um tenuipalpídeo que também pode causar amarelecimento e causar a queda prematura das folhas atacadas. Este trabalho teve como objetivo estudar os efeitos de duas concentrações dos agroquímicos acefato, dicofol, endosulfan, formetanate, metomil, monocrotofós, óxido de fenbutatina e propargite sobre $C$. heveae e $T$. heveae, em laboratório. Com exceção de acefato, nas duas concentrações estudadas, todos os produtos causaram alta mortalidade de $C$. heveae. Apenas dicofol, nas duas concentrações estudadas, causou alta mortalidade de $T$. heveae. As maiores doses de endosulfan e monocrotofós causaram níveis médios de mortalidade de $T$. heveae, enquanto as menores doses destes produtos e todos os demais produtos, nas duas doses, causaram baixa mortalidade de $T$. heveae. 


\section{EFFECT OF DIFFERENT CONCENTRATIONS OF AGROCHEMICALS ON Calacarus heveae FERES AND Tenuipalpus heveae BAKER (ACARI: ERIOPHYDAE AND TENUIPALPIDAE)}

\section{SUMMARY}

Calacarus heveae Feres and Tenuipalpus heveae Baker have been considered the most important phytophagous mites on rubber tree (Hevea brasiliensis Muell. Arg.) in southwest and southeast Brazil. $C$. heveae is an Eriophyidae that may cause the leaves to loose their brightness, turn them progressively yellow and brownish, resulting frequently in premature leaf fall. $T$. heveae is a Tenuipalpidae that can also turn the leaves yellow and cause premature leaf fall. The objective of this work was to study the effect of two concentrations of the agrochemicals acephato, dicophol, endosulfan, formetanate, methomil, monocrotophos, oxid of fenbutanine and propargite on $C$. heveae and $T$. heveae in the laboratory. With the exception of the acephato, in both concentrations, all products caused high mortality of $C$. heveae. Only dicophol, in both concentrations, caused high mortality of $T$. heveae. The highest doses of endosulfan and monocrotophos caused median levels of mortality of $T$. heveae, while the lowest doses of these products and all other products, in both doses, caused low mortality of T. heveae. 


\subsection{INTRODUÇÃO}

A seringueira (Hevea brasiliensis Muell. Arg.) é comumente atacada por diversas espécies de insetos e ácaros nas áreas onde é cultivada, sendo algumas destas consideradas pragas de suma importância (Manual Técnico, 1983; Silva, 1972). Os ácaros passaram a ser considerados economicamente importantes a partir da década de 1991, quando foram responsabilizados por danos causados a esta cultura (Feres, 1992).

Devido às altas populações observadas, ao dano causado às folhas e à freqüência com que ocorrem em seringais do Estado do Mato Grosso(Capitulos 4 e 5), Calacarus heveae Feres e Tenuipalpus heveae Baker são considerados os ácaros fitófagos mais importantes nesta cultura naquele estado.

C. heveae foi descrito por Feres (1992) com base em espécimes coletados em plantas de seringueira na região noroeste do Estado de São Paulo. Este ácaro ocorre preponderantemente na face adaxial dos folíolos, sendo encontrado na face abaxial quando em altas populações (Capítulo 5). Causa perda do brilho, amarelecimento e bronzeamento das folhas de seringueira e sua conseqüente queda prematura (Feres, 2000; Capitulo 5). Segundo Feres (2000), alguns produtores de seringueira estimam que $C$. heveae ocasione perdas de até $30 \%$ na produção de látex em clones de $\mathrm{H}$. brasiliensis.

T. heveae foi descrito por Baker (1945) de fêmeas coletadas no Estado do Pará. Este ácaro é conhecido como o ácaro vermelho da seringueira, ocorrendo predominantemente na face abaxial dos folíolos, embora, quando em altas infestações, seja também encontrado na face adaxial (Capítulo 5). Causa amarelecimento e contribui para a queda prematura das folhas atacadas.

Altas populações de $C$. heveae e $T$. heveae são observadas em plantações de seringueira nos estados das regiões centro-oeste e sudeste do Brasil, onde esta cultura foi introduzida. Devido aos danos provocados, os agricultores se vêem obrigados a controlar as populações destes ácaros com o uso de produtos químicos. Este trabalho teve como objetivo estudar o efeito, em laboratório, de alguns agroquímicos utilizados ocasionalmente no controle de $C$. heveae e de $T$. heveae na cultura da seringueira e 
outros produtos com potencial de serem utilizados.

\subsection{MATERIAL E MÉTODOS}

Este trabalho foi realizado nos laboratórios do Departamento de Entomologia, Fitopatologia e Zoologia Agrícola da Escola Superior de Agricultura Luiz de Queiroz (ESALQ/USP), em Piracicaba, São Paulo, de março a julho de 1999. Foram utilizados ácaros provenientes de colônias de laboratório iniciadas com indivíduos coletados em folhas de seringueira colhidas em Pindorama, Estado de São Paulo, cerca de 3 meses antes do início do trabalho.

As colônias de ambas as espécies foram estabelecidas em folíolos destacados do clone PB 260 mantidos sobre espuma de náilon umedecida no interior de bandejas de alumínio. C. heveae foi mantido sobre a face adaxial e $T$. heveae sobre a face abaxial dos folíolos, cujas bordas foram recobertas com tiras de algodão hidrófilo, também umedecido. Para manter alta a umidade relativa, a bandeja foi coberta com uma placa de vidro, deixando um espaço lateral aberto de cerca de $1 \mathrm{~cm}$ para evitar a condensação de água sobre o folíolo. As bandejas foram mantidas em câmara de germinação a $25,5 \pm 1^{\circ} \mathrm{C}$, fotoperíodo de 12 horas e umidade relativa de $90 \pm 5 \%$.

\subsubsection{Produtos testados}

Foram testados 8 agroquímicos em 2 concentrações, com 4 repetições para cada tratamento, utilizando-se o delineamento experimental inteiramente casualizado (Tabela 5). A concentração maior de cada produto correspondeu à média recomendada pelo fabricante para o controle de ácaros em culturas para as quais o produto é registrado. A menor concentração correspondeu a um valor intermediário das doses recomendadas para o controle de pragas naquelas culturas. O tratamento testemunha constou da aplicação de água destilada. 
Tabela 5. Agroquímicos testados quanto ao efeito em Calacarus heveae e Tenuipalpus heveae. Piracicaba. 1999.

\begin{tabular}{|c|c|c|c|c|c|c|}
\hline Nome técnico & $\begin{array}{l}\text { Formu } \\
\text { Concen }\end{array}$ & $\begin{array}{l}\text { lação } \\
\text { tração } 1\end{array}$ & $\begin{array}{c}\text { Classe } \\
\text { Toxicológica }^{2}\end{array}$ & Grupo Químico & $\begin{array}{l}\text { Dose utilizada } \\
\text { (ppm) }\end{array}$ & $\mathrm{Uso}^{3}$ \\
\hline Acefato & PS & 750 & III & Organofosforado & 180 e 560 & A, I \\
\hline Dicofol & $\mathrm{CE}$ & 480 & II & Organoclorado & 100 e 360 & A \\
\hline Endosulfan & $\mathrm{CE}$ & 350 & I & $\begin{array}{l}\text { Éster do ácido } \\
\text { sulfuroso de diol } \\
\text { cíclico }\end{array}$ & 320 e 1000 & A, I \\
\hline $\begin{array}{l}\text { Formetanate } \\
\text { HCI }\end{array}$ & PS & 500 & I & Carbamato & 32 e 100 & A, I \\
\hline Metomil & $\mathrm{CE}$ & 215 & I & Carbamato & 90 e 280 & I \\
\hline Monocrotofós & $\mathrm{CE}$ & 400 & I & Organofosforado & 560 e 1800 & A, I \\
\hline $\begin{array}{l}\text { Óxido de } \\
\text { fenbutatina }\end{array}$ & $\mathrm{SC}$ & 500 & III & Organoestânico & 100 e 320 & A \\
\hline Propargite & $\mathrm{CE}$ & 720 & II & Fenoxiciclohexil & 320 e 750 & A \\
\hline
\end{tabular}

1. $\mathrm{g} / \mathrm{kg}$ ou $1(\mathrm{CE}=$ concentrado emulsionável; $\mathrm{PS}=$ pó solúvel; $\mathrm{SC}=$ solução concentrada).

2. Classe de toxicidade, conforme Portaria Interministerial MA/MS $n^{\circ} 220$ de 14/03/1979 (I - altamente tóxico; II - medianamente tóxico; III - pouco tóxico).

3. $\mathrm{A}=$ Acaricida; $\mathrm{I}=$ Inseticida.

\subsubsection{Procedimentos experimentais}

Utilizou-se o método de bioensaio de contato residual (Jeppson et al., 1975). Círculos de 2,0 $\mathrm{cm}$ de diâmetro foram recortados de folhas de seringueira para serem usados como substrato onde os ácaros foram mantidos durante os testes. O tipo de unidade experimental utilizada para cada espécie de ácaro foi aquele que em testes preliminares se mostrou mais adequado para esta finalidade, tendo em vista os diferentes comportamentos de $C$. heveae e $T$. heveae. Para $C$. heveae, os círculos foram colocados 
em placas de Petri de $13 \mathrm{~cm}$ de diâmetro, contendo um pedaço de espuma de náilon umedecida. Em cada placa foram colocados quatro círculos com a face adaxial voltada para cima. Para T. heveae, cada círculo foi colocado sobre ágar a $2 \%$ de concentração, no interior de placas de plástico de $3,5 \mathrm{~cm}$ de diâmetro.

Para a pulverização dos produtos foi utilizada uma torre de Potter calibrada para a deposição de $1,5 \mathrm{mg}$ de cada solução/ $\mathrm{cm}^{2}$, à pressão de 10 libras $/ \mathrm{pol}^{2}$. Antes da pulverização de cada produto, a torre foi lavada com água destilada, álcool absoluto e acetona. Os primeiros três jatos de cada produto foram sempre eliminados, reduzindo a possibilidade de contaminação com o produto anteriormente utilizado.

Após a aplicação, os círculos foram postos a secar em condições de laboratório por cerca de uma hora. Vinte adultos de cada espécie, tomados ao acaso das colônias de manutenção, foram então transferidos para cada círculo.

Os círculos foram mantidos em câmara de germinação a $25 \pm 1^{\circ} \mathrm{C}$, fotofase de 12 horas e umidade relativa de $90 \pm 5 \%$.

\subsubsection{Critérios utilizados na avaliação}

A mortalidade foi avaliada 24 horas após a aplicação dos produtos. Foram considerados como mortos os ácaros que não se movimentavam quando tocados com um pincel e aqueles que apresentavam movimento irregular, mostrando sinais claros de intoxicação.

As porcentagens de mortalidade dos tratamentos em relação à testemunha foram corrigidas pela fórmula de Abbott (1925): $\mathrm{Mc}=100(\mathrm{~T}-\mathrm{i} / \mathrm{T})$, onde $\mathrm{Mc}=$ mortalidade corrigida, $\mathrm{T}=$ número de ácaros vivos na testemunha e $\mathrm{i}=$ número de ácaros vivos no tratamento. Foram considerados válidos somente os testes em que a mortalidade no tratamento testemunha foi de no máximo $20 \%$.

Em todos os tratamentos considerados, os erros tiveram variância homogênea. Portanto, não foi necessário fazer a transformação dos dados para a análise estatística. As

médias de mortalidade em cada tratamento foram comparadas pelo teste de Tukey, 
utilizando-se o programa estatístico SANEST, desenvolvido pelo Centro de Informática na Agricultura da Escola Superior de Agricultura "Luiz de Queiroz" da Universidade de São Paulo.

\subsection{RESULTADOS}

Com exceção de acefato, nas duas concentrações estudadas, todos os produtos causaram alta mortalidade de $C$. heveae (Tabela 6).

Apenas dicofol, nas duas concentrações testadas, causou alta mortalidade de $T$. heveae. As maiores doses de endosulfan e monocrotofós causaram níveis médios de mortalidade de $T$ : heveae, enquanto as menores doses destes produtos e todos os outros tratamentos apresentaram baixa mortalidade deste ácaro.

Tabela 6. Mortalidade corrigida de Calacarus heveae e Tenuipalpus heveae (terro padrão da média) em diferentes concentrações de agroquímicos, após 24 horas da aplicação de diferentes produtos.

\begin{tabular}{lcc}
\hline Agroquímico $(\mathrm{ppm})$ & Calacarus heveae & Tenuipalpus heveae \\
\hline Acefato 180 & $15,0 \pm 10,5 \mathrm{c}$ & $5,0 \pm 4,0 \mathrm{~g}$ \\
Acefato 560 & $45,0 \pm 19,2 \mathrm{~b}$ & $13,7 \pm 6,2 \mathrm{fg}$ \\
Dicofol 100 & $90,0 \pm 7,5 \mathrm{a}$ & $100 \pm 0 \mathrm{a}$ \\
Dicofol 360 & $97,0 \pm 3,4 \mathrm{a}$ & $100 \pm 0 \mathrm{a}$ \\
Endosulfan 320 & $98,0 \pm 5 \mathrm{a}$ & $41,2 \pm 10,3 \mathrm{~cd}$ \\
Endosulfan 1000 & $99,0 \pm 2,5 \mathrm{a}$ & $61,2 \pm 23,9 \mathrm{bc}$ \\
Formetanate 32 & $100 \pm 0 \mathrm{a}$ & $15,0 \pm 4,0 \mathrm{efg}$ \\
Formetanate 100 & $100 \pm 0 \mathrm{a}$ & $40,0 \pm 9,1 \mathrm{cde}$ \\
Metomil 90 & $100 \pm 0 \mathrm{a}$ & $11,2 \pm 4,7 \mathrm{efg}$ \\
Metomil 280 & $100 \pm 0 \mathrm{a}$ & $32,5 \pm 12,5 \mathrm{def}$ \\
Monocrotofos 560 & $100 \pm 0 \mathrm{a}$ & $41,2 \pm 16,5 \mathrm{~cd}$ \\
\hline
\end{tabular}




\begin{tabular}{lcc}
\hline Agroquímico (ppm) & Calacarus heveae & Tenuipalpus heveae \\
\hline Monocrotofos 1800 & $100 \pm 0 \mathrm{a}$ & $71,2 \pm 6,2 \mathrm{~b}$ \\
Óxido de fenbutatina 100 & $95,0 \pm 4,0 \mathrm{a}$ & $10,0 \pm 9,1 \mathrm{fg}$ \\
Óxido de fenbutatina 320 & $100 \pm 0 \mathrm{a}$ & $40,0 \pm 4,0 \mathrm{cde}$ \\
Propargite 320 & $99,0 \pm 2,5 \mathrm{a}$ & $2,5 \pm 5,0 \mathrm{~g}$ \\
Propargite 750 & $100 \pm 0 \mathrm{a}$ & $21,2 \pm 13,1 \mathrm{defg}$
\end{tabular}

Na mesma coluna, valores seguidos da mesma letra não diferem estatisticamente entre si pelo teste de Tukey a $5 \%$ de probabilidade.

\subsection{DISCUSSÃO}

Nenhuma informação sobre o efeito dos agroquímicos testados sobre $T$. heveae e $C$. heveae foi encontrado na literatura.

Os resultados deste trabalho indicaram que $C$. heveae é sensivel a uma amplitude maior de agrotóxicos que T. heveae. Mesmo nas doses mais baixas, quase todos os produtos causaram alta mortalidade de $C \cdot$ heveae. Por outro lado, $T$. heveae, em geral, se mostrou muito pouco sensível aos agroquímicos testados. De forma semelhante ao que se observou neste trabalho, os resultados de outros autores envolvendo estes mesmos agroquímicos demostraram maior sensibilidade de espécies de Eriophyidae que de espécies de Tenuipalpidae (Sampaio \& Myazaki, 1982; Ferreira \& Veiga, 2000; Moraes et al., 1987). A metodologia empregada neste trabalho não permitiu identificar a razão da diferença de sensibilidade das espécies estudadas.

A considerável mortalidade, de $C$. heveae, mesmo nas doses mais baixas dos produtos testados, indicam uma conveniência de estudos adicionais envolvendo doses ainda menores que as utilizadas neste estudo para se definir os possíveis níveis a serem considerados em estudos de campo, visando ao registro daqueles produtos para controle destes ácaros. Outro ponto a considerar, para o futuro estabelecimento de um programa de manejo, é o efeito de cada produto promissor nos inimigos naturais de C. heveae e $T$. heveae existentes em diferentes locais onde estes ocorrem. 


\subsection{CONCLUSÕES}

1) Dicofol é o único agroquímico que causa alta mortalidade de $C$. heveae e $T$. heveae. 


\section{OVIPOSIÇÃO DOS PREDADORES Agistemus floridanus, Euseius concordis E Neoseiulus anonymus (ACARI) EM DIFERENTES TIPOS DE ALIMENTO}

\section{RESUMO}

Ácaros Phytoseiidae e Stigmaeidae são os predadores mais comuns em folhas de seringueira no Estado do Mato Grosso, associados a ácaros fitófagos que pertencem às famílias Eriophyidae, Tenuipalpidae e Tetranychidae. $\mathrm{O}$ objetivo deste trabalho foi comparar o efeito de diferentes tipos de alimento, incluindo diferentes espécies de ácaros comumente encontradas em seringueira no Mato Grosso e um tipo de pólen, na oviposição dos predadores Agistemus floridanus Gonzalez (Stigmaeidae), Euseius concordis (Chant) e Neoseiulus anonymus (Chant \& Baker) (ambos Phytoseiidae). Estes predadores são comumente encontrados em folhas de seringueira no Mato Grosso. Nos testes com A. floridanus, foram utilizados como substrato círculos de $2 \mathrm{~cm}$ de diâmetro recortados de folhas de seringueira, enquanto que para os testes com E. concordis e $N$. anonymus, foram utilizados folíolos inteiros de seringueira. Como alimento, foram oferecidos aos predadores os ácaros Calacarus heveae Feres, Oligonychus gossypii (Zacher), Polyphagotarsonemus latus (Banks), Tenuipalpus heveae Baker e Tetranychus mexicanus (McGregor), e pólen de Typha angustifolia L.. A. floridanus aceitou uma

variedade maior de alimento que outros predadores. Este foi o único predador a apresentar alta oviposição quando alimentado com $C$. heveae e $T$. heveae, os ácaros fitófagos considerados mais importantes na cultura da seringueira. E. concordis e $A$. floridanus apresentaram aproximadamente os mesmos níveis de oviposição quando alimentados com pólen de $T$. angustifolia (cerca de 1,0 ovo por fêmea por dia). $N$. anonymus apresentou maior oviposição que os demais predadores testados quando 
alimentado com $O$. gossypii e T. mexicanus. P. latus foi o alimento menos adequado para as espécies de predadores estudadas.

\section{OVIPOSITION OF THE PREDATORS Agistemus floridanus, Euseius concordis AND Neoseiulus anonymus (ACARI) IN DIFFERENT KINDS OF FOOD.}

\section{SUMMARY}

Phytoseiidae and Stigmaeidae are the most common predatory mites on rubber tree leaves in the State of Mato Grosso, associated with phytophagous mites of the families Eriophyidae, Tenuipalpidae and Tetranychidae. The aim of this work was to compare the effect of different kinds of food, including different species of mites commonly found on the rubber tree in Mato Grosso, and one kind of pollen, on the oviposition of the predators Agistemus floridanus Gonzalez (Stigmaeidae), Euseius concordis (Chant) and Neoseiulus anonymus (Chant \& Baker) (both Phytoseiidae). Those predators are common on rubber tree leaves in Mato Grosso. For the tests with $A$. floridanus, circles of $2 \mathrm{~cm}$ in diameter of rubber tree leaves were used as substrate. For the tests with $E$. concordis and $N$. anonymus, entire folioles of rubber tree leaves were used as substrate. The kinds of food provided to the predators were the mites Calacarus heveae Feres, Oligonychus gossypii (Zacher), Polyphagotarsonemus latus (Banks), Tenuipalpus heveae Baker and Tetranychus mexicanus (McGregor), and pollen of Typha angustifolia L.. A. floridanus accepted a larger variety of food than other predators. This was the only predator with high oviposition rate when fed $C$. heveae and $T$. heveae, the phytophagous mites considered most important on rubber trees. E. concordis and $A$. floridanus had nearly the same oviposition rates when fed pollen of T. angustifolia (ca. 1,0 egg per female per day). $N$. anonymus had the highest oviposition rate than other predators when fed $O$. gossypii and T. mexicanus. P. latus was the least suitable food for the predators studied. 


\subsection{INTRODUÇÃO}

As espécies mais comuns de ácaros fitófagos em folhas de seringueira (Hevea brasiliensis Muell. Arg.) no Estado do Mato Grosso pertencem às famílias Eriophyidae, Tarsonemidae, Tenuipalpidae e Tetranychidae (Capítulo 4). Devido às altas populações observadas, ao dano causado às folhas e à freqüência com que ocorrem em seringais do Estado do Mato Grosso, Calacarus heveae Feres e Tenuipalpus heveae Baker são considerados os ácaros fitófagos mais importantes nesta cultura (Capítulos 4 e 5). De acordo com Vieira \& Gomes (1999), C. heveae pode provocar níveis de desfolha acima de 75\% em clones RRIM 600. Segundo Feres (2000), alguns produtores afirmam que $C$. heveae ocasiona perdas de até $30 \%$ na produção de látex de alguns clones de $H$. brasiliensis. T. heveae ataca principalmente a face abaxial dos folíolos (Feres, 2000), causando o amarelecimento destes e aparentemente contribuindo para sua queda prematura. Além destas, outras espécies de ácaros fitófagos provocam danos a esta cultura. Polyphagotarsonemus latus (Banks) fica restrito às brotações, podendo provocar o aparecimento de folhas deformadas ou fendidas (Flechtmann \& Arleu, 1984). Oligonychus gossypii (Zacher) e Tetranychus mexicanus (McGregor) podem aparecer ocasionalmente em altos níveis na estação seca, após o enfolhamento das plantas e antes da intensificação das precipitações (Feres, 2000; Fazolin \& Pereira, 1989). Estes ácaros e algumas outras espécies foram também encontradas em um estudo faunístico conduzido nos municípios de Itiquira e Pontes e Lacerda, no Mato Grosso (Capítulo 4).

Ácaros Phytoseiidae e Stigmaeidae são os predadores mais comuns em folhas de seringueira no sudeste e centro-oeste do Brasil, sendo a maior diversidade apresentada pelos fitoseídeos (Feres, 2000; Capítulo 4). Conhecer a interação de predadores e presas na cultura da seringueira é importante para subsidiar estudos populacionais de inimigos naturais e oferecer subsídio para o manejo de pragas nesta cultura. O objetivo deste trabalho foi dar um primeiro passo neste sentido, determinando a aceitação de ácaros fitófagos comuns em seringueira como fonte de alimento para Agistemus floridanus Gonzalez, Euseius concordis (Chant) e Neoseiulus anonymus (Chant \& Baker), em comparação com um tipo de pólen que em outros estudos tem se 
mostrado alimento favorável a vários predadores. A aceitação destes alimentos foi inferida a partir de uma análise dos níveis de oviposição destes predadores em condições de laboratório.

\subsection{MATERIAL E MÉTODOS}

Este trabalho foi realizado nos laboratórios da Escola Superior de Agricultura Luiz de Queiroz (ESALQ/USP), em Piracicaba, São Paulo, utilizando ácaros provenientes de colônias de laboratório iniciadas com espécimes coletados em folha de seringueira no Estado do Mato Grosso, havia cerca de 3 meses. E. concordis e $A$. floridanus foram provenientes de Itiquira e $N$. anonymus, de Pontes e Lacerda.

A colônia de $A$. floridanus foi mantida em unidades de criação constituídas por folíolos de seringueira postos com a face adaxial para baixo, sobre um pedaço de espuma de náilon umedecida, em uma bandeja plástica parcialmente coberta com um pedaço de papelão para evitar a incidência de luz direta sobre as unidades. Estes ácaros foram alimentados com uma mistura de diferentes estádios de $O$. gossypii e $T$. heveae.

As colônias de $E$. concordis e $N$. anonymus foram mantidas em unidades de criação semelhantes às descritas por McMurtry \& Scriven (1965). Cada unidade constou de uma placa de Paviflex® colocada sobre um pedaço de espuma umedecida no interior de uma bandeja plástica, também parcialmente coberta com um pedaço de papelão. Estes ácaros foram alimentados com pólen de Typha angustifolia L. e uma mistura de diferentes estádios de Tetranychus urticae Koch, sobre pedaços folhas de feijão-deporco (Canavalia ensiformis D.C.) infestadas. Os grãos de pólen foram colocados sobre lamínulas de microscopia e estas foram postas na unidade de criação; a cada dois dias, as lamínulas foram substituídas por novas lamínulas com pólen. Os diferentes estádios de T. urticae foram também oferecidos a cada 2 dias.

O tipo de unidade experimental utilizada para cada espécie de predador foi aquela que em testes preliminares se mostraram mais adequadas para esta finalidade, tendo em vista o diferente comportamento de cada predador. Os tratamentos consistiram da alimentação de cada espécie de ácaro predador com uma mistura de diferentes 
estádios de T. mexicanus, O. gossypii, T. heveae, C. heveae e $P$. latus, ou com pólen de T. angustifolia.

As unidades de criação, assim como as unidades experimentais, foram mantidas em uma câmara climatizada a $25 \pm 1{ }^{\circ} \mathrm{C}$, fotofase de 12 horas e umidade relativa de $80 \pm 5 \%$.

\subsubsection{Procedimentos experimentais com Agistemus floridanus}

Círculos de $2 \mathrm{~cm}$ de diâmetro recortados de folíolos de seringueira foram colocados com a face adaxial para baixo dentro de placas de plástico de $2,5 \mathrm{~cm}$ de diâmetro x 1,5 cm de altura, cobertas com uma película de plástico (Magipack®). Para cada tipo de alimento, foram utilizados 15 círculos, cada um com uma fêmea. As fềmeas utilizadas nos testes foram retiradas ao acaso da criação estoque de predadores e mostravam-se aparentemente sadias. Estas foram transferidas para novas arenas a cada 3 dias. Fêmeas mortas até o quarto dia não foram consideradas nos cálculos.

\subsubsection{Procedimentos com Euseius concordis e Neoseiulus anonymus}

Os testes com estes predadores foram feitos sobre folíolos de seringueira postos com a face adaxial para baixo sobre pedaços de esponja umedecida no interior de bandejas de alumínio. As margens dos folíolos foram recobertas com tiras de algodão hidrófilo também umedecido.

Para cada tipo de alimento, utilizaram-se 4 repetições em um delineamento experimental inteiramente casualizado. Cada parcela foi constituída por 10 fềmeas aparentemente sadias, tomadas ao acaso da unidade de criação. As fêmeas foram transferidas para novos substratos a cada 3 dias.

\subsubsection{Parâmetro avaliado e análise}

Cada teste teve duração de 11 dias, fazendo-se diariamente a contagem e a 
retirada dos ovos postos. Para a realização dos cálculos, descartou-se o primeiro dia de oviposição, devido à possível interferência da alimentação anterior do ácaro.

As médias de oviposição dos diferentes tratamentos foram comparadas pelo teste de Tukey, utilizando o programa estatístico SANEST, desenvolvido pelo Centro de Informática na Agricultura da Escola Superior de Agricultura 'Luiz de Queiroz" da Universidade de São Paulo (ESALQ/USP).

\subsection{RESULTADOS}

A oviposição diária de $A$. floridanus foi igual ou superior a 1,0 ovo por fêmea quando estes ácaros foram alimentados com C. heveae, T. heveae, T. mexicanus, e pólen de T. angustifolia, diferindo significativamente da oviposição quando alimentando-se de O. gossypii e P. latus (Tabela 7).

E. concordis teve oviposição diária de cerca de 1,0 ovo por fềmea quando alimentado com pólen de T. angustifolia, enquanto que com os demais tipos de alimento a oviposição foi significativamente menor e sempre muito baixa.

O maior nível de oviposição diária de $N$. anonymus foi observada quando o predador foi alimentado com T. mexicanus, atingindo 2,0 ovos por fềmea; já com outro tetraniquídeo, O. gossypii, a oviposição diária foi pouco acima de 1,0 ovo por fêmea. Estes niveis de oviposição foram maiores que aqueles obtidos por outros predadores quando alimentados com estes mesmos tetraniquídeos. Para os demais tipos de alimento, a oviposição foi menor que 0,5 ovo por fêmea, diferindo significativamente dos demais tratamentos. Esta espécie não ovipositou quando alimentada com T. heveae.

E. concordis e $A$. floridanus apresentaram níveis de oviposição semelhantes quando alimentados com pólen. $P$. latus foi o alimento menos adequado para as espécies de predadores estudadas. 
Tabela 7. Oviposicão média diária ( \pm erro padrão da média) de Agistemus floridanus, Euseius concordis e Neoseiulus anonymus em diferentes tipos de alimento, a $25 \pm 1^{\circ} \mathrm{C}$, fotofase de 12 horas e umidade relativa de $80 \pm 5 \%$.

\begin{tabular}{lccc}
\hline Tipos de alimento & Agistemus floridanus & Euseius concordis & $\begin{array}{c}\text { Neoseiulus } \\
\text { anonymus }\end{array}$ \\
\hline Calacarus heveae & $1,5 \pm 0,1 \mathrm{a}$ & $0,01 \pm 0,2 \mathrm{~b}$ & $0,01 \pm 0 \mathrm{c}$ \\
Oligonychus gossypii & $0,4 \pm 0,1 \mathrm{~b}$ & $0,09 \pm 0,01 \mathrm{~b}$ & $1,2 \pm 0,4 \mathrm{~b}$ \\
Polyphagotarsonemus latus & $0,3 \pm 0,2 \mathrm{~b}$ & $0,05 \pm 0,01 \mathrm{~b}$ & $0,4 \pm 0,1 \mathrm{c}$ \\
Tenuipalpus heveae & $1,7 \pm 0,2 \mathrm{a}$ & $0,1 \pm 0,2 \mathrm{~b}$ & $0 \mathrm{c}$ \\
Tetranychus mexicanus & $1,0 \pm 0,1 \mathrm{a}$ & $0,04 \pm 0,08 \mathrm{~b}$ & $2,0 \pm 0,1 \mathrm{a}$ \\
Pólen de Typha angustifolia & $1,0 \pm 0,1 \mathrm{a}$ & $0,9 \pm 0,2 \mathrm{a}$ & $0,01 \pm 3,1 \mathrm{c}$
\end{tabular}

Médias seguidas da mesma letra, em cada coluna, não diferem estatisticamente entre si, pelo teste de Tukey, a 5\% de probabilidade.

\subsection{DISCUSSÃO}

A aceitação de uma maior diversidade de alimentos por $A$. floridanus, indica que este ácaro possa se manter mais facilmente em seringueiras. Dentre as espécies estudadas, este pode ser o ácaro predador mais importante no controle de $C$. heveae e $T$. heveae, de vez que este foi o único predador a apresentar oviposição relativamente alta quando alimentada com aquelas espécies. Assim, em seringais onde se julgar necessário o controle químico de pragas, deve-se optar por produtos que não afetem a população de A. floridanus.

Os resultados deste trabalho concordam com a sugestão de White (1976) de que os eriofideos são presas naturais dos estigmeídeos. Trabalhando com Zetzellia mali Ewing, Delattre (1974) e Santos (1991) também constataram a preferência daquela espécie de estigmeídeo por eriofideos em relação aos tetraniquídeos.

Os resultados deste trabalho são semelhantes àqueles obtidos por outros autores 
citados por McMurtry \& Croft (1997), que também determinaram ser pólen o alimento preferido de espécies de Euseius. Segundo McMurtry \& Croft (1997), espécies daquele gênero pertencem a um grupo de predadores que apresentam taxa reprodutiva mais alta quando alimentados com pólen, em comparação a outros tipos de alimento. Moraes \& Lima (1983) já haviam verificado ser pólen de Ricinus communis L., favorável à oviposição de E. concordis. Aqueles autores, além disso, obtiveram índices de oviposição relativamente altos quando $E$. concordis foi alimentado com o eriofideo Aculops lycopersici (Massee), praga de tomateiro. Os resultados do presente trabalho indicam que nem todos os eriofideos são aceitos por E. concordis como alimento, de vez que o nível de oviposição deste predador foi extremamente baixo quando $C$. heveae foi oferecido como alimento.

Poucos estudos têm sido conduzidos comparando-se o efeito de diferentes tipos de alimento na oviposição de $N$. anonymus, mas estes têm demonstrado a aceitação de tetraniquídeos como presa para aquele predador (Gondim et al., 1996; Mesa \& Bellotti, 1986). No estudo conduzido por Gondim Jr. et al., (1996), N. anonymus apresentou oviposição diária 1,5 ovos por fềmea, quando alimentado com $T$. urticae $\mathrm{e}$ Mononychellus tanajoa (Bondar), comparável aos resultados do presente trabalho. Segundo classificação estabelecida por McMurtry \& Croft (1997), N. anonymus pertence a um grupo de predadores que apresentam alta taxa de oviposição alimentandose de várias espécies de ácaros da família Tetranychidae.

Fazolin \& Pereira (1989) relataram altas populações destes ácaros em seringueira no Estado do Acre. Entretanto, de uma maneira geral, os ácaros desta família são encontrados em baixos níveis populacionais nesta cultura, o que possivelmente se dá pela ação dos ácaros predadores presentes nesta cultura. De acordo com os resultados observados neste estudo e pela freqüência observada no Capítulo $5, N$. anonymus parece ser uma espécie importante no controle das populações de tetraniquídeos nesta cultura. 


\subsection{CONCLUSÕES}

1) Agistemus floridanus tem maior oviposição quando alimentado com $C$. heveae e $T$. heveae, ácaros considerados danosos à seringueira.

2) Neoseiulus anonymus apresenta maior oviposição quando alimentado com tetraniquídeos do que quando alimentado com outros ácaros comuns em seringueira. 


\section{RESUMO}

A seringueira (Hevea brasiliensis Muell. Arg.) é hospedeira de várias espécies de ácaros fitófagos no Brasil. Estudos conduzidos no Estado do Mato Grosso mostraram a presença do predador Agistemus floridanus Gonzalez (Stigmaeidae) em plantas de seringueira associados ao ácaro Tenuipalpus heveae Baker. O objetivo deste trabalho foi estudar a biologia daquele predador em laboratório, quando alimentado com $T$. heveae. $\mathrm{O}$ estudo foi iniciado com 22 ovos, que resultaram 15 fềmeas que atingiram à fase adulta. Para verificar o efeito da fecundação sobre a oviposição foram utilizadas 30 fềmeas, sendo metade destas mantidas isoladas e as demais mantidas juntamente com machos durante toda a fase adulta. O estádio de ovo foi o mais longo, com duração de mais de 4,0 dias. A duração total de ovo-adulto foi 10,2 dias. Cada fềmea depositou um total médio de 38,4 ovos, a uma taxa diária de oviposição de 2,3 ovos por fềmea. A duração de cada fase do estádio adulto, a oviposição diária e a longevidade foram diferentes entre as fềmeas acasaladas e não acasaladas. Todos os ovos das fềmeas não acasaladas deram origem a machos, caracterizando desta forma o desenvolvimento por partenogênese arrenótoca. Os resultados indicaram que $A$. floridanus tem uma capacidade de aumento de 13,2 vezes em cada geração, que a duração média de uma geração é de cerca de 19,2 dias, que a razão intrínseca de incremento populacional $\left(\mathrm{r}_{\mathrm{m}}\right)$ é de 0,16 fềmea por fềmea por dia, e que 1,1 fềmeas por fềmeas são adicionadas diariamente à população. 


\section{LIFE TABLE OF Agistemus floridanus (ACARI: STIGMAEIDAE)}

\section{SUMMARY}

The rubber tree (Hevea brasiliensis Muell. Arg.) is attacked by various species of phytophagous mites in Brazil. Studies conducted in the State of Mato Grosso showed the presence of Agistemus floridanus Gonzalez (Stigmaeidae) on rubber trees, associated with the mite Temuipalpus heveae Baker. The aim of this work was to study the biology of that predator in the laboratory, when fed with $T$. heveae as prey. The study was started with 22 eggs, which resulted in 15 females reaching adult hood. To determine the effect of mating on oviposition , 30 females were used; half of those were maintained isolated and the remaining were maintained then with males during the whole adult stage. The stage of egg was the longest, with a duration of more than 4,0 days. The total duration of the immature phase was 10,2 days. Each female oviposited an average of 38,4 eggs, with a daily oviposition rate of 2,3 eggs per female. The duration of each adult phase, the daily oviposition rate and the longevity were different between the mated females and non-mated females. All eggs produced by non-mated originated males, characterizing, in this way, the development through arrhenothokous parthenogenesis. The results showed that $A$. floridanus has an innate increase capacity of 13,2 times in each generation, that the average duration of one generation is 19,2 days, that the intrinsic rate of increase (rm) is about 0,16 female per female per day and that the number of females added daily to the population is 1,1 . 


\subsection{INTRODUÇÃO}

A seringueira (Hevea brasiliensis Muell. Arg.) é hospedeira de várias espécies de ácaros fitófagos nas diversas regiões onde é cultivada no Brasil. Espécies de Phytoseiidae e Stigmaeidae são os ácaros predadores mais comuns na seringueira em associação com ácaros fitófagos (Feres, 2000; Capítulos 4 e 5).

As espécies de Stigmaeidae encontradas em seringueira nos Estados do Mato Grosso e São Paulo pertencem aos gêneros Agistemus e Zetzellia. Espécies dos gêneros Agistemus e Zetzellia são geralmente conhecidas como predadoras ativas de ovos de tetraniquídeos (Ehara, 1985; Gerson \& Smiley, 1990; Laing \& Knop, 1982; McMurtry et al., 1970).

Tenuipalpus heveae Baker é um tenuipalpídeo presente na cultura da seringueira, sendo encontrado mais comumente na face abaxial dos folíolos. Entretanto, quando em grandes populações, pode ser observado na face adaxial (Feres, 2000; Capítulo 5). Causa amarelecimento e contribui para a queda prematura das folhas.

Agistemus floridanus Gonzalez é um predador da família Stigmaeidae encontrado em altas populações associado a $T$. heveae e Calacarus heveae Feres em seringueira no Estado do Mato Grosso (Capitulo 5). A oviposição deste predador foi uma das mais altas quando alimentado com $C$. heveae e $T$. heveae (Capítulo 8). Nenhum estudo foi realizado até momento para conhecer a tabela de vida e a fertilidade deste predador. $\mathrm{O}$ conhecimento de predadores com capacidade de controle de $T$. heveae dará suporte ao estabelecimento de programas de manejo que enfatizem o uso daqueles nesta cultura.

O objetivo deste trabalho foi obter informações sobre a biologia de $A$. floridanus quando alimentado com $T$. heveae.

\subsection{MATERIAL E MÉTODOS}

Este trabalho foi realizado nos laboratórios da Escola Superior de Agricultura "Luiz de Queiroz" (ESALQ/USP), em Piracicaba, São Paulo, utilizando-se ácaros 
provenientes de colônias de laboratório iniciadas com espécimes coletados no campo havia cerca de 2 meses. Os ácaros foram retirados de folhas de seringueira provenientes das Plantações Edouard Michelin Ltda., no município de Itiquira, Estado do Mato Grosso.

A colônia de $A$. floridamus foi mantida em unidades de criação formadas por folíolos de seringueira destacados, colocados sobre esponja umedecida no interior de uma bandeja plástica. Para que os ácaros permanecessem na penumbra, as bandejas foram mantidas parcialmente cobertas. Os ácaros foram alimentados com uma mistura de diferentes estádios de Oligonychus gossypii (Zacher) e $T$. heveae, transferindo-se os predadores semanalmente para novas unidades de criação.

\subsubsection{Biologia de Agistemus floridanus}

Quadrados de $3 \mathrm{~cm}^{2}$ foram recortados de folíolos de seringueira e colocados com a face adaxial para baixo sobre esponja umedecida em uma bandeja de alumínio. As margens dos quadrados foram cobertas por uma faixa de algodão hidrófilo. Junto ao algodão, foi colocado um filete de cola utilizada para captura de insetos (Bio Controle $\left.{ }^{\circledR}\right)$, para evitar a fuga dos ácaros.

O estudo foi iniciado com ovos obtidos como se segue. Inicialmente, uma fềmea de $A$. floridanus foi transferida da criação de manutenção para cada unidade de criação de $3 \mathrm{~cm}^{2}$. Após um período de 6 horas, as unidades foram examinadas retirandose as fêmeas daquelas onde havia ocorrido a oviposição, assim como os ovos excedentes, deixando-se apenas 1 ovo por unidade. $O$ restante das unidades foram examinadas novamente após outro período de 6 horas, repetindo-se o processo até que se obtivesse um total de 22 ovos. As arenas foram examinadas 3 vezes ao dia, às $7,12 \mathrm{e} 17$ horas, até que os ácaros atingissem o estádio adulto, para se determinar o estádio de desenvolvimento em que o ácaro se encontrava. Na fase adulta, as arenas foram observadas uma vez ao dia (14 horas), para verificar o número de ovos postos. 
Para se avaliar o efeito da fecundação sobre a oviposição, um teste adicional foi conduzido. Para tal, ácaros imaturos foram retirados da unidade de criação e individualizados em arenas semelhantes às descritas anteriormente.

Os ácaros foram trocados de arena uma vez por semana e em cada troca, 30 indivíduos de diferentes estádios de $T$. heveae foram passados para as novas arenas, para servir de alimento. Trinta fêmeas de A. floridanus foram utilizadas para este estudo. Quinze destas foram mantidas isoladas, enquanto que cada uma das demais foi mantida juntamente com um macho durante toda a fase adulta. Os machos foram obtidos da arena de criação, sendo substituído por novos machos, quando morriam.

As arenas foram mantidas em câmara climatizada a $25 \pm 1^{\circ} \mathrm{C}$, fotoperíodo de 12 horas e umidade relativa de $80 \pm 5 \%$.

\subsection{RESULTADOS}

\subsubsection{Biologia}

A. floridanus apresentou durante seu desenvolvimento os estádios de ovo, larva, protoninfa, deutoninfa e adulto. O período de ovo-adulto durou 10,2 dias (Tabela 8). $\mathrm{O}$ estádio de ovo foi o mais longo, com duração de 4,1 dias e os estádios de larva, protoninfa e deutoninfa duraram 1,2, 1,0 e 1,6 dias, respectivamente.

Todos os ovos das fêmeas não fecundadas originaram machos, caracterizando desta forma o desenvolvimento por partenogênese arrenótoca. As fêmeas acasaladas deram origem a machos e a fêmeas, sendo que a razão sexual foi de $85 \%$ de fêmeas. 
Tabela 8. Duração média, em dias ( \pm erro padrão da média) das fases imaturas e adulta e viabilidade de Agistemus floridanus alimentando-se de Tenuipalpus heveae, a $25 \pm 1^{\circ} \mathrm{C}$, fotofase de 12 horas e umidade relativa de $80 \pm 5 \%$.

\begin{tabular}{lcc}
\hline Estádios & Duração & Viabilidade (\%) \\
\hline Ovo & $4,1 \pm 0,04$ & 100 \\
Larva & $1,2 \pm 0,1$ & 81 \\
Protocrisálida & $0,9 \pm 0,2$ & 100 \\
Protoninfa & $1,0 \pm 0,09$ & 83 \\
Deutocrisálida & $0,6 \pm 0,08$ & 100 \\
Deutoninfa & $1,6 \pm 0,2$ & 100 \\
Teliocrisálida & $0,5 \pm 0,06$ & 100 \\
Ovo-Adulto & $10,2 \pm 0,2$ & 68 \\
\hline
\end{tabular}

As fềmeas acasaladas tiveram períodos de pré-oviposição, oviposição e longevidade significativamente menores que as fêmeas não acasaladas (Tabela 9). A média diária de oviposição foi significativamente maior para fêmeas acasaladas que para fêmeas não acasaladas. Para os dois grupos estudados, a oviposição total e a pósoviposição não apresentaram diferenças estatisticamente significativas.

\subsubsection{Tabela de vida de fertilidade}

A taxa líquida de reprodução $\left(R_{0}\right)$ observada foi de 13,2 vezes a cada geração, com duração média de uma geração (T) de cerca de 19,2 dias. A razão intrínseca de incremento populacional $\left(r_{m}\right)$ foi de 0,16 fêmea por fềmea por dia, enquanto a razão finita de aumento $(\lambda)$, isto é, o número de fềmeas adicionadas à população por dia, foi de 1,1 fềmea por fềmea. 
Tabela 9. Parâmetros médios ( \pm erro padrão da média) da biologia de fềmea adultas de Agistemus floridanus acasaladas e não acasaladas, alimentando-se de Tenuipalpus heveae, a $25 \pm 1^{\circ} \mathrm{C}$, fotofase de 12 horas e umidade relativa de $80 \pm 5 \%$.

\begin{tabular}{lcc}
\hline Fases & Acasaladas & Não acasaladas \\
\hline Pré-oviposição & $1,6 \pm 0,1 \mathrm{a}$ & $2,7 \pm 0,3 \mathrm{~b}$ \\
Oviposição & $16,6 \pm 1,4 \mathrm{a}$ & $23,4 \pm 3,9 \mathrm{~b}$ \\
Pós-oviposição & $7,0 \pm 1,9 \mathrm{a}$ & $6,8 \pm 1,0 \mathrm{a}$ \\
Longevidade & $25,3 \pm 2,7 \mathrm{a}$ & $34,6 \pm 4,1 \mathrm{~b}$ \\
Ovos/fêmea & $38,4 \pm 3,5 \mathrm{a}$ & $31,6 \pm 5,1 \mathrm{a}$ \\
Ovos/fêmea/dia & $2,3 \pm 0,1 \mathrm{a}$ & $1,3 \pm 0,08 \mathrm{~b}$ \\
\hline
\end{tabular}

Em cada linha, médias seguidas da mesma letra não diferem estatisticamente entre si, pelo teste t, a $5 \%$ de probabilidade.

\subsection{DISCUSSÃO}

$\mathrm{O}$ ácaro $T$. heveae demonstrou ser uma presa adequada para o desenvolvimento e a reprodução do predador $A$. floridanus. Esses resultados sugerem que uma das razões das altas populações de $A$. floridanus nos clones PB 260 e PR 255 em Itiquira (Capítulo 5) seja a presença de $T$. heveae.

Entre as três espécies de ácaros predadores comuns em seringueira no Estado do Mato Grosso, Euseius concordis (Chant), Neoseiulus anonymus (Chant \& Baker) $e$ A. floridanus, a última foi a única espécie que apresentou alta oviposição alimentando-se de (Capítulo 8). Como C. heveae e T. heveae são consideradas pragas importantes desta cultura, a presença deste predador contribui para manter os níveis populacionais desta espécie abaixo do nível de dano.

No Brasil, os estigmeídeos são ácaros predadores importantes em pomares macieira (Lorenzato, 1987; Ferla \& Moraes, 1998) e seringueira (Feres, 2000). Até o 
momento, nenhum estudo foi desenvolvido para conhecer a tabela de vida e fertilidade destas espécies no Brasil.

Zetzellia mali (Ewing) é o Stigmaeidae mais bem conhecido, devido ao papel atribuído a esta espécie como inimigo natural de Panonychus ulmi (Koch) e Aculops schlechtendali (Nalepa) na cultura da macieira. Alimentando-se de A. schlechtendali, esta espécie apresentou duração média de uma geração de cerca de 21 dias e uma taxa líquida de reprodução $\left(\mathrm{R}_{0}\right)$ de 0,109 (White \& Laing, 1977). Agistemus denotatus Gonzalez, alimentado com Brevipalpus phoenicis (Geijskes), teve uma geração com uma duração de cerca de 50,6 dias e taxa líquida de reprodução $\left(\mathrm{R}_{0}\right)$ baixa, de cerca de 0,061 (Oomen, 1982).

Devido à dificuldade de conseguir grandes populações de $A$. floridanus para realizar liberações inundativas, a melhor estratégia seria a liberação inoculativa em locais onde esta espécie não esteja presente, ou a definição de estratégias para conservar esta espécie nos ambientes. Até o momento, não se conhece nenhum programa que envolva a liberação inundativa com espécies da família Stigmaeidae, sendo que o principal problema é a ausência de metodologia para a criação massal de espécies desta família. Devido à utilização ocasional de agroquímicos em seringueira, é necessário a realização de estudos de seletividade de produtos em relação a este predador. Estudos de seletividade não foram realizados com $A$. floridanus, pois estes testes foram programados para serem realizados apenas com Euseius concordis (Chant) e Neoseiulus anonymus (Chant \& Baker), as espécies mais comumente encontradas em seringueira no Estado do Mato Grosso (Capítulos 4 e 5).

\subsection{CONCLUSÕES}

1) Agistemus floridanus apresenta alta fertilidade quando alimentado com $T$ : heveae. 


\section{SELETIVIDADE DE AGROQUíMICOS EM ÁCAROS PREDADORES COMUMENTE ENCONTRADOS EM SERINGUEIRA NO CENTRO-OESTE DO BRASIL}

\section{RESUMO}

Euseius concordis (Chant) e Neoseiulus anonymus (Chant \& Baker) são ácaros predadores da família Phytoseiidae comumente encontrados em seringueira (Hevea brasiliensis Muell. Arg.) no centro-oeste do Brasil. Estes predadores se alimentam de ácaros fitófagos que atacam a seringueira. Este trabalho foi realizado para verificar o efeito dos agroquímicos ocasionalmente empregados em plantações de seringueira, e outros que teriam potencial para serem empregados contra diferentes grupos de pragas e patógenos nesta cultura, sobre E. concordis e $N$. anonymus. Utilizou-se o método residual de pulverização em superfície, recomendado como padrão pelo Grupo de Trabalho "Pesticidas e Artrópodes Benéficos", da Organização Internacional de Controle Biológico e Integrado de Plantas e Animais Nocivos/Seção Regional do Paleártico Oeste (IOBC/WPRS). Duas concentrações de cada um dos seguintes agroquímicos foram utilizadas: acefato, dicofol, endosulfan, formetanate, metomil, monocrotofós, óxido de fenbutatina e propargite. Uma das concentrações utilizadas foi uma média daquelas sugeridas pelos fabricantes para o controle de ácaros e insetos fitófagos presentes em outras culturas, de vez que nenhum dos produtos testados tem registro para o uso em seringueira. A outra dosagem correspondeu a cerca de um terço da primeira dosagem. Endosulfan a $320 \mathrm{ppm}$, dicofol a $100 \mathrm{ppm}$ e óxido de fenbutatina a 100 e 320 ppm foram inócuos a E. concordis, enquanto que endosulfan a $320 \mathrm{ppm}$ e dicofol a 100 ppm foram inócuos a $N$. anonymus. Acefato e monocrotofós, nas duas 
concentrações testadas, foram nocivos às duas espécies.

\section{SELECTIVITY OF PESTICIDES TO PREDATORY MITES COMMONLY FOUND IN RUBBER-TREES IN MID-WEST BRAZIL}

\section{SUMMARY}

Euseius concordis (Chant) and Neoseiulus anomymus (Chant \& Baker) are predatory mites of the family Phytoseiidae commonly found on rubber trees (Hevea brasiliensis Muell. Arg.) in the mid-west Brazil. These predators feed on phytophagous mites that attack rubber trees. This work was conducted to verify the effect of pesticides occasionally used in rubber tree plantations, and other products that could be used against different groups of pests and pathogens in this crop, on $E$. concordis and $N$. anonymus. The residual contact spray method in glass surface was used. This method is recommended is the working Group on "Pesticides and Benefic Arthropods", of the International Organization of Biologic and Integrated Control of Noxious Plants and Animals / Regional Section of the West Paleartic (IOBC/WPRS). Two concentrations of the following pesticides were used: acephato, dicophol, endosulfan, formetanate, metomil, monocrotophos, oxid of fenbutanine and propargite. For each product, one of the concentrations was an average of the concentrations recommended by the manufacturers for the control of mites and phytophagous insects in other crops, as none of the tested products are registered for use on rubber tree. The other concentration corresponded to ca. a third of the former concentration. Endosulfan at $320 \mathrm{ppm}$, dicophol at $100 \mathrm{ppm}$ and fenbutanine oxid at 100 and $320 \mathrm{ppm}$ were harmless to $E$. concordis, while endosulfan at $320 \mathrm{ppm}$ and dicophol at $100 \mathrm{ppm}$ were harmless to $N$. anonymus. Acephato and monocrotophos, in both concentrations, were harmful to both species. 


\subsection{INTRODUÇÃO}

A seringueira (Hevea brasiliensis Muell. Arg.) é comumente atacada por diversas espécies de insetos e ácaros no centro-oeste do Brasil e no Estado de São Paulo, sendo algumas espécies acarinas consideradas pragas importantes (Feres, 2000). Os ácaros passaram a ser considerados economicamente importantes a partir dos anos 90 , quando foram responsabilizados por danos causados a esta cultura e pela conseqüente redução de produtividade. Os ácaros fitófagos mais importantes na cultura da seringueira pertencem às famílias Eriophyidae, Tenuipalpidae e Tetranychidae (Fazolin \& Pereira, 1989; Flechtmann, 1989; Feres, 2000; ver também Capítulo 4).

Duas espécies de ácaros predadores da família Phytoseiidae têm sido freqüentemente encontradas no centro-oeste do Brasil, Euseius concordis (Chant) e Neoseiulus anonymus (Chant \& Baker) (Capítulo 5). De acordo com resultados apresentados no Capítulo 4, estes são alguns dos ácaros predadores mais comuns na cultura da seringueira. Os resultados apresentados no Capítulo 8 indicam que estas espécies ovipositam quando alimentadas com ácaros fitófagos que atacam a seringueira.

Nenhum agroquímico é registrado para o controle de insetos e ácaros na cultura da seringueira. Até o momento, não foram realizados estudos no sentido de conhecer os produtos que apresentam seletividade às espécies de ácaros predadores mais comuns nesta cultura.

Este trabalho foi realizado para verificar o efeito de produtos que são ocasionalmente empregados na plantação da seringueira e outros, que teriam potencial para serem empregados contra diferentes grupos de pragas e patógenos, sobre $E$. concordis e $N$. anonymus.

\subsection{MATERIAL E MÉTODOS}

Este trabalho foi realizado nos laboratórios da Escola Superior de Agricultura "Luiz de Queiroz" (ESALQ/USP), em Piracicaba, São Paulo, de novembro de 1999 a fevereiro de 2000, utilizando-se ácaros provenientes de colônias de laboratório iniciadas 
com indivíduos coletados de folhas de seringueira cerca de 2 meses antes do início do trabalho. E. concordis foi coletado em Itiquira e $N$. anonymus, em Pontes e Lacerda, ambos no Estado do Mato Grosso.

As colônias de manutenção de ambos os predadores foram mantidas em unidades de criação semelhantes às descritas por McMurtry \& Scriven (1965). Cada unidade constou de uma placa de Paviflex ${ }^{\circledR}$ colocada sobre esponja de náilon umedecida no interior de uma bandeja plástica, permanecendo totalmente coberta com um pedaço de papelão para evitar a incidência direta da luz sobre os ácaros. Os ácaros foram alimentados com pólen de taboa (Typha angustifolia L.) e com uma mistura de diferentes estádios do ácaro rajado (Tetranychus urticae Koch). Os grãos de pólen foram colocados sobre lamínulas de microscopia postas na unidade de criação. A cada dois dias, estas lamínulas foram substituídas por novas lamínulas com pólen. Todos os estágios do ácaro rajado foram oferecidos também a cada 2 dias, sobre pedaços de folhas de feijão-de-porco (Canavalia ensiformis D.C.).

\subsubsection{Produtos testados}

Oito pesticidas foram testados, em duas concentrações. Incluiu-se também um tratamento controle, que consistiu da aplicação de água destilada (Tabela 10). Cada tratamento teve 5 repetições, em um delineamento experimental inteiramente casualizado. Uma das concentrações utilizadas foi uma média daquelas sugeridas pelos fabricantes para o controle de ácaros e insetos fitófagos presentes em outras culturas, de vez que nenhum dos produtos testados tem registro para o uso em seringueira. Outra concentração de cada produto correspondeu a aproximadamente um terço da primeira concentração. 
Tabela 10. Agroquímicos testados quanto ao efeito sobre Euseius concordis e Neoseiulus anonymus. Piracicaba. 1999-2000.

\begin{tabular}{|c|c|c|c|c|c|}
\hline Nome técnico & $\begin{array}{l}\text { Formulação e } \\
\text { Concentraçãol }\end{array}$ & $\begin{array}{c}\text { Classe } \\
\text { Toxicológica2 }\end{array}$ & Grupo Químico & $\begin{array}{c}\text { Dose } \\
\text { utilizada } \\
\text { (ppm) }\end{array}$ & Uso3 \\
\hline Acefato & PS 750 & III & Organofosforado & 180 e 560 & $\mathrm{~A}, \mathrm{I}$ \\
\hline Dicofol & CE 4100 & II & Organoclorado & 100 e 360 & A \\
\hline Endosulfan & CE 350 & I & $\begin{array}{l}\text { Éster do ácido } \\
\text { sulfuroso de diol } \\
\text { cíclico }\end{array}$ & 320 e 1000 & A, I \\
\hline Formetanate $\mathrm{HCI}$ & PS 500 & I & Carbamato & 32 e 100 & $\mathrm{~A}, \mathrm{I}$ \\
\hline Metomil & CE 215 & I & Carbamato & 90 e 280 & I \\
\hline Monocrotofós & CE 400 & I & Organofosforado & 560 e 1800 & $A, I$ \\
\hline $\begin{array}{ll}\text { Óxido de } & \text { de } \\
\text { fenbutatina }\end{array}$ & SC 500 & III & Organoestânico & 100 e 320 & A \\
\hline Propargite & CE 720 & II & Fenoxiciclohexil & 320 e 750 & A \\
\hline
\end{tabular}

1. $\mathrm{g} / \mathrm{kg}$ ou $1(\mathrm{CE}=$ concentrado emulsionável; $\mathrm{PS}=$ pó solúvel; $\mathrm{SC}=$ solução concentrada).

2. Classe de toxicidade, conforme Portaria Interministerial MA/MS $\mathrm{n}^{\circ} 220$ de 14/03/1979 (I = altamente tóxico; II - medianamente tóxico; pouco tóxico).

3. $\mathrm{A}=$ Acaricida $\mathrm{I}=$ Inseticida

\subsubsection{Procedimentos experimentais}

Utilizou-se o método de resíduo de pulverização em uma superficie inerte. Este método é recomendado como padrão pelo Grupo de Trabalho "Pesticidas e Artrópodes Benéficos", da Organização Internacional de Controle Biológico e Integrado de Plantas e Animais Nocivos/Seção Regional do Paleártico Oeste (IOBC/WPRS) para testar efeitos adversos de agroquímicos em ácaros predadores (Hassan et al., 1985; Hassan et al., 1994; Overmeer, 1988; Overmeer \& Van Zon, 1982).

Círculos de $2 \mathrm{~cm}$ de diâmetro foram recortados de folhas de seringueira para serem usados como superficie para aplicação dos produtos e suporte para os ácaros durante os testes. 
Para a pulverização dos produtos, foi utilizada uma torre de Potter para a deposição de $1,5 \mathrm{mg}$ do produto/ $\mathrm{cm}^{2}$, à pressão de $10 \mathrm{libras} / \mathrm{pol}^{2}$. Antes da pulverização de cada produto, a torre foi cuidadosamente lavada com água destilada, álcool e acetona. Os primeiros três jatos de cada produto foram sempre eliminados, reduzindo a possibilidade de contaminação com o produto anteriormente utilizado.

Após a aplicação, os círculos foram postos a secar em condições ambientais de laboratório por cerca de uma hora, sendo posteriormente colocados sobre a água no interior de uma placa de Petri plástica, sem tampa, de $3,5 \mathrm{~cm}$ de diâmetro $\mathrm{x} 1 \mathrm{~cm}$ de profundidade, recebendo então o alimento. O círculo permanecia no centro da placa, servindo a água para ser ingerida pelos ácaros e como barreira à sua fuga. E. concordis foi alimentado com pólen de $T$. angustifolia, e $N$. anonymus, com uma mistura de todos os estádios de Tetranychus mexicanus (McGregor).

Cinco fêmeas aparentemente sadias foram tomadas ao acaso, com pincel e transferidas da unidade de criação para cada círculo tratado.

Cada teste teve duração de oito dias, contando-se e retirando-se diariamente as fêmeas mortas. Os círculos sobre os quais os ácaros foram mantidos não foram trocados durante a realização do teste. Os ovos postos foram transferidos das arenas tratadas para outras arenas similares, igualmente tratadas quando da aplicação dos demais círculos, onde foram mantidos para determinar a viabilidade.

Os círculos com os ácaros foram mantidos em câmara climatizada a $25 \pm 1^{\circ} \mathrm{C}$, fotofase de 12 horas e umidade relativa de $80 \pm 5 \%$.

\subsubsection{Critérios utilizados na avaliação}

O efeito total ou adverso foi calculado levando em conta a mortalidade das fêmeas no tratamento, corrigida em função da mortalidade na testemunha, e o efeito na reprodução (Bakker et al., 1992; Hassan et al., 1985; Overmeer, 1988; Overmeer \& van Zon, 1982). Foram considerados válidos somente os testes em que a mortalidade na testemunha foi de no máximo 20\% (Bakker et al., 1992). A fórmula utilizada para o cálculo do efeito total foi $E=100 \%-\left(100 \%-M_{\mathcal{C}}\right) \times E_{r}$, na qual $E=$ efeito total, $M_{c}=$ 
mortalidade corrigida (Abbott, 1925) e $\mathrm{E}_{\mathrm{r}}=$ efeito na reprodução. $\mathrm{O}$ efeito na reprodução foi calculado pela divisão da oviposição das fềmeas em cada tratamento pela oviposição média na testemunha $\left(\mathrm{E}_{\mathrm{r}}=\mathrm{R}\right.$ tratamento $\left./ \mathrm{R}_{\text {testemunha }}\right)$. A oviposição média por fêmea $(\mathrm{R})$ foi obtida através da relação: $\mathrm{R}$ = total de ovos viáveis/número de fêmeas vivas no final do teste.

O valor do efeito total obtido para cada produto foi classificado em uma escala de 1 a 4, conforme critérios estabelecidos pela IOBC/WPRS (Bakker et al., 1992; Hassan et al., 1994), sendo classe 1: $\mathrm{E}<30 \%$ (inócuo, não nocivo); classe 2: $30 \%<\mathrm{E}<$ $79 \%$ (levemente nocivo); classe 3: 79\% $<\mathrm{E}<99 \%$ (moderadamente nocivo) e classe 4 : $\mathrm{E}>99 \%$ (nocivo).

Em todos os tratamentos considerados, os erros tiveram variância homogênea. Portanto, não foi necessário fazer a transformação dos dados para a análise estatística. As médias de mortalidade em cada tratamento foram comparadas pelo teste de Tukey a $5 \%$, utilizando o programa estatístico SANEST, desenvolvido pelo Centro de Informática na Agricultura da Escola Superior de Agricultura "Luiz de Queiroz" da Universidade de São Paulo.

\subsection{RESULTADOS}

\subsubsection{Mortalidade corrigida}

A Tabela 11 apresenta a mortalidade corrigida de E. concordis e $N$. anonymus nas diferentes concentrações dos agroquímicos testados.

Dicofol, endosulfan e óxido de fenbutatina causaram baixa mortalidade de $E$. concordis nas menores concentrações testadas. Entretanto, nas maiores concentrações, apenas óxido de fenbutatina apresentou baixa mortalidade desta espécie. Todos os demais produtos testados provocaram mortalidade acima de $80 \%$ para esta espécie.

Assim como para E. concordis, dicofol, endosulfan e óxido de fenbutatina apresentaram baixa mortalidade de $N$. anonymus nas menores concentrações testadas. Nas menores concentrações dos outros produtos e nas maiores concentrações de todos os 
produtos testados a mortalidade de $N$. anonymus foi sempre maior que $70 \%$.

Tabela 11. Mortalidade corrigida (\%) de Euseius concordis e Neoseiulus anonymus em teste residual em diferentes concentrações de agroquímicos, após 8 dias, a $25 \pm 1^{\circ} \mathrm{C}$, fotofase de 12 horas e umidade relativa de $80 \pm 5 \%$.

\begin{tabular}{lcc}
\hline Agroquímico (ppm) & Euseius concordis & Neoseiulus anonymus \\
\hline Acefato 1100 & $100 \mathrm{a}$ & $100 \mathrm{a}$ \\
Acefato 560 & $100 \mathrm{a}$ & $100 \mathrm{a}$ \\
Dicofol 100 & $33,3 \mathrm{~cd}$ & $34,2 \mathrm{~cd}$ \\
Dicofol 360 & $100 \mathrm{a}$ & $75,3 \mathrm{ab}$ \\
Endosulfan 320 & $42,8 \mathrm{bcd}$ & $4,1 \mathrm{~d}$ \\
Endosulfan 1000 & $100 \mathrm{a}$ & $71,7 \mathrm{abc}$ \\
Formetanate 32 & $100 \mathrm{a}$ & $96,2 \mathrm{a}$ \\
Formetanate 100 & $100 \mathrm{a}$ & $100 \mathrm{a}$ \\
Metomil 90 & $100 \mathrm{a}$ & $100 \mathrm{a}$ \\
Metomil 2100 & $100 \mathrm{a}$ & $92,1 \mathrm{a}$ \\
Monocrotofos 560 & $100 \mathrm{a}$ & $100 \mathrm{a}$ \\
Monocrotofos 11000 & $100 \mathrm{a}$ & $100 \mathrm{a}$ \\
Óxido de fenbutatina 100 & $20,6 \mathrm{~d}$ & $41,5 \mathrm{bcd}$ \\
Óxido de fenbutatina 320 & $10,2 \mathrm{~d}$ & $100 \mathrm{a}$ \\
Propargite 320 & $100 \mathrm{a}$ & $90,2 \mathrm{a}$ \\
Propargite 750 & $100 \mathrm{a}$ & $77,1 \mathrm{ab}$
\end{tabular}

Em cada coluna, médias seguidas da mesma letra não diferem estatisticamente entre si, pelo teste de Tukey, a 5\% de probabilidade.

\subsubsection{Efeito sobre a reprodução}

Óxido de fenbutatina e endosulfan, nas duas concentrações, e dicofol, na menor concentração, tiveram efeito positivo sobre a oviposição de E. concordis (Figura 21). Nas duas concentrações testadas, dicofol teve efeito positivo na oviposição de $N$. 
anonymus. As menores concentrações de endosulfan e propargite e as maiores concentrações de metomil e óxido fenbutatina também tiveram efeito positivo sobre a oviposição de $N$. anonymus. Efeito negativo sobre a oviposição de $N$. anonymus foi verificado nos tratamentos de formetanate, metomil, óxido de fenbutatina, nas menores concentrações, e endosulfan e propargite, nas maiores concentrações.

Os produtos e/ou concentrações não mencionadas causaram mortalidade total de E. concordis e $N$. anonymus, e por isso nenhuma oviposição foi observada nestes casos

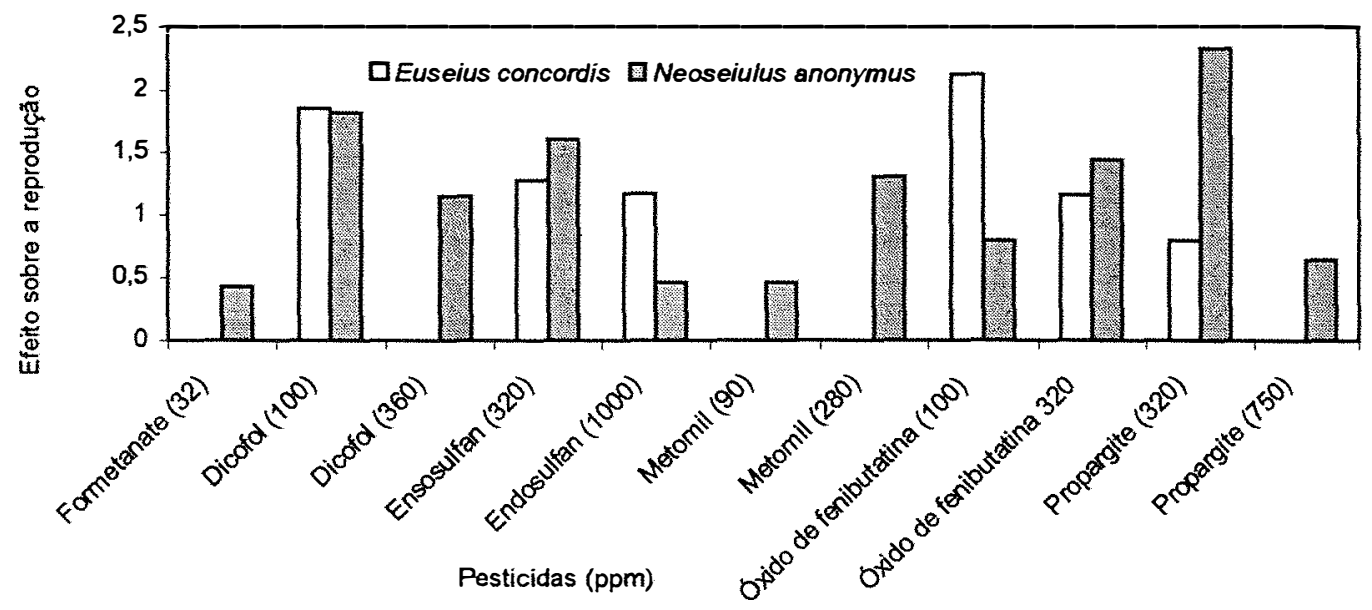

Figura 21 - Efeito sobre a reprodução Euseius concordis e Neoseiulus anonymus calculada através da divisão da oviposição das fềmeas em cada tratamento pela oviposição média da testemunha, mantidos sobre círculos de folhas de seringueira tratados com diferentes produtos químicos. Piracicaba. 1999. 


\subsubsection{Efeito total dos agroquímicos sobre os predadores}

Óxido de fenbutatina, à maior concentração, e dicofol, à menor concentração, tiveram efeito total positivo sobre E. concordis. Endosulfan e óxido de fenbutatina, às menores concentrações, tiveram pequeno efeito adverso sobre esta espécie. Todos os demais produtos e ou concentrações tiveram efeito altamente adverso sobre $E$. concordis (Figura 22).

Endosulfan, à menor concentração, e dicofol, à maior concentração, tiveram efeito total positivo sobre $N$. anonymus. Óxido de fenbutatina, nas duas concentrações, dicofol, à maior concentração, e propargite, à menor concentração, tiveram efeito adverso mediano sobre $N$. anonymus. Os demais produtos e ou concentrações tiveram efeito altamente adverso sobre esta espécie.

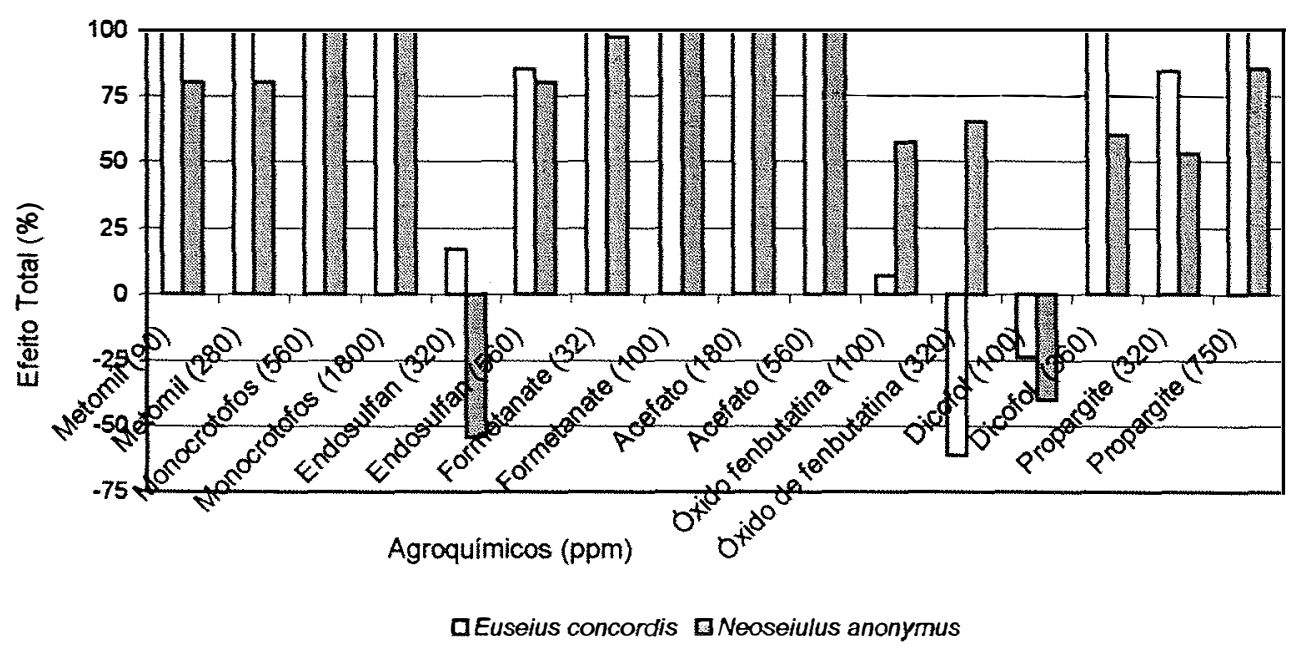

Figura 22 - Efeito total calculado levando em conta a mortalidade das fêmeas de Euseius concordis e Neoseiulus anonymus no tratamento, corrigida em função da mortalidade na testemunha e o efeito na reprodução. Piracicaba. 1999-2000. 


\subsubsection{Toxicidade dos pesticidas}

A Tabela 12 mostra a classe de toxicidade a que pertence cada produto testado em relação a E. concordis e $N$. anonymus. A maioria dos produtos testados apresentou efeito nocivo ou moderadamente nocivo aos predadores, sendo que de maneira geral $E$. concordis foi pouco mais suscetível que $N$. anonymus aos produtos.

Acefato e monocrotofós, nas duas concentrações testadas, foram nocivos às duas espécies.

Tabela 12.Classe de toxicidade ${ }^{1}$ de pesticidas sobre fềmeas adultas de Euseius concordis e Neoseiulus anonymus em teste residual de laboratório, de acordo com a escala estabelecida pela IOBC/WPRS. Piracicaba, 1999.

\begin{tabular}{lcc}
\hline Agroquímicos (ppm) & Euseius concordis & Neoseiulus anonymus \\
\hline Acefato 1100 & 4 & 4 \\
Acefato 560 & 4 & 4 \\
Dicofol 100 & 1 & 1 \\
Dicofol 360 & 4 & 2 \\
Endosulfan 320 & 1 & 1 \\
Endosulfan 1000 & 3 & 3 \\
Formetanate 32 & 4 & 3 \\
Formetanate 100 & 4 & 4 \\
Metomil 90 & 4 & 3 \\
Metomil 2100 & 4 & 3 \\
Monocrotofós 560 & 4 & 4 \\
Monocrotofós 11000 & 4 & 4 \\
Óxido de Fenbutatina 100 & 1 & 2 \\
Oxido de Fenbutatina 320 & 1 & 2 \\
Propargite 320 & 3 & 2 \\
Propargite 750 & 4 & 3 \\
1- Classe 1-inócuo; Classe 2 - levemente nocivo; Classe 3-moderadamente nocivo; Classe \\
4-nocivo.
\end{tabular}


duas espécies na menor concentração.

\subsection{DISCUSSÃO}

Os resultados obtidos neste estudo contribuem para a escolha dos agroquímicos a serem utilizados em programas de manejo integrado na cultura da seringueira que procuram preservar os ácaros predadores $E$. concordis e $N$. anonymus. Estas foram as espécies mais comumente encontradas em avaliações realizadas em plantações de seringueira de Itiquira e Pontes e Lacerda, ambas no Estado do Mato Grosso (Capítulo 4). A manutenção dos inimigos naturais no a mbiente pode propiciar uma maior pressão de controle sobre as populações dos ácaros fitófagos sobre as quais aqueles predadores atuam.

A maioria dos agroquímicos testados não se mostrou seletivo a E. concordis $\mathrm{e}$ $N$. anonymus. Apenas dicofol e endosulfan, em baixas concentrações, e óxido de fenbutatina, nas duas concentrações, demonstraram ser seletivos aos predadores. Óxido de fenbutatina também foi considerado inócuo a espécies de fitoseídeos por Hassan et al. (1983); Hassan et al. (1987); Moraes et al. (1987); Oomen et al. (1991); Overmeer \& van Zon (1981); Reis et al. (1998); Samsoe-Petersen (1983); Streibert (1981) e de baixa toxicidade por Hoy \& Conley (1987) e Tanigoshi \& Fargerlund (1984). Estes resultados sugerem que este produto poderia ser indicado para o uso em programas de manejo integrado na seringueira.

Óxido de fenbutatina apresentou efeito negativo à menor concentração e efeito positivo à maior concentração sobre E. concordis. Estes resultados possivelmente se devam a alterações fisiológicas nos predadores que apresentaram maior oviposição quando em presença de maiores concentrações deste produto.

Considerando as conclusões de Hoy \& Conley (1987) de que a toxicidade dos produtos observadas no laboratório também ocorra no campo, a maioria dos resultados obtidos nesse estudo passam a ser conclusivos para E. concordis, sendo que para $N$. anonymus apenas monocrotofos e carbamato a presentam resultados conclusivos.

No Capítulo 7, são apresentados os efeitos dos mesmos agroquímicos, nas 
mesmas concentrações, sobre $C$. heveae e $T$. heveae, que são ácaros fitófagos considerados mais importantes na cultura da seringueira. C. heveae se mostrou mais sensível a uma amplitude maior de agroquímicos que $T$. heveae. Dicofol e endosulfan, nas menores concentrações, e óxido de fenbutatina, nas duas concentrações, demonstraram ser eficientes no controle de $C$. heveae. O fato de apresentarem grande capacidade de controle sobre de $C$. heveae e serem seletivos aos ácaros predadores em laboratório indica que estes produtos são promissores para a utilização na cultura da seringueira.

\subsection{CONCLUSÕES}

1) Dicofol e endosulfan, em baixas concentrações, e óxido de fenbutatina, nas duas concentrações, são seletivos a $E$. concordis e $N$. anonymus. 


\section{CONCLUSÕES GERAIS}

* Calacarus heveae Feres exibe distribuição agregada no campo.

* Os ácaros fitófagos mais freqüentemente encontrados em seringueira no Estado do Mato Grosso pertencem às famílias Eriophyidae, Tenuipalpidae e Tetranychidae.

* C. heveae e Phyllocoptruta seringueirae Feres são os ácaros mais freqüentemente encontrados no Estado do Mato Grosso.

- A maior diversidade de ácaros fitófagos em seringueira no Estado do Mato Grosso pertence às famílias Eriophyidae e Tetranychidae.

* Phytoseiidae é o grupo de ácaros predadores mais diverso em seringueira no Estado do Mato Grosso.

- Euseius concordis (Chant) e Neosiulus anonymus (Chant \& Baker) são as espécies de ácaros predadores mais comuns em seringueira no Estado do Mato Grosso.

* $C$ heveae apresentou ciclo biológico e fecundidade comparável à outras espécies de Eriophyidae.

* Dicofol é o único agroquímico que causa alta mortalidade de $C$. heveae $\mathrm{e}$ Tenuipalpus heveae Baker.

* Agistemus floridanus Gonzalez tem maior oviposição quando alimentado com $C$. heveae e $T$. heveae, ácaros considerados danosos à seringueira.

- N. anonymus apresenta maior oviposição quando alimentado com tetraniquídeos do que quando alimentado com outros ácaros comuns em seringueira.

* Agistemus floridanus apresenta alta fertilidade quando alimentado com T. heveae.

* Dicofol e endosulfan, em baixas concentrações, e óxido de fenbutatina, nas duas concentrações, são seletivos a $E$. concordis e $N$. anonymus. 


\section{REFERÊNCIAS BIBLIOGRÁFICAS}

ABBOT, W.S. A method of computing the effectiveness of an insecticide. Journal of Economic Entomology, v.18. p.265-267, 1925.

AMRINE Jr., J.W.; MANSON, D.C.M. Preparation, mounting and descriptive study of eriophyoid mites. In: LINDQUIST, E.E.; SABELIS, M.W.; BRUIN, J. Eriophyoid mites. Amsterdan: Elsevier, 1996. p.383-396.

BAKER, E.W. Mites of the genus Tenuipalpus (Acarina: Trichadenidae). Proceedings of the Entomological Society of Washington, v.47, n.2, p.33-44, 1945.

BAKER, E.W. The genus Lorryia. Annals of the Entomological Society of America, v.61, n.4, p.986-1008, 1968.

BAKER, E.W.; PRITCHARD, A.E. A review of the false spider mite genus Tenuipalpus Donnadieu (Acarina: Phytoptipalpidae). Annals of the Entomological Society of America, v.46, n.3, p.317-336, 1953.

BAKER, E.W.; PRITCHARD, A.E. The tetranychoid mites of Africa. Hilgardia, v.29, n.11, p.455-574, 1960.

BAKER, E.W.; TUTTLE, D.M. The false spider mites of Mexico (Tenuipalpidae: Acari). Washington: USDA, 1987. 237p. (Technical Bulletin, 1706). 
BAKER, E.W.; TUTTLE, D.M.; ABBATIELLO. The false spider mites of northwestern and north central Mexico (Acarina: Tenuipalpidae). Smithson Contribution Zoologique, v.194, p.1-23, 1975.

BAKKER, F. M.; GROVE, A .; BLÜMEL, S., et al. Side-effect test for phytoseiids and their rearing methods. IOBC/WPRS Bulletin, v.15, n.3, p.61-81, 1992.

BANKS, N. Class III, Arachnida, Order I, Acarina, four new species of injurious mites. Journal of the Entomological Society of New York, v.12: 53-56, 1904.

BERGMANN, E.C.; ARAUJO, S.L.; SILVA, M.N. et al. Ácaros fitófagos e predadores em seringueira, em Bálsamo, SP. In: REUNIÃO ANUAL DO INSTITUTO BIOLÓGICO, 4, 1991, São Paulo. Resumos: do Instituto Biológico, São Paulo. P.13.

CHANT, D.A. Notes on mites of the genus Typhlodromus Scheuten, 1857 (Acarina:Laelaptidae), with descriptions of the males of some species and the female of a new species. Canadian Entomologist, v.87, n.11, p.496-503, 1955.

CHANT, D.A. Phytoseiid mites (Acarina: Phytoseiidae). Part I. Bionomics of seven species in southeastern England. Part II. A taxonomic review of the family Phytoseiidae, with descriptions of thirty-eight new species. Canadian Entomologist, v.91, n.12, p.1-166, 1959.

CHANT, D. A.; BAKER, E. W. The Phytoseiidae (Acarina) of Central America. Memoirs of the Entomological Society of Canada, v.41, p.1-56, 1965.

CHANT, D.A.; MCMURTRY, J.A. A review of the subfamilies Phytoseinae and Typhlodrominae (Acari: Phytoseiidae). International Journal of Acarology, v.20, p.4, p.222-311, 1994. 
CHANT, D. A.; YOSHIDA-SHAUL, E. A world review of the simplex species group in the genus Typhlodromus Scheuten: Part II. The conspicuus and cornus groups (Acarina:Phytoseiidae). Canadian Journal of Zoology, v.61, p.1041-1057, 1983

CHANT, D. A.; YOSHIDA-SHAUL, E. A world review of the occidentalis species group in the genus Typhlodromus Scheuten (Acarina: Phytoseiidae). Canadian Journal of Zoology, v.62, p.1860-1871, 1984.

CHANT, D. A.; YOSHIDA-SHAUL, E. A world review of the ecclesiasticus group in the genus Typhlodromus Scheuten (Acarina: Phytoseiidae) Canadian Journal of Zoology, v.64, p.447-466, 1986a.

CHANT, D. A.; YOSHIDA-SHAUL, E. A new subfamily, Cydnodromellinae, in the family Phytoseiidae (Acari: Gamasina) Canadian Journal of Zoology, v. 64, p.2811-2823, $1986 b$.

CHIAVEGATO, L.G. Ácaros da cultura dos citros, p. 469-501. In: RODRIGUEZ, O.; VIÉGAS, F.C.P. (Ed.). Citricultura brasileira. Campinas: Fundação Cargill, 1980. $739 \mathrm{p}$

COOREMAN, J. Notes et observations sur les Acariens. VII- Photia graeca n.sp. (Acaridia, Canestriniidae) et Lorryia formosa n.sp. (Stomatostigmata, Tydeidae). Bulletin del'Institut Royal des Sciences Naturelles de Belgique, v.41, p.73-76, 1958

CORTEZ, J.V.; MARTIN, N.B. A sazonalidade da produção da seringueira e a política brasileira de contingenciamento da importação de borracha natural. Informações Econômicas, v.26, n.7, p.45-54, 1996. 
DELATTRE, P. Étude de l'efficacité prédatrice de Zetzellia mali (Acarina: Stigmaeidae) Entomophaga, v. 19, n. 1, p.13-31, 1974.

DELEON, D. Three new Typhlodromus from southern Florida (Acarina: Phytoseiidae). Florida Entomologist, v.40, p.141-144, 1957.

DELEON, D. Four new Typhlodromus from southern Florida (Acarina: Phytoseiidae). Florida Entomologist, v.41, p.73-76, 1958.

DELEON, D. The genus Brevipalpus in Mexico. Part II (Acarina: Temuipalpidae). Florida Entomologist, v.44, n.1, p.41-52, 1961.

DELEON, D. Twenty-three new Phytoseiidae, mostly from southeastern United States (Acarina: Phytoseiidae). Florida Entomologist, v.45, n. 1, p.11-27, 1962.

DELEON, D. Phytoseiidae of British Guyana with keys to species (Acarina: Mesostigmata). Studies on the Fauna of Suriname and other Guyanas. v.8. p.81102, 1966.

DELEON, D. Some mites of the Caribbean Area. Part I. Acarina on plants in Trinidad, West Indies. Kansas: Allen Press, 1967. 66p.

DENMARK H.A.; MUMA, M.H. Some Phytoseiidae mites of Paraguay (Phytoseiidae: Acarina). Florida Entomologist, v.53, n.4, p.219-227, 1970.

DENMARK, H.A.; MUMA, M.H. Some Phytoseiidae of Colombia (Acarina: Phytoseiidae). The Florida Entomologist, v.55, n.1, p.19-29, 1972.

DENMARK, H.A.; MUMA, M.H. Phytoseiid mites of Brazil (Acarina: Phytoseiidae). Revista Brasileira de Biologia, v.33, p.235-276, 1973. 
DENMARK, H.A.; MUMA, M.H. A revision of the genus Amblyseius Berlese, 1914 (Acari: Phytoseiidae). Occasional Paper of the Florida State Collection of Arthropods, v.4, p.1-149, 1989.

EHARA, S. A new species of the genus Agistemus Summers from Hokkaido (Acarina: Stigmaeidae). Proceedings Japan Academic, v. 61, p. 60-66, 1985.

EVANS, G.O. Principles of acarology. Wallingford: CAB International, 1992. 563p.

EWING, H.E. A revision of the mites of the subfamily Tarsoneminae of North America, the west Indies and the Hawaiian Islands. United State Department of Agriculture, Technical Bulletin, v. 653, p.1-63, 1939.

FARIAS, A.R.; FLECHTMANN, C.H.W.; MORAES, G.J. de et al. Predadores do ácaro verde da mandioca, no nordeste do Brasil. Pesquisa Agropecuária Brasileira, v.16, n.3, p.313-317, 1981.

FAZOLIN, M.; PEREIRA, L.V. Ocorrência de Oligonychus gossypii (Zacher, 1920) (Acari: Tetranichidae) em seringueiras cultivadas. Anais da Sociedade Entomólogica do Brasil, v.18, n. 1, p.199-202, 1989.

FERES, R.J.F. A new species of Calacarus Keifer (Acari, Eriophyidae, Phyllocoptinae) from Hevea brasiliensis Muell. Arg. (Euphorbiaceae) from Brazil. International Journal of Acarology, v. 18, n. 1, p.61-65, 1992.

FERES, R.J.F. Two new Phyllocoptinae mites (Acari, Eriophyidae,) from Hevea brasiliensis Muell. Arg. (Euphorbiaceae) from Brazil. International Journal of Acarology, v.24, n.1, p.69-74, 1998. 
FERES, R.J.F. Levantamento e observações naturalísticas da acarofauna (Acari, Arachnida) de seringueiras cultivadas (Hevea spp., Euphorbiaceae) no Brasil. Revista Brasileira de Zoologia, v. 17, n. 1, p. 157-173, 2000.

FERES, R.J.F. Primeiro registro de ácaros eriofiídeos (Acari: Eriophyidae) em seringueiras (Hevea brasiliensis Muell. Arg., Euphorbiaceae) da Floresta Amazônica, Brasil. Revista Brasileira de Zoologia, v. 18, Supl. 1, p.343-345, 2001.

FERES, R.J.F.; MORAES, G. J. de. Phytoseidae mites (Acari: Phytoseiidae) from woody areas in the State of São Paulo, Brazil. Sistematic \& Applied Acarology, v.3, p.125-132, 1998.

FERLA, N.J. ; MORAES, G.J. de. Ácaros predadores em pomares de maçã no Rio Grande do Sul. Anais da Sociedade Entomológica do Brasil, v.27, n.4, p. 649-654, 1998.

FERREIRA, P. F.; VEIGA, A. F. S. L. Eficiência do controle químico do ácaro alaranjado do abacaxizeiro, Dolichotetranychus floridanus (Banks, 1900) (Acari: Tenuipalpidae) em Pernambuco. Revista de Agricultura, v.75, n.2, p. 153-163, 2000.

FLECHTMANN, C.H.W. Elementos de acarologia. São Paulo: Livraria Nobel, 1975. $344 p$.

FLECHTMANN, C.H.W. A report on the Tetranychidae (Acari) of Brasil: an emmendation. Revista Brasileira de Entomologia, v.20, n.2, p.115-116, 1976.

FLECHTMANN, C.H.W. Ácaros de importância agrícola. São Paulo : Nobel, 1977. $189 \mathrm{p}$. 
FLECHTMANN, C.H.W. Tuckerella ornata (Tucker), um ácaro novo para o Brasil e outros Tetranychoidea (Acari) do Estado do Pará. Anais da Escola Superior de Agricultura, v.36, p.615-620, 1979.

FLECHTMANN, C.H.W. Ácaros em produtos armazenados. Piracicaba : FEALQ, 1986. 97p.

FLECHTMANN, C.H.W. Seringueira (Hevea sp.) um novo hospedeiro para Oligonychus gossypii (Zacher, 1920) (Acari: Tetranychidae). Boletim do Museu Paraense Emílio Goeldi, v.5, n. 1, p. 127-128, 1989.

FLECHTMANN, C.H.W.; ABREU, J.M. Ácaros fitófagos do Estado da Bahia, Brasil. Ciência e Cultura, v.25, n.3, p.244-251, 1973.

FLECHTMANN, C.H.W.; ARLEU, R.J. Oligonychus coffeae (Nietner, 1961), um ácaro tetraniquídeo da seringueira (Hevea brasiliensis) novo para o Brasil e observações sobre outros ácaros desta planta. Ecossistema, v. 9, p. 123-125, 1984.

FLECHTMANN, C.H.W.; BAKER, E.W. A preliminary report on the Tetranychidae (Acarina) of Brazil. Annals of the Entomological Society of America, v.63, n.1, p.156-163, 1970 .

FLECHTMANN, C.H.W.; BAKER, E.W. A report on the Tetranychidae (Acari) of Brazil. Revista Brasileira de Entomologia, v.19, n.3, p.111-122, 1975.

FURQUIM, G.V. Flutuação populacional de ácaros e caracterização de sintomas de Calacarus heveae em clones de seringueira (Hevea brasiliensis Muell. Arg.) cultivados em Jaboticabal - SP. Jaboticabal, 1994. 33p. Trabalho (Graduação) Universidade do Noroeste do Estado de São Paulo. 
GEIJSKES, D.C. Beitraege zur Kenntnis der europeaischen Spinnmilben (Acari: Tetranychidae), mit besonderer Beruecksichtigung der niederlaendishen Arten. Mededeelingen Van de Landbouwhoogeschool te Wageningen, v.42, n.4, p. 1-68, 1939.

GERSON, U.; SMILEY, R. L. Acarine biocontrol agents. London, Chapman \& Hall, 1990, 174.

GONÇALVES, P. S.; PAIVA, J.R. SOUZA, R.A. Retrospectiva e atualidade do melhoramento genético da seringueira (Hevea spp.) no Brasil e em países asiáticos. Manaus: Embrapa, CNPSD, 1983. 69p.

GONDIM Jr, M.G.C; MORAES, G.J. de; OLIVEIRA, J.V. et al. Biologia de Neoseiulus anonymus (Acari: Phytoseiidae). Anais da Sociedade Entomológica do Brasil, v.25, n.3, p.451-455, 1996.

GONZALES, R.H. A taxonomic study of the genera Mediolata, Zetzellia and Agistemus. University of California Publications in Entomology, v.41, p.1-64, 1965

GONZALES, R.H. Revision of the Brevipalpus phoenicis "complex", with descriptions of new species from Chile and Thailand (Acarina: Tenuipalpidae). Acarologia, v.17, n.1, p. 82-91, 1975.

GRAVENA, S. Manejo integrado de pragas em citros: uma visão atual. In: DONADIO, L.C.; GRAVENA, S. (Ed.). Manejo integrado de pragas dos citros. Campinas: Fundação Cargill, 1994. p. 41-56.

GUTIERREZ, J. Tetranychidae nouveaux de Madagascar (Quatrième note). Acarologia, v.10, n. 1, p.13-28, 1968. 
HASSAN, S.A.; ALBERTT, R.; BIGLER, F. et al. Results of the third joint pesticide testing program by the IOBC/WPRS - Working Group "Pesticides and beneficial Organisms". Journal of Applied Entomology, v. 103, p.92-107, 1987.

HASSAN, S.A.; BIGLER, F.; BLAISINGER, P. et al. Standard method to test the sideeffects of pesticides on natural enemies of insects and mites developed by the IOBC/WPRS Working Group "Pesticides and Beneficial Organisms". Bulletin OEPP, v.15, p.214-255, 1985.

HASSAN, S.A.; BIGLER, F.; BOGENSCHÜTZ, H. et al. Results of the second joint pesticide testing programme by the IOBC/WPRS - Working Group "Pesticides and Beneficial Arthropods". Zeitschrift für Angewandte Entomologie, v.95, p.151-158, 1983.

HASSAN, S.A.; BIGLER,F.; BOGENSCHÜTZ,H. et al. Results of the sixth joint pesticide testing program of the IOBC/WPRS - Working Group "Pesticides and Beneficial Organisms". Entomophaga, v.39, n.1, p.107-19, 1994.

HOY, M. A.; CONLEY, J. Toxicity of pesticides to the western predatory mite. California Agriculture, v.41, n.7,8, p.12-4, 1987.

JEPPSON, L.R.; KEIFER, H.H.; BAKER, E.W. Mites injurious to economic plants. Berkeley: University of California Press, 1975. 614p.

KARADINOS, M. G. Optimum sample size and comments on some published formulae. Bulletin of the Entomological Society of America, v.22, p.417-421, 1976. 
KOMATSU, S.S. Aspectos bioetológicos de Euseius concordis (Chant, 1959) (Acari:Phytoseiidae) e seletividade dos acaricidas convencionais nos citros. Piracicaba,1988. 117p. Dissertação (Mestrado) - Escola Superior de Agricultura "Luiz de Queiroz" - Universidade de São Paulo.

KRANTZ, G.W. A manual of acarology. 2. ed. Corvallis: Oregon State University, 1978. 509p.

KREITER, S.; MORAES, G. J. de. Phytoseiid mites (Acari: Phytoseiidae) from Guadalupe and Martinique. Florida Entomologist, v.80, n.3, p.376-382, 1997.

LAING, J.E.; KNOP, N.F. Potential use of predaceous mites other than Phytoseiidae for biological control of orchards pests. In: HOY, M.A.; CUNNINGHAM, G.L.; KNUTSON L. Biological control of pests by mites. Berkeley: University of California Press, 1982. p.28-35.

LINDQUIST, E.E. The world genera of Tarsonemidae (Acari: Heterostigmata): A morphological, phylogenetic, and systematic revision, with a reclassification of family-group taxa in the Heterostigmata. Memoirs of the Entomological Society of Canada, v.136, p.1-517, 1986.

LOFEGO, A.C.; MORAES, G.J. de; MCMURTRY, J.A.. Three new species of phytoseiid mites (Acari: Phytoseiidae) from Brazil. Anais da Sociedade Entomológica do Brasil, v.29, n.3, p.461-467, 2000.

LORENZATO, D. Controle biológico de ácaros fitófagos na cultura da macieira no município de Farroupilha, RS. Agronomia Sulriograndense, v.23, n.2, p.167-183, 1987.

MANUAL TÉCNICO. Cultura da seringueira. Brasília: EMBRATER, 1983. 135p. 
McGREGOR, E.A. Four new tetranychids. Annals of the Entomological Society of America, v.7, p.354-364, 1914.

McGREGOR, E.A. The red spiders of America and a few European species likely to be introduced. Proceedings United States Natural Museum, v.56, p.641-579, 1919.

McGREGOR, E.A. Mites of the family Tetranychidae. The American Midland Naturalist, v.44, n.2, p.257-420, 1950.

McMURTRY, J.A. Phytoseiid mites from Guatemala, with descriptions of two new species and redefinitions of the genera Euseius, Typhloseiopsis, and the Typhlodromus occidentalis species group (Acari: Mesostigmata). International Journal of Entomology, v.25, p.249-272, 1983.

McMURTRY, J.A.; CROFT, B.A. Life-styles of phytoseiid mites and their roles in biological control. Annual Review of Entomology, v.42, p.291-321, 1997.

McMURTRY, J.A.; SCRIVEN, G.T. Insectary production of phytoseiid mites. Journal of Economic Entomology, v.58, n.2, p.282-284, 1965.

McMURTRY, J. A.; HUFFAKER; C. B. VAN DE VRIE, M. Ecology of tetranychid mites and their natural enemies: a review. 1. Tetranychid enemies: Their biological characters and the impact of spray practices. Hilgardia, v.40, n.11, p.331-390, 1970.

MESA, N.C.; BELLOTTI, A.C. Ciclo de vida y hábitos alimentícios de Neoseiulus anonymus, predador de ácaros Tetranychidae en yuca. Revista Colombiana de Entomologia, v. 12, n.1, p.54-66, 1986. 
MEYER, M.K.P.S. A revision of the Tetranychidae of Africa (Acari) with a key to the genera of the world. Entomological Memoirs, n.36, p.1-291, 1974.

MEYER, M.K.P.S. The Tenuipalpidae (Acari) of Africa with keys to the world fauna. Entomological Memoirs, n. 50, p.1-135, 1979.

MEYER, M.K.P.S. African Tetranychidae (Acari: Prostigmata), with reference to the world genera. Entomological Memoirs, n.69, p.1-175, 1987.

MEYER, M.K.P.S.; RODRIGUEZ, M.D.A. C. Acari associated with cotton in southern Africa (with reference to the other plants). Garcia de Orta, v.13, n.2, p. 195-226, 1965.

MORAES, G.J. de. Controle biológico de ácaros fitófagos. Informe Agropecuário, v.15, n. 167, p.53-55, 1991.

MORAES, G.J. de; LIMA, H.C. Biology of Euseius concordis (Chant) (Acarina: Phytoseiidae) a predator of the tomato russet mite. Acarologia, v.24, n.3, p.251-255, 1983.

MORAES, G.J. de; MCMURTRY, J.A.. Phytoseiid mites (Acarina) of northeastern Brazil, with descriptions of four new species. International Journal of Acarology, v.9, n. 3, p.131-148, 1983.

MORAES, G.J. de; MESA, N. C.. Mites of the family Phytoseiidae (Acari) in Colombia, with descriptions of three new species. International Journal of Acarology, v. 14, n. 2, p.71-88, 1988.

MORAES, G.J. de; OLIVEIRA, J.V. de. Phytoseiidae mites of coastal Pernambuco in northeasthern Brazil. Acarologia, v.23, n.4, p.315-318, 1982. 
MORAES, G. J. de; DENMARK, H.A.; GUERRERO, J. M. Phytoseiid mites of Colombia (Acarina: Phytoseiidae). International Journal of Acarology, v.8, n.1, p.15-22, 1982.

MORAES, G. J. de; DENMARK, H.A.; MCMURTRY, J.A. A catalog of the mite family Phytoseiidae: references to taxonomy, synonymy, distribution and habitat. Brasília: EMBRAPA, DDT, 1986. 353p.

MORAES, G.J. de; KREITER, S.; LOFEGO, A.C. Plant mites (Acari) of the French Antilles. 3. Phytoseiidae (Gamasida). Acarologia, v.40, n.3, p.237-264, 2000.

MORAES, G.J. de; MESA, N. C.; BRAUN, A. Some phytoseiid mites of Latin America (Acari: Phytoseiidae). International Journal of Acarology, v.17, n.2, p.117-139, 1991.

MORAES, L. A. H. de; PORTO, O. M.; CHOUENE, E. C. et al. Controle químico do ácaro da ferrugem (Phyllocoptruta oleivora) (Asmead, 1879) (Acari, Eriophyidae) dos citros. Agronomia Sulriograndense, v.23, n.2, p. 193-202, 1987.

MUMA, M.H. Subfamilies, genera, and species of Phytoseiidae (Acarina: Mesostigmata). Florida State Museum Bulletin Biology Sciences, v.5, p.267-302, 1961 .

MUMA, M.H.; DENMARK, H.A. Phytoseid of Florida Arthropods of Florida and neighboring land areas. Gainnesville: Florida Department Agriculture Cons. Serv., Div. Plant Ind., 1970. 150p.

NIETNER, J. Observation on the enemies of the coffee tree in Ceylon. 1861.31p. 
NESBITT, H.H.J. A taxonomic study of the Phytoseiinae (Family: Laelapidae) predaceous upon Tetranychidae of economic importance. Zoologische verhandelingen vitgegeven door het Rijksmuseum van Naturlijke Historie te Leiden. v.12, p.1-64, 1951

OLDFIELD, G.N.; HOBZA, R.F.; WILSON, N. Discovery and characterization of spermathophores in the Eriophyoidea (Acari). Annals of the Entomological Society of America, v.63, n.2, p.520-526, 1970

OLDFIELD, G.N.; MICHALSKA, K. Spermtophore deposition, mating behavior and population mating structure. In: LINDQUIST, E.E.; SABELIS, M.W.; BRUIN, J. (Ed.). Eriophyoid mites: their biology, natural enemies and control. Amsterdan: Elsevier, 1996. p. 185-198.

OOMEN, P.A. Studies on population dynamics of the scarlet mite, Brevipalpus phoenicis, a pest of tea in Indonesia. Wageningen, 1982. 110p. Thesis (Ph.D.) Landbouwhogeschool.

OOMEN, P.A.;ROMEIJN, G.; WIEGRS, G.L. Side-effects of 100 pesticides on the predatory mite Phytoseiulus persimilis, collected and evaluated according to the EPPO guideline. Bulletin EPPO, v.21, p.701-712, 1991.

OVERMEER, W.P.J. Laboratory method for testing side-effects of pesticides on the predacious mites Typhodromus pyri and Amblyseius potentillae (Acari: Phytoseiidae). IOBC/WPRS Bulletin, v.11, n.4, p.65-69, 1988.

OVERMEER, W.P.J.; VAN ZON, A.Q. A comparative study of the effects of some pesticides on three predaceous mite species: Typhodromus pyri, Amblyseius potentillae and A. bibens (Acarina: Phytoseiidae). Entomophaga, v.26, n.10, p.3-9, 1981. 
OVERMEER, W.P.J; VAN ZON, A.Q. A standardized method for testing the sideeffects of pesticides on the predaceous mite Amblyseius potentillae (Acarina: Phytoseiidae). Entomophaga, v.27, n.4, p.357-364, 1982.

PASCHOAL, A.D. Nova relação de ácaros de plantas do Brasil. Revista Peruana de Entomologia, v.14, n. 1, p.174-176, 1971.

PERRIN, T.M.; McMURTRY, J.A. Other predatory arthropods. In: LINDQUIST, E.E.; SABELIS, M.W.; BRUIN, J. (Ed.) World crop pests: eriophyoid mites. their biology, natural enemies and control. Amsterdan: Elsevier Society, 1996. p.471-479.

PRITCHARD, A. E.; BAKER, E.W. A revision of the spider mite family Tetranychidae. San Francisco: The Pacific Coast Entomological Society, 1955. 472p. (Memoirs Series, 2).

PRITCHARD, A. E.; BAKER, E.W. The false spider mites (Acarina: Tenuipalpidae). University of California Publications in Entomology, v.14, n.3, p.175-274, 1958.

REIS, P.R.; CHIAVEGATO, L.G.; ALVES, E.B. et al. Ácaros da família Phytoseiidae associados aos citros no município de Lavras, Sul de Minas Gerais. Anais da Sociedade Entomológica do Brasil, v.29, n. 1, p.95-104, 2000.

REIS, P.R.; ChIAVEgato, L.G.; MORAES, G.J. de et al. Seletividade de agroquímicos ao ácaro predador Iphiseiodes zuluagai Denmark \& Muma (Acari: Phytoseiidae). Anais da Sociedade Entomológica do Brasil, v.27, n.2, p.65-274, 1998.

RODRIGUES, M.DA C. Acarina de Moçambique - Catálogo das espécies relacionadas com a agricultura. Agronomia Moçambicana, v.2, n.4, p.215-256, 1968. 
SAMPAIO, A.S.; MYAZAKI, I. Ensaio preliminar de combate químico ao ácaro do abacaxizeiro. Pesquisa Agropecuária Brasileira, v.17, n.4, p.659-661, 1982.

SAMSOE-PETERSEN, L. Laboratory method for testing side effect of pesticides on juvenile stages of the predatory mite, Phytoseiulus persimilis (Acarina: Phytoseiidae) based on detached bean leaves. Entomophaga, v.28, n.2, p.167-178, 1983.

SANTOS, M.A. Searching behavior and association response of Zetzellia mali (Acarina: Stigmaeidae). Experimental and Applied Acarology, v.11, p.81-87, 1991.

SAYED, M.T. Description of Tenuiapalpus granati nov. spec. and Brevipalpus pyri nov. spec. Entomological Bulletin of Society Fouad, v.30, p.99-104, 1946.

SCHALLJE, G.B.; BUTTS, R.A.; LYSYK, T.J. Simulation studies of binomial samplings: a new variance estimator and density predictor with special reference to the russian wheat aphid (Homoptera: Aphididae). Journal of Economical Entomology, v.84, n.1, p.140-147, 1991.

SCHICHA, E.; ELSHAFIE, M. Four new species of phytoseiid mites from Australia, and three species from America redescribed (Acari: Phytoseiidae). Journal of the Australian Entomological Society, v. 19, p.27-36, 1980.

SILVA, P. Pragas da seringueira no Brasil, problemas e perspectivas. In: SEMINÁRIO NACIONAL DA SERINGUEIRA, 1., 1972. Anais Cuiabá: CEPLAC, 1972. p.143152.

SMILEY, R.L. Some Tarsonemidae from the Republic of the Congo (Acarina). Proceedings of the Entomological Society of Washington, v.66, p. 145-150, 1967. 
SMILEY, R.L. Cunaxidae (Acari) of the World with a new classification. Michigan: Indira Publishing House, 1992. 356p.

STREIBERT, H.P. A standardized laboratory rearing and testing method for effects pesticides on predatory mite Amblyseius fallacis (Garman). Zeitschrift für Angewandte Entomologie, v.92, p.121-127, 1981.

TANIGOSHI, L.K.; FARGERLUND, J. Implications of parathion resistance of Euseius hibisci (Chant) (Acarina: Phytoseiidae) from the San Joaquin Valley of California. Journal of Economic Entomology, v.77, n.3, p.789-93, 1984.

TANZINI, M.R; ALVES, S.B.; TAMAI, M.A. et al. An epizootic of Calacarus heveae (Acari: Eriophyidae) caused by Hirsutella thompsoni on rubber trees. Experimental and Applied Acarology, v.24, p. 141-144, 2000.

TAYLOR, L. R. Aggregation variance and the mean. Nature, v.189, p.732-735, 1961.

VAN DEN BOSCH, R.; MESSENGER, P.S.; GUTIERREZ, A. P. An introduction to biological control. New York: Plenum Press, 1982. 247p.

VAN DER MERVE, G.G.; COATES, T.J. Biological study of the grey mite Calacarus citrifolii Keifer. South Africa Journal of Agricultural Science, v.8, p.817-824, 1965.

VETORAZZI, A E.; VIEGAS, I. J.M. História e importância econômica. In: HAAG, H.P. Nutrição e adubação da seringueira no Brasil. Campinas: Fundação Cargill. 1983. p.1-10. 
VIEIRA, M.R.; GOMES, E.C. Sintomas, desfolhamento e controle de Calacarus heveae Feres. 1992 (Acari: Eriophyidae) em seringueira (Hevea brasiliensis Muell. Arg.). Cultura Agronômica, v.8, n. 1, p.53-71, 1999.

VIRGENS FILHO, A.C. Programa regional de pesquisas - seringueira. Ilhéus: CEPLAC, CEPEC, 1983. 80p.

WHITE, N.D.G. Some aspects of the biology of the predaceous mite Zetzellia mali (Ewing) (Acarina: Stigmaeidae) found in southern Ontario apple orchards. Ontario, 1976. 89p. Dissertation (M.Sc.) - University of Guelph.

WHITE, N.D.; LAING, J.E. Some aspects of the biology and a laboratory life table of the acarine predator Zetzellia mali. The Canadian Entomologist, v.109, p.12751281, 1977.

WILSON, L.T.; ROOM, P. M. Clumping patterns of fruit and arthropods in cotton, with implications for binomial sampling. Environmental Entomology, v.2, p.50-54, 1983.

ZACHER, F. Neue und wenig bekannte Spinnmilben. Zeitschrift für Angewandte Entomologie, v.7, p.181-187, 1921.

ZAR, J.H. Biostatistical analysis. 2.ed., Englewood Cliffs: Prentice Hall, 1984. 718p. 